\title{
Norois
}

Environnement, aménagement, société

$235 \mid 2015$

La directive cadre sur l'eau à l'échéance 2015. Les

façades océaniques

\section{Les façades océaniques : éléments de caractérisation en géographie physique}

Oceanic façades: physiographical characterization

\section{Dominique Sellier}

\section{CpenEdition}

\section{Journals}

Édition électronique

URL : http://journals.openedition.org/norois/5628

DOI : $10.4000 /$ norois. 5628

ISBN : 978-2-7535-4775-9

ISSN : $1760-8546$

\section{Éditeur}

Presses universitaires de Rennes

\section{Édition imprimée}

Date de publication : 15 novembre 2015

Pagination : 89-152

ISBN : 978-2-7535-4771-1

ISSN : 0029-182X

\section{Référence électronique}

Dominique Sellier, «Les façades océaniques : éléments de caractérisation en géographie physique », Norois [En ligne], 235 | 2015, mis en ligne le 15 novembre 2017, consulté le 23 avril 2019. URL : http:// journals.openedition.org/norois/5628; DOI : 10.4000/norois.5628 


Presses
Universitaires
de Rennes
www.pur-editions.fr
Revue en ligne : $h$ ttp://norois.revues.org

\title{
Les façades océaniques : éléments de caractérisation en géographie physique
}

\author{
Oceanic Façades: Physiographical Characterization
}

\author{
Dominique SELLIER
}

LETG-Nantes-Géolittomer - UMR 6554 CNRS, Université de Nantes, IGARUN, Campus du tertre, BP 81227,

44312 Nantes Cedex 3, France. (dominique.sellier@univ-nantes.fr)

Résumé : Les façades océaniques sont des entités géographiques peu étudiées en géographie physique, alors qu’elles permettent de considérer les interactions des principaux flux naturels sur le globe à partir de l'interface continent-océan. L'objectif de ce travail introductif est double. Il est d’abord de préciser la définition des façades (espaces longiformes, généralement méridiens ou subméridiens, franchis par de puissants flux lithosphériques, hydrosphériques et atmosphériques), de présenter les critères de leur caractérisation (facteurs dynamiques et paramètres statiques fondamentaux) et d'examiner quelques-unes des interactions dont elles sont le siège (influences réciproques des continents, des océans et des climats). Le second objectif concerne l'identification, la comparaison et la segmentation régionale des façades, en traitant de leurs propriétés à différents niveaux d'échelle avant d'en établir une revue. Le travail porte ainsi, successivement, sur les façades atlantiques, péripacifiques et gondwaniennes de l'océan Indien. Il traite ensuite des articulations, limites et bordures des façades océaniques, avant de montrer leur intérêt comme marqueurs de la mobilité des milieux naturels.

\begin{abstract}
Oceanic façades are geographical entities especially suitable to show connections between natural fluxes from continent-ocean interface, but not sufficiently studied amongst physiographical topics. The first aim of this paper is to specify façade definition (long, narrow, meridian or submeridian spaces, usually crossed by strong lithospheric, hydrospheric and atmospheric fluxes), to suggest references for characterisation of them (dynamic factors and main static parameters) and to consider mutual relationships between continents, oceans and climates). The second objective concerns identification, comparison and regional division of façades, to deal with their characters at several scales and to present a wide-ranging review of them. Then the paper successively deals with Atlantic, Peripacific and Indianogondwanian façades. It finally deals with several kinds of facade boundaries, before to emphasize their interest as indicators of natural environments shifts.
\end{abstract}

Mots clés : échelle climatique - typologie - façade atlantique - littoral - géomorphologie - interface

Keywords: climatological scales - typology - Atlantique façade - coastline - géomorphology - interface 


\section{INTRODUCTION}

Les façades océaniques demeurent des entités géographiques peu étudiées en tant que telles dans le champ de la géographie physique. L'objectif est ici de préciser leur définition et de présenter leurs caractères, généraux et régionaux, à partir des interfaces continents-océans. Il implique une vision des faits à partir des plaques lithosphériques, de la circulation atmosphérique, de la circulation océanique, des zones climatiques et de la répartition des terres et des mers, qui servent ordinairement de références à l'ordonnance physiographique du globe. Les façades constituent un objet complexe parce qu'elles correspondent à des lieux d'interactions de mécanismes géomorphologiques, hydrologiques et atmosphériques à tous les niveaux d'échelle, mais aussi parce qu'elles comptent parmi les milieux les plus mobiles à tous les pas de temps. Elles connaissent, en tout cas, des phénomènes physiques, ordinaires ou accidentels, qui conduisent tout observateur à reconnaître leur réalité. Plusieurs de ces phénomènes tiennent au simple contact entre la terre et la mer, comme les reliefs littoraux, les embouchures de fleuves, les courants côtiers, mais aussi la fréquence du vent et la modération des températures qui participent à l'effet de façade. D'autres relèvent de dynamiques d'une ampleur supérieure et intéressent des faits qui s'appliquent à des espaces immenses. Certains proviennent de la tectonique globale, qui se manifeste avec vigueur sur les marges continentales, en particulier sur les marges actives, et qui engendre des reliefs plus contrastés que partout ailleurs, comme ceux qui naissent de la juxtaposition des fosses et des chaînes de subduction. D'autres résultent de l'existence d'un domaine océanique gigantesque, dont les influences hydrologiques (circulation des courants, marées) et aréologiques (régulation thermique, surface d'évaporation, activité pluviogène) s'exercent sur une partie des continents, à commencer par les façades. Les derniers tiennent aux transformations de la nature et des propriétés de l'atmosphère au-dessus des océans, puis à leurs effets vers l'intérieur des continents. Les manifestations de ces dynamiques à travers le globe sont connues et représentées dans tous les atlas.

Pour être spécialement dynamiques, les façades sont également connues comme des espaces à risques, qui retiennent, de ce fait, l'attention du public. Au-delà de contraintes permanentes, comme celles qui procèdent de l'érosion des côtes, de l'englacement des mers, ou de l'existence des déserts côtiers, ces risques se manifestent par des cortèges d'événements soudains et violents : tempêtes et cyclones, inondations et submersions, séismes et tsunamis, activités volcaniques associées à la Ceinture de Feu du Pacifique... Leurs conséquences sont d'autant plus redoutables que les façades constituent souvent, par ailleurs, des milieux attractifs qui comprennent de grandes concentrations de populations en raison des potentialités justement liées au contact des terres et des mers.

\section{I/ LES FAÇADES OCÉANIQUES : DÉFINITION, CARACTÉRISATION ET DYNAMIQUES}

\section{1/ Les propriétés générales des façades océaniques}

Les façades océaniques correspondent avant tout aux lieux de contact entre les continents et les océans. Elles partagent cette propriété avec les littoraux, mais surpassent largement ces derniers par leurs dimensions. Ce sont les façades de continents donnant sur des océans, ce qui justifierait pareillement de les désigner sous l'appellation de façades continentales. Le terme de façade océanique s'impose cependant, parce qu'elles s'identifient initialement par le nom de l'océan sur lequel elles s'ouvrent, en géographie physique comme en géographie humaine : façades atlantiques de l'Ancien et du Nouveau Monde, façades pacifiques américaine ou asiatique, façades de l'océan Indien plus fragmentées, à la fois africaines, indiennes et australiennes. Les façades océaniques sont, en tout cas, des entités géographiques originales qui impliquent une analyse conjointe des milieux continentaux et des milieux océaniques.

\section{$111 /$ Des interfaces majeures à la surface du globe}

Une interface se définit comme une limite commune à deux ensembles ou comme une surface de séparation entre deux états de la matière. Une façade 
océanique constitue évidemment une interface majeure à l'échelle du globe, puisqu'elle sépare un continent et un océan. Elle correspond en fait à un triple contact entre la lithosphère, l'hydrosphère et l'atmosphère, milieux effectivement différents par leur état, solide, liquide et gazeux. Elle met subsidiairement en contact les eaux douces d'origine continentale (liquides par les embouchures ou glacées, donc solides, par l'intermédiaire de glaciers à front marin) et les eaux océaniques (elles-mêmes liquides ou superficiellement englacées sous forme de banquise). Les façades partagent ces propriétés avec les littoraux, mais avec aucune autre sorte d'interface sur la Terre. Les trois milieux considérés sont mobiles à tous les niveaux d'échelle spatio-temporels : mobilité de la croûte lithosphérique dans le temps (divergence ou convergence) et déformations de sa surface dans l'espace (orogenèse ou subsidence), variation du niveau des mers dans le temps (transgression ou régression) et déplacement du trait de côte dans l'espace (recul ou avancée), instabilité du climat dans le temps (réchauffement ou refroidissement) et fluctuations des zones bioclimatiques dans l'espace (vers le nord ou vers le sud). Ils enregistrent en permanence de puissants transferts de matière, tant, là encore, solide, que liquide ou gazeuse : déplacement de croûte lithosphérique continentale à l'emplacement des continents et création de croûte océanique au fond des mers sous l'effet de la tectonique globale, déplacement de masses d'eau océanique sous l'influence de différents mouvements (eustatisme, houles, marées, courants), déplacement de masses d'air sous l'effet de la circulation atmosphérique ou de circonstances locales. L'expression et l'extension de ces transferts de matière entre milieux voisins dépendent évidemment de la forme et de la disposition des façades.

\section{2/ Des espaces longiformes}

Les façades se rangent parmi les mêmes entités que les vallées et les montagnes à chaînes parallèles, en raison de leur ordonnance linéaire. Elles s'établissent effectivement à partir d'un littoral, donc d'un rivage, qui est le contact le plus élémentaire entre un océan et un continent et qui se réduit à une ligne précise dans l'espace, quoiqu'instable dans le temps. En revanche, les façades ne se réduisent pas plus à un trait de côte que les vallées ne se réduisent à un talweg, ou les montagnes à une ligne de crête, ce qui soulève d'emblée le problème de leur étendue latérale vers les terres et vers le large.

Les façades se présentent en effet comme des espaces aux limites plurielles et indécises, qui dépendent de plusieurs critères et qui impliquent des dégradations (océanisation vers l'extérieur, continentalisation et étagement bioclimatique vers l'intérieur). On peut donc admettre, en s'inspirant pour cela du vocabulaire des géographes maritimistes, qu'une façade s'identifie à partir d'un littoral, séparant un avant-pays océanique, qui s'étend jusqu'à une limite externe, et un arrière-pays continental, qui s'étend jusqu'à une limite interne. Les façades sont de ce fait des milieux asymétriques, par opposition aux vallées (encadrées par des interfluves) ou aux montagnes (limitées par des talwegs ou par des piedmonts).

Les façades s.s. se caractériseraient, pour le moins, par des reliefs côtiers, une sédimentation relativement grossière (en regard de celle des domaines pélagiques), par une influence thermique déterminante de l'océan et par l'intervention de pluies littorales éventuelles, par des formations végétales spécifiques (comme la pelouse littorale tempérée ou la mangrove tropicale) et par des interpénétrations océan-continent à l'emplacement des embouchures et des marais littoraux. Les façades l.s. seraient des espaces sans limites internes ou externes universelles, sinon sans limites précises dans l'espace ni fixes dans le temps, parce que conçues à partir de marqueurs climatiques, hydrologiques, sédimentologiques ou biogéographiques qui se dégradent progressivement, ce qui n'est pas le moindre intérêt des entités géographiques en question.

Les limites externes peuvent être établies vers le large à partir de plusieurs repères selon les endroits : rebord de la pente continentale, fond de fosse de subduction, voire parfois de rift médioocéanique, aires de dépôts des sédiments d'origine continentale vers l'avant-pays... (comme, en sens inverse, les algues flottantes, graines ou noix de coco, oiseaux perdus comme des mouettes ou des passereaux, animaux fixés sur des épaves comme les anatiphes ou les balanes, icebergs significatifs du voisinage d'un relief englacé, bois de flottage issus d'embouchures, étaient autant de signes annonciateurs de la «terre » pour les navigateurs). Il est évident que ces limites externes ne peuvent être systématiquement étendues jusqu'aux limites 
des plaques, au risque d'englober tous les reliefs sous-marins.

Les limites internes sont aussi hétérogènes et souvent aussi floues. Les premières sont d'ordre climatique et sont l'objet de questionnements déjà anciens, notamment sur la «continentalisation» des climats à partir des côtes. Les deuxièmes sont d'ordre biogéographique et passent par la définition des aires de plantes « océaniques » par les botanistes (Dupont, 1962). Les dernières sont d'ordre hydrologique et sédimentologique et s'appliquent aux bassins versants, concernées par le transfert des sédiments corrélatifs de l'érosion des continents vers les océans, sans devoir s'étendre partout jusqu'aux lignes de partage des cours d'eau qui véhiculent ces sédiments (en domaines exoréïques), ce qui rendrait la notion de façade pareillement caduque.

\section{3/ Des espaces principalement méridiens ou subméridiens}

Cette disposition vaut pour les façades atlantiques et pacifiques. Elle est moins évidente pour les façades de l'océan Indien. Elle ne s'applique pas aux bordures de l'Arctique et de l'Antarctique, qui constituent des ensembles géographiques distincts. Elle a deux conséquences fondamentales. Le tracé des façades détermine leur exposition aux courants atmosphériques associés à la circulation générale (et indirectement aux courants océaniques); il contribue donc à justifier les conditions de pénétration des influences océaniques vers l'intérieur. Il perturbe, par ailleurs, la zonalité climatique et bioclimatique générale du globe (Birot, 1968). La proximité de l'océan est responsable, par exemple, des anomalies thermiques spécifiques des climats océanisés. Les façades se présentent ainsi comme des entités transzonales, ce qui leur confère un autre caractère commun avec les chaînes de montagnes et les vallées de certains grands fleuves, à cette différence près que les façades perturbent la zonalité dans le sens transversal (courants de direction ouest-est ou est-ouest), alors que les vallées la perturbent par des transferts hydrauliques méridiens (comme dans les cas du Nil ou du Niger) et que les montagnes la perturbent par des dégradations altitudinales.

\section{4/ Des espaces franchis par de puissants flux lithosphériques, hydrosphériques et atmosphériques}

Ces flux s'effectuent dans chaque sens comme l'illustrent quelques exemples. Les flux tectoniques qui proviennent des déplacements divergents ou convergents de croûte, continentale ou océanique, sont responsables de la répartition des continents et des océans, donc de la configuration générale des façades océaniques et de leur relief. Ils sont également responsables de la définition des marges : marges actives d'océan en voie de fermeture (comme l'océan Pacifique) et marges stables - ou passives - d'océans en expansion (comme l'Atlantique ou la majeure partie de l'océan Indien). Les flux climatiques sont produits par advection, affrontement ou brassage de masses d'air, caractérisées par des températures et une humidité spécifiques, dans le sens océan-continent ou continent-océan. Les flux thermiques et hygrométriques d'origine océanique dirigés vers l'atmosphère (calories, évaporation, humidité) sont orientés vers les continents par la circulation atmosphérique générale ou par les courants marins (comme le Gulf Stream). Ils déterminent ainsi les propriétés du climat et des paysages désormais qualifiés d'océanisés (Vigneau, 2000). Cette océanité (ou océanicité) atténue les effets de la zonalité à toutes les latitudes à cause du rôle de régulateur thermique de la mer, de l'exposition à des masses d'air humide et de la vitesse des vents élevée sur les surfaces marines. Elle relève du phénomène azonal connu sous l'appellation d'effet de façade. L'effet de façade résulte d'abord de la pénétration des influences océaniques sur l'arrière-pays. Ces influences sont inégales selon les façades. Elles sont déterminées par des moteurs (circulation, courants). Elles subissent des obstacles orographiques (montagnes) ou climatiques (circulation des vents de l'arrière-pays vers l'avant-pays). Les flux hydrauliques sont responsables des apports d'eau douce vers les océans qui s'inscrivent dans le cycle de l'eau. Ils servent de vecteurs à la majeure partie des flux sédimentaires qui accompagnent le transfert des matériaux corrélatifs de l'érosion des continents et qui recouvrent les fonds océaniques. À une échelle différente, les estuaires connaissent, au contraire, une pénétration des eaux de mer vers l'intérieur, qui s'accompagne d'une salinité graduée 
des milieux environnants. Les façades océaniques sont diversement exposées aux influences des flux entre continent, océan et atmosphère selon leur latitude et leur orientation. Elles se différencient d'abord selon le sens de ces flux. Elles s'étendent vers l'intérieur, comme vers le large, en fonction de l'ampleur de ces mêmes flux, par un processus de commutation de l'interface.

Les flux s'inscrivent dans des cellules convectives d'origine principalement thermique, qui dépendent de la tectonique globale (accrétion le long des dorsales, subduction le long des fosses), de la circulation atmosphérique générale (ascendance et subsidence de l'air), ou de la circulation océanique générale (plongement et remontée des eaux océaniques en fonction de la température et de la salinité). Ces mécanismes fondamentaux induisent des mécanismes séquentiels, d'origine thermique ou gravitaire : cycle de l'eau, qui s'inscrit dans la circulation générale des climats, cycle sédimentaire, qui s'inscrit lui-même dans les effets de la tectonique des plaques et des cycles d'érosion. Ces cycles séquentiels relèvent des interactions dynamiques complexes qui s'exercent le long des façades océaniques entre continents, océans et atmosphère $(\$ 13)$.

Ces mécanismes, quels qu'ils soient, s'expriment en fait dans les trois dimensions. Les cellules convec- tives sont initialement verticales (tectonique des plaques, circulation atmosphérique, circulation de l'eau), mais s'expriment dans les autres dimensions (chaînes de montagnes, courants marins, champs de pressions et centres d'action, anticyclones pelliculaires des milieux froids). Les façades se situent à l'interface de plusieurs cellules de même catégorie ou de catégories différentes : cellules lithosphériques (marges continentales associées au contact de la croûte continentale et de la croûte océanique), cellules océaniques (courants déviés par la force de Coriolis et par les littoraux). Elles peuvent être franchies par les cellules climatiques (cellules anticycloniques ou dépressionnaires). Chaque façade fonctionne donc comme un système particulier qui résulte de la combinaison de plusieurs facteurs et de plusieurs paramètres définis $(\$ 12)$.

Dans ces conditions, les façades océaniques se présentent effectivement comme des interfaces majeures et comme des entités géographiques dotées d'une dynamique singulière. Une façade pourrait se définir comme : un espace longiforme axé sur un littoral, associant un avant-pays océanique et un arrière-pays continental, entre lesquels s'établissent des combinaisons de flux d'origine tectonique, océanique et atmosphérique, responsables de transferts de matière et parfois de changement d'état de la matière (figure 1).

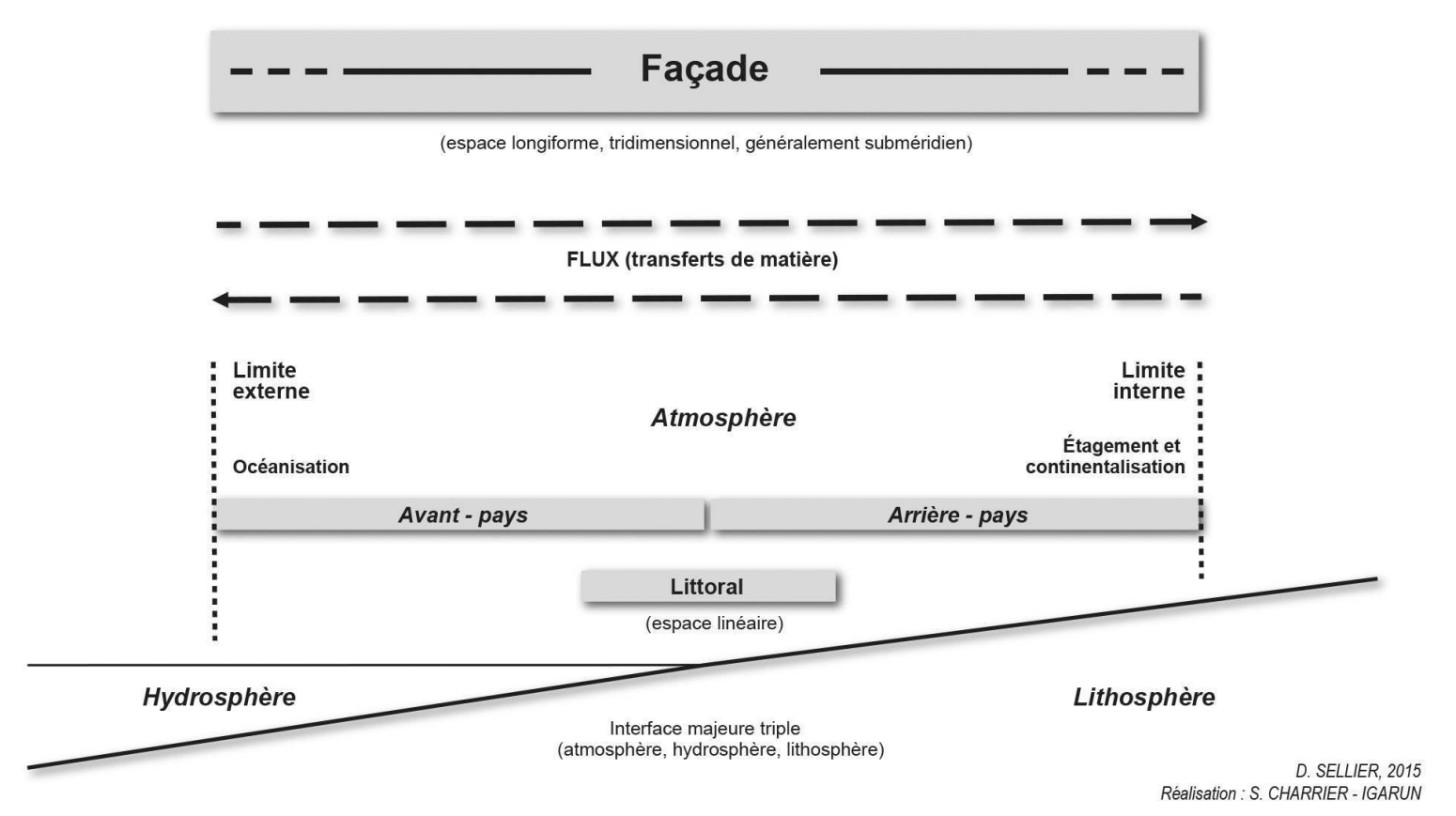

Figure 1 : Les propriétés générales des façades océaniques General properties of oceanic façades 


\section{2/ Les critères de caractérisation des façades océaniques}

Ils comprennent trois facteurs dynamiques, relatifs à la tectonique des plaques, à la circulation océanique (en surface) et à la circulation atmosphérique, ainsi que deux paramètres situationnels et plus statiques : la zonalité et l'orientation (hormis la répartition des terres et des mers, à l'origine d'un déséquilibre initial de la répartition des façades selon les hémisphères). Ils peuvent servir aussi de critères de différenciation (figure 2).

\section{$121 /$ Les trois facteurs dynamiques essentiels de la caractérisation des façades}

La tectonique des plaques est évidemment l'élément fondateur des façades océaniques, puisqu'elle détermine leur disposition et leurs propriétés générales. La croûte continentale, épaisse de $35 \mathrm{~km}$ en moyenne, constitue l'armature des continents. La croûte océanique, partout postérieure au Jurassique, plus mince ( $7 \mathrm{~km}$ en moyenne) et essentiellement composée de basaltes, est masquée par des sédiments marins, épais de $2 \mathrm{~km}$ au centre des océans à $15 \mathrm{~km}$ au pied des pentes continentales. Les plaques lithosphériques qui glissent sur l'asthénos- phère sont parfois exclusivement formées de croûte océanique, mais sont généralement composées de croûte océanique et de croûte continentale. Leurs limites, soulignées par des ceintures sismiques et volcaniques, correspondent à des phénomènes géodynamiques majeurs : dorsales océaniques, fosses et chaînes de subduction, sinon chaînes de collision entre plaques continentales. Leur dynamique détermine les types de marges continentales : marges de convergence, dites actives, ou marges de divergence, dites stables, auxquelles s'ajoutent, par endroits, des marges de coulissement (Boillot et Coulon, 1988; Allègre, 1999).

Les marges continentales constituent donc l'armature lithosphérique des façades océaniques. Elles résultent de mouvements latéraux, à résultante verticale : chaînes plissées sur les marges actives ou bourrelets marginaux sur les marges stables, au niveau des reliefs continentaux, précontinents ou fosses de subduction, au niveau des reliefs sous-marins. Le véritable contact océan-continent correspond au rebord immergé d'un continent (Vanney, 2003). Ce contact s'étend au moins jusqu'à la pente continentale. Il peut aussi s'étendre jusqu'à la rencontre de deux plaques : dorsales océaniques ou fosses de subduction, qui constituent les limites dynamiques dont dépendent les reliefs sous-marins et continen-

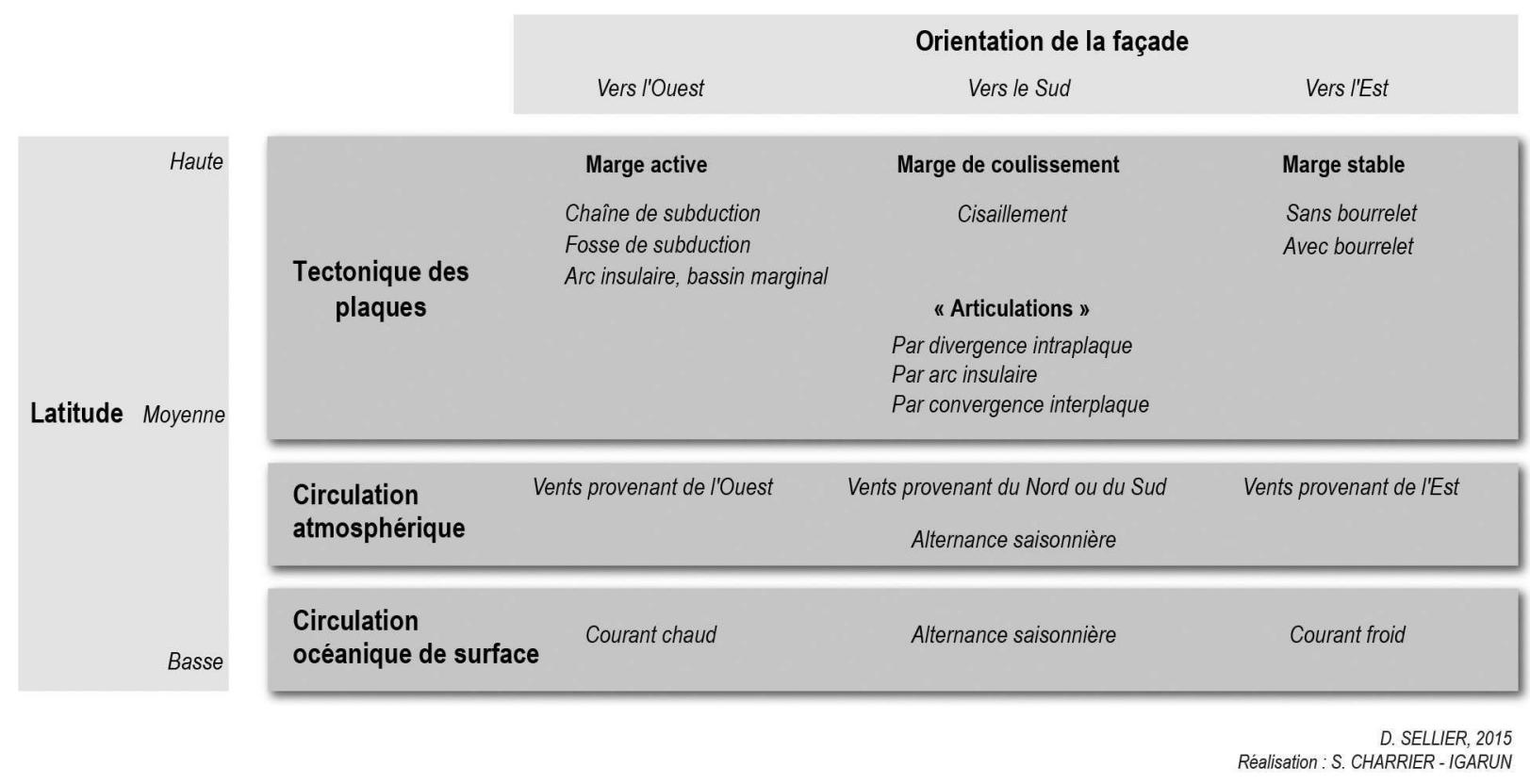

Figure 2 : Les critères de caractérisation des façades océaniques Characterization factors of oceanic façades 
taux. Par leur disposition, leurs dimensions et leurs origines, les façades océaniques sont donc à dissocier de simples façades maritimes situées en bordure de mers intracontinentales (Méditerranée, mer Noire, Caraïbes).

Les marges stables s'inscrivent dans une dynamique distensive, marquée par un rifting (déchirure continentale), survenu au cours d'une séquence de spreading (ouverture et expansion océanique à partir d'une dorsale océanique). Une marge stable voit donc le contact de deux ensembles solidaires, le premier formé de croûte continentale (plate-forme continentale et pente continentale, composant le précontinent), le second formé de croûte océanique (bassins océaniques et dorsales océaniques qui servent d'axe dynamique à l'ensemble). La marge est stable parce que le contact croûte océanique-croûte continentale est fixe à la base de la pente continentale. L'avant-pays d'une façade s'étend donc au moins jusqu'à la pente continentale. L'arrière-pays est stable et normalement formé de plates-formes (boucliers et tables ou massifs anciens et bassins sédimentaires); il est parfois rehaussé, près des côtes, par un bourrelet marginal, éventuellement doté d'un grand escarpement du côté océanique, comme dans le cas des Scandes : héritage persistant du rehaussement provoqué par l'intumescence de la croûte lors de la déchirure continentale qui a précédé l'ouverture d'un océan (Birot et Godard, 1982 ; Vanney, 1982).

Les marges actives s'inscrivent dans une dynamique compressive et présentent des caractères opposés. Elles proviennent de la subduction d'une plaque océanique sous une plaque continentale, relativement moins dense. Une marge active jalonne donc la rencontre de deux ensembles convergents, matérialisés par le couple fosse océanique-chaîne de subduction. Elle se caractérise aussi par une sismicité et par un volcanisme spécifiques, qui se manifestent au large et surtout dans l'arrière-pays, parfois jusqu'à $250 \mathrm{~km}$ des côtes (Rougerie, 2003). L'étendue, vers l'intérieur, des manifestations tectoniques de la marge active et de la subduction contribue à déterminer les limites internes d'une façade océanique.

Ainsi, les relations océan-continent s'établissent d'abord à partir de la tectonique globale et sont fondamentales pour caractériser et classer les façades océaniques. Les océans doivent leur existence à la déchirure et à la dérive des continents, événement fondateur des marges stables. Les chaînes de montagnes doivent leur formation à la fermeture d'un océan, événement fondateur des marges actives. Les façades comptent donc parmi les espaces où la tectonique engendre les effets géomorphologiques les plus éminents. Sur les marges actives se trouvent les chaînes plissées de subduction (reliefs de «montagnes jeunes »), mais aussi les fosses de subduction sous les océans, un volcanisme continental et une sismicité continentale et sous-marine (tsunamis). C'est le cas des façades pacifiques américaines ou asiatiques. Sur les marges stables se trouvent les bourrelets marginaux (reliefs de " montagnes vieilles ») et les plates-formes continentales les plus étendues. C'est le cas des façades atlantiques de l'Ancien Monde et du Nouveau Monde.

L'appartenance d'une façade à telle plaque et à tel type de marge (active ou stable) constitue le premier critère de sa caractérisation.

La circulation océanique générale est le deuxième facteur dynamique de la caractérisation des façades. Les océans recouvrent $71 \%$ de la surface du globe et l'océanité du climat est l'une des composantes essentielles des façades océaniques. Cette océanité tient d'abord à trois propriétés générales des océans et des climats océaniques authentiques, c'est-à-dire de ceux qui règnent au-dessus des océans, comme l'a justement énoncé Vigneau (2000). Les propriétés de ces climats océaniques proviennent d'abord des conditions d'échange d'énergie à l'interface océanatmosphère. Les eaux marines ont une capacité de stockage d'énergie plus importante que celle des continents («l'avantage énergétique des océans »). Par ailleurs, elles présentent une forte inertie thermique, résistance à l'échauffement comme au refroidissement, donc une faible amplitude thermique à tous les pas de temps (diurne à annuel). Les océans exercent par conséquent un effet pondérateur sur l'atmosphère et sur les régions maritimes. C'est le rôle bien connu de régulateur thermique qui s'exerce auprès des côtes et de l'arrière-pays et qui contribue à la caractérisation des façades. Les océans fournissent par ailleurs les surfaces d'évaporation les plus vastes qui soient. Ils imprègnent les masses d'air océanique de vapeur d'eau. Ils exercent un rôle pluviogène et sont généralement responsables de précipitations fréquentes et élevées qui se poursuivent au-delà des côtes par l'intermédiaire 
des pluies littorales et autres types de précipitations, ce qui contribue également à la caractérisation des façades. L'océan exerce enfin un rôle propagateur des vents. Les champs de pressions sont semblables au-dessus des océans et des continents, mais les océans forment des plans propices au déplacement rapide des masses d'air sous les effets du vent. La force et la fréquence du vent font donc aussi partie des effets de façade. Toutes ces propriétés déterminent celles des masses d'air qui transitent audessus des océans. Ces masses d'air sont humides, peu contrastées thermiquement et instables. Ces propriétés sont ensuite transmises aux masses d'air qui surmontent les continents en produisant les climats océanisés, normalement plus humides, moins contrastés et plus ventés que les climats continentaux. Leur pénétration dans l'arrière-pays dépend de la circulation atmosphérique générale et des reliefs.

Les océans sont animés par des mouvements qui participent également aux propriétés des façades : marées, houles et courants de surface. Les marées sont d'ampleur (marnage) et de rythmes (semidiurnes, diurnes...) qui diffèrent selon les endroits dans le monde; elles animent des courants de marée. Les houles résultent principalement des vents géostrophiques, eux-mêmes conditionnés par la circulation générale. Les courants, froids ou chauds, proviennent de la circulation atmosphérique générale (vents dominants) et de la circulation thermo-haline des océans (plongée des eaux les plus froides et des eaux les plus salées, entraînant des mouvements de compensation dans les trois dimensions) (Vanney, 1991 ; Vigneau, 2000). Leurs trajectoires sont déviées par la force de Coriolis. Leur organisation est globalement symétrique par rapport à l'équateur, mais se trouve également influencée par la configuration des continents et des océans. Ces courants sont de puissants agents de transferts thermiques longitudinaux, donc méridiens et transzonaux; ils contribuent au réchauffement ou au refroidissement des façades océaniques et, ainsi, aux anomalies thermiques qui les affectent. Trois circuits majeurs se distinguent en premier lieu : les courants zonaux équatoriaux, de sens est-ouest, déterminés par les alizés et les courants méridiens chauds qui véhiculent des eaux tropicales vers les régions tempérées ou froides, dont le Gulf Stream constitue un cas emblématique. S'y ajoutent la dérive nord-pacifique et le Kouro-Shivo et, au sud, le courant du Brésil, le courant des Aiguilles et le courant d'Australie orientale. Tous ces courants sont générateurs d'anomalies thermiques positives sur les façades concernées. Les courants méridiens froids, issus, pour leur part, des eaux polaires : courant du Labrador, courant du Groenland oriental et Oya-Shivo sur les façades orientales, et, au sud, courant de Humboldt, courant de Benguela et courant d'Australie occidentale sur les façades occidentales entraînent des anomalies thermiques négatives le long des continents concernés. Une mention est à réserver aux courants d'upwelling, courants de façade par excellence qui résultent d'interactions à la fois orographiques, atmosphériques et océaniques ( $\$ 13$ ).

L'exposition d'une façade à tel courant de surface, chand ou froid, est un deuxième critère fondamental de sa caractérisation.

La circulation atmosphérique générale est le dernier des facteurs dynamiques de la caractérisation des façades. Elle contribue à l'extension des influences océaniques vers l'intérieur des continents (Planchon, 2000). Les climats océanisés se caractérisent en premier lieu par des propriétés thermiques et pluviométriques zonales; ils portent d'abord les marques des masses d'air arctique, polaire ou tropicale auxquelles ils se rapportent. Ils portent également les marques azonales de l'océanité, qui s'expriment par une diminution des amplitudes thermiques et par une augmentation de l'humidité de l'air, donc des précipitations. C'est aux latitudes tempérées que ces marques d'océanité s'expriment le mieux parce qu'elles s'appliquent à un substrat climatique déjà sans excès. La pénétration des influences océaniques vers l'arrière-pays, dont résulte l'effet de façade, dépend de la circulation atmosphérique générale, donc de l'orientation des façades et de leur relief. Elle contribue évidemment à définir leurs propriétés, dont la largeur de leur arrière-pays.

La circulation générale s'exprime en trois dimensions, comme la circulation océanique, et dépend des anneaux troposphériques de disposition zonale qui contrôlent les cellules de circulation : les deux anneaux qui se côtoient aux latitudes équatoriales, formés des cellules de Hadley nord et sud et les deux anneaux qui leur succèdent vers le nord et vers le sud, formés des cellules de Ferrel nord et sud. Ces anneaux tiennent aux conditions d'insolation du globe. Ils déterminent à leur tour les grands centres d'action (dépressions équatoriales, anticy- 
clones subtropicaux, dépressions des hautes latitudes). Ces centres d'action sont les moteurs des vents, qui assurent ensuite la pénétration éventuelle des influences océaniques vers l'arrière-pays des façades océaniques. Les conditions de cette pénétration déterminent des situations qui annoncent déjà celles de la zonalité.

L'influence d'une circulation des masses d'air vers l'ouest ou vers l'est est un troisième critère de caractérisation d'une façade.

\section{2/ Les deux principaux paramètres statiques de la caractérisation des façades}

Il s'agit des paramètres qui tiennent à la situation des façades par rapport aux influences climatiques et océaniques précitées sur le globe.

La situation latitudinale et la zonalité dues à l'exposition aux radiations solaires intéressent d'abord les propriétés thermiques des façades océaniques : façades chaudes, tempérées, ou froides, devenant gelées et englacées vers les pôles. Elles concernent ensuite les propriétés pluviométriques de ces façades : sèches ou humides. Elles concernent enfin le sens de la circulation générale qui peut être réduite, ici, à trois mouvements principaux. La circulation générale d'ouest, ou Westerlies, intéresse les moyennes et les hautes latitudes; elle est associée aux influences prépondérantes des fronts polaires et de leurs perturbations pluviogènes qui impliquent, en particulier, une prépondérance des précipitations d'automne ou d'hiver. La circulation d'est sous l'effet des alizés règne aux latitudes subtropicales et tropicales; elle est associée aux influences prépondérantes du front intertropical de convergence qui déterminent la prépondérance des pluies d'été, en fonction du passage du soleil au zénith (Dresch, 1982). Les moussons, requalifiées d'alizés transéquatoriaux déviés, s'expriment aux endroits où les alizés de l'hémisphère austral parviennent à franchir l'équateur (Asie du Sud-Est, façades de l'océan Indien et golfe de Guinée) (Vigneau, 2000). C'est cette ordonnance zonale fondamentale que viennent perturber les façades par leur disposition.

La situation par rapport à une zone déterminée est donc un quatrième critère de caractérisation d'une façade.
L'orientation des façades océaniques, rendue spécialement déterminante par leur tracé méridien, implique une dissymétrie ouest-est qui s'ajoute au déséquilibre entre les terres et les mers et qui justifie, par exemple, l'absence de façades tempérées étendues dans l'hémisphère sud. L'orientation détermine l'exposition aux effets de la circulation atmosphérique générale et des vents, donc la portée des influences océaniques selon les façades en fonction des flux qui viennent d'être rappelés. Aux latitudes tempérées, les façades ouest, très océanisées quand le relief l'autorise, s'opposent aux façades est, peu océanisées (comme de part et d'autre de l'Eurasie). Aux latitudes tropicales, les façades ouest, peu océanisées (en raison de la direction des alizés), s'opposent aux façades est, plus océanisées (comme de part et d'autre de l'Amérique latine), en dehors du cas de l'exposition aux moussons qui concerne, notamment, les façades asiatiques de l'océan Indien. De même façon, l'orientation détermine l'exposition aux effets de la circulation océanique et des courants. Ainsi, par exemple, les façades des latitudes tempérées de l'hémisphère nord se trouvent sous l'influence de courants chauds à l'ouest et froids à l'est des continents; à l'inverse, celles de l'hémisphère sud se trouvent sous l'influence de courants froids à l'ouest et chauds à l'est.

L'orientation est ainsi responsable de la dilatation latitudinale des milieux tempérés océanisés sur les façades occidentales des continents, où ces milieux débordent de leurs latitudes ordinaires, comme en Europe (et en Amérique du Nord, puisque toute la façade pacifique des États-Unis est soumise à des climats tempérés de types divers). Elle justifie, en contrepartie, la contraction latitudinale des mêmes milieux sur les façades orientales des continents en Amérique du Nord, mais aussi en Asie, puisque le Japon est soumis à des climats froids au nord et à la mousson d'été au sud (Lageat, 2004).

L'orientation est donc responsable d'une dissymétrie particulièrement évidente entre les façades occidentales et orientales des continents, sur le plan thermique et pluviométrique. Elle entraîne plusieurs formes de dissymétries subordonnées, qui s'appliquent aux formations végétales zonales et à leurs contacts (comme l'écotone forêt boréaletoundra qui s'observe à $52^{\circ}$ de latitude nord dans l'Est canadien, mais entre 60 et $70^{\circ}$ le long des côtes de Norvège), ou aux aires de répartition de 
certaines espèces animales (comme des manchots qui remontent vers le tropique sur les façades ouest de l'Afrique du Sud, de l'Amérique du Sud, ou de la Nouvelle-Zélande). Elle a même concerné, exemple historique cette fois, la répartition d'établissements humains aux limites de l'œcoumène, comme les colonies norses implantées à l'ouest du cap Farewell (où circule un courant ascendant et chaud) et non à l'est (où circule le courant du Groenland oriental, descendant et froid).

L'orientation est ainsi le cinquième critère de caractérisation d'une façade.

\section{3/ Les interactions dynamiques le long des façades océaniques}

Elles sont le propre des façades, par leur multiplicité et par leur portée. Elles procèdent des influences de chacun des trois facteurs dynamiques précités sur les deux autres : l'un continental, impliquant principalement les types de marges, l'autre océanique, impliquant principalement les courants, le dernier climatique, impliquant les masses d'air, la circulation générale et les vents. Ces influences s'établissent selon des relations doubles ou triples, souvent complexes. Leur hiérarchie contribue à caractériser les façades et à justifier leurs limites.

\section{1/ Les influences des continents sur les océans et sur les climats le long des façades}

Les influences des continents sur les océans s'expriment d'abord par l'approvisionnement de ces derniers en eau, au même titre que les précipitations directes à leur surface. Les façades se situent à l'interface de la principale surface d'évaporation (celle des océans), de la source des précipitations (l'atmosphère) et des lieux de l'écoulement (les continents). Elles se situent au terme des bassins versants continentaux jalonnés par les embouchures (estuaires ou deltas). Elles se singularisent par la juxtaposition de réseaux hydrographiques mal hiérarchisés, de dimensions contrastées (grands fleuves comme cours d'eau côtiers minuscules), auxquels s'associent éventuellement des marais littoraux et des zones humides. La configuration générale du relief et la typologie morphostructurale des marges (chaînes plissées ou plates-formes) conditionnent, par ailleurs, la profondeur des lignes de partage des eaux, donc l'étendue des bassins versants vers l'arrière-pays. Les chaînes plissées les plus élevées et les plus proches des côtes restreignent l'étendue de ces bassins versants, sans forcément réduire leurs apports sédimentaires, en raison d'une érosion théoriquement plus agressive, en modes d'écoulement équivalents.

Les façades sont en effet des sites privilégiés du transit sédimentaire, puisqu'aux apports en eau se combinent les apports en sédiments solides ou en solution vers l'avant-pays, avant leur accumulation finale sur le précontinent puis au fond des océans. La sédimentation océanique marque ainsi le terme de processus d'érosion en action sur les continents, le stade du dépôt après ceux de l'ablation et du transport. Il existe en l'occurrence une double relation continent-océan : la dynamique océanique (ouverture ou fermeture) crée les reliefs montagneux aux dépens desquels s'exerce l'érosion (bourrelets marginaux ou chaînes de subduction); en retour, le relief continental contrôle les conditions de la sédimentation océanique par les recouvrements des bassins océaniques. Il détermine auparavant les stocks de sédiments corrélatifs de l'érosion des continents le long des façades. Ainsi, les marges stables comprennent des marges maigres en avant des reliefs continentaux les plus bas, où la sédimentation demeure inférieure à un ou deux milliers de mètres d'épaisseur (comme au nord du golfe de Gascogne), et les marges grasses, associées aux reliefs les plus élevés ou aux embouchures des fleuves les plus chargés et à une sédimentation parfois épaisse de 10000 à 15000 m (comme au sud du golfe de Gascogne). La typologie sédimentologique de ces marges, maigres ou grasses, fournit un moyen de classification complémentaire des façades océaniques. Les façades sont aussi à l'origine de processus et de modelés sous-marins commandés par la proximité des continents : stocks sédimentaires fournis par les embouchures, dépôts relativement grossiers près des côtes et granulo-décroissance des matériaux vers le large, mais aussi deltas sous-marins sur les platesformes continentales et avalanches sous-marines provoquées par la surcharge sédimentaire des plateaux continentaux sur la pente continentale.

L'une des principales influences du relief des marges continentales sur les courants s'exerce par le mécanisme de l'upwelling (ou upwelling côtier), qui implique en fait des relations entre facteurs oro- 
graphiques, atmosphériques et océaniques et qui constitue donc un phénomène de façade par excellence. Ces courants mettent en cause les anticyclones tropicaux situés au large des côtes (Pacifique sud, Atlantique sud, Açores) et les reliefs continentaux (surtout des chaînes plissées, comme les Andes). Ces anticyclones dynamiques sont maintenus à l'écart des côtes par les reliefs, qui provoquent un renforcement des vents, en l'occurrence les alizés, provenant du sud-est dans l'hémisphère sud ou du nord-est dans l'hémisphère nord. Les alizés sont renforcés par ces reliefs et s'éloignent des côtes, en repoussant les couches d'eaux chaudes superficielles vers le large et en entraînant la remontée d'eaux profondes plus froides vers la surface, ce qui constitue le phénomène d'upwelling. Ce dernier entraîne donc le refroidissement des eaux océaniques superficielles, des espaces côtiers voisins et des masses d'air les plus basses sur des façades où des courants, déjà issus de latitudes tempérées ou froides, circulent vers l'équateur (courants de Californie, de Humboldt, de Benguela, des Canaries, d'Australie occidentale). La subsidence atmosphérique créée par les anticyclones tropicaux dynamiques est accentuée par une subsidence thermique liée à l'air froid. Celle-ci entraîne à son tour la présence de déserts littoraux (aussi appelés déserts brumeux en raison d'une nébulosité persistante provoquée par les advections d'air marin, humide et froid, vers les côtes). Le phénomène d'upwelling, actif en Basse-Californie, en Mauritanie et en Namibie, est spécialement prononcé sur la façade océanique du Chili et du Pérou, où il se trouve périodiquement perturbé par le phénomène El Niño. Les causes de ce dernier se produisent au large : le contre-courant équatorial, de direction ordinaire ouest-est, se renforce certaines années, en ramenant des eaux chaudes vers la façade pacifique de l'Amérique du Sud, en modifiant la stratification des eaux océaniques (notamment la profondeur de la thermocline), en réchauffant l'atmosphère (en particulier à basses altitude), en déclenchant des ascendances (d'origine convective) et en entraînant, par endroits, des précipitations exceptionnellement abondantes ainsi qu'un cortège de désordres écologiques.

Les influences des continents sur les climats, notamment celles des reliefs des marges continentales sur les climats des façades océaniques, sont au moins de trois ordres. L'océanité des façades dépend du sens de la circulation atmosphérique, de l'orientation des façades, donc de l'exposition à cette circulation, et du relief qui favorise ou qui contrarie la pénétration des influences océaniques vers l'arrière-pays. Il existe, de ce fait, des montagnes-barrières comme les Andes et les Rocheuses (chaînes côtières), ou au contraire de larges couloirs de pénétration, comme les plaines de l'Europe du Nord, où la continentalisation progressive du climat prive de limites internes fixées sur des seuils évidents. En contrepartie, des déserts d'abri s'étendent en arrière de montagnes côtières. Ces déserts résultent de la présence des reliefs qui bloquent les influences des masses d'air humide d'origine océanique (Dresch, 1982). Ils apparaissent surtout à l'arrière de chaînes de subduction associées aux façades occidentales des continents, en particulier en Amérique du Nord (chaîne des Cascades, Sierra Nevada et désert Mohave) et en Amérique du Sud (Chihuahua au Mexique, Puna de Atacama au Chili, désert péruvien et diagonale aride des Andes en Bolivie, Argentine, Patagonie). Enfin, les climats de montagne, associés à des chaînes de subduction autant qu'à des bourrelets marginaux, désorganisent eux aussi la zonalité, en créant des conditions climatiques qui prolongent les milieux froids en direction de l'équateur. Ils contrarient les effets de façade en introduisant ceux de l'altitude et des étagements par la réduction des températures, par l'augmentation des amplitudes, du gel et des précipitations littorales et orographiques (qui atteignent des totaux considérables comme au nord-ouest des Rocheuses), par l'accroissement des taux de nivosité et, finalement, par l'apparition d'un étage glacio-nival.

\section{2/ Les influences océaniques sur les climats et sur les continents le long des façades}

L'influence de l'océan sur les climats des façades, que l'effet de façade illustre de façon emblématique, passe par l'intermédiaire des climats océaniques authentiques, dont les propriétés principales ont été exposées. Cet effet de façade, au sens traditionnel du terme, s'exprime lui-même à travers les propriétés des climats océanisés. Subordonné à la zonalité, il se traduit partout, mais à des degrés divers, par des valeurs thermiques moins contrastées qu’à 
l'intérieur des continents (donc par des amplitudes moyennes annuelles réduites), des régimes thermiques décalés, des précipitations abondantes et fréquentes, une nébulosité élevée et des types de temps instables. Les façades sont directement exposées aux vents géostrophiques lorsqu'ils proviennent du large. Elles sont aussi soumises aux vents locaux, parfois alternatifs, jusqu'au niveau des brises de mer (et des brises de terre). L'effet de façade, tel qu'il vient d'être résumé, s’intègre aux dissymétries climatiques qui s'observent sur les côtés opposés des continents et qui ont plusieurs implications, en particulier sur la répartition des formations végétales. Ces dissymétries sont accrues par les courants, notamment par les courants chauds ou froids qui longent les façades des moyennes et hautes latitudes. Il convient de distinguer à ce sujet les courants chauds apportant chaleur et humidité vers les pôles, comme le Gulf Stream et la dérive nord-pacifique, et les courants froids apportant froid et sécheresse vers l'équateur, justifiant les aridités côtières précitées, qui s'ajoutent parfois à celles de déserts zonaux. Les courants sont donc de puissants agents d'échange méridiens, en particulier d'eaux froides vers les moyennes latitudes et d'eaux chaudes vers les hautes latitudes, où ils contribuent à la compensation des déficits du bilan radiatif.

Les façades tiennent aussi de l'océan une exposition à des accidents météorologiques désastreux. Il s'agit des tempêtes qui surviennent à des fréquences variées sous toutes les latitudes, d'abord en mer et ensuite à partir des côtes. Il s'agit surtout des cyclones tropicaux, également dénommés ouragans ou typhons, qui naissent d'une conjonction de conditions océaniques et climatiques particulières. Les cyclones sont des systèmes dépressionnaires à rotation rapide, nuageux et pluviogènes de plusieurs centaines de kilomètres de diamètre, caractérisés par un gradient très élevé et par un creux central parfois inférieur à $900 \mathrm{hPa}$ (Vigneau, 2000). Ils ne se forment qu'au-delà de $5^{\circ}$ de latitude, au-dessus d'océans dont la température, portée à $26^{\circ} \mathrm{C}$, alimente une ascendance brutale d'air chaud et humide. Ils suivent ensuite une trajectoire sinueuse à une vitesse de 15 à $30 \mathrm{~km} / \mathrm{h}$. Les vents peuvent souffler à plus de $300 \mathrm{~km} / \mathrm{h}$ et les pluies dépasser $1000 \mathrm{~mm}$ en 24 heures. En dehors de la haute mer, les cyclones tropicaux sont principalement actifs sur les façades orientales des continents: Afrique du Sud-Est, Caraïbes et sud des Etats-Unis, Asie du Sud-Est. Ils s'accompagnent de tempêtes de marée particulièrement dangereuses sur les côtes. Ils perdent progressivement de leur puissance après leur course océanique parce que les conditions de leur fonctionnement ne sont plus entretenues audelà des côtes. Ils se rangent parmi les phénomènes de façades en raison de leur formation, de leur répartition et de leur dégradation. Deux autres phénomènes météorologiques majeurs, qui ne tiennent pas aux océans pour leur genèse, mais qui doivent beaucoup au rôle pluviogène de ces derniers, sont très actifs sur certaines façades et contribuent ainsi à leur caractérisation. Le premier agit dans les domaines tropicaux. Il concerne la mousson, quand elle vient de l'océan, au-dessus duquel les masses d'air se saturent en humidité avant d'entraîner des abats d'eau très élevés sur les façades abordées. Le second agit essentiellement aux latitudes tempérées. Il concerne les perturbations qui se produisent au niveau des fronts, en particulier du front polaire. En raison des effets d'une circulation atmosphérique soumise à des flux d'ouest prépondérants, ces perturbations sont à l'origine des principaux apports pluviaux sur les façades occidentales des domaines tempérées, où elles constituent l'une de leurs spécificités climatiques.

L'influence directe des océans se manifeste à l'interface océan-continent par une érosion littorale parfois rapide, en tout cas quantifiable à l'échelle historique. Cette érosion s'applique à partir du trait de côte, défini par Pinot (1998) comme "la ligne qui marque la limite jusqu’à laquelle peuvent parvenir les eaux marines ». Elle constitue un système d'érosion complet, qui comprend des processus d'ablation, de transport et de dépôt spécifiques à plusieurs niveaux d'échelle. Ces processus sont conditionnés par la houle, les marées, les courants, l'eustatisme, donc par les mouvements des masses océaniques à différentes dimensions spatio-temporelles. Ils engendrent des modelés, par nature linéaires, qui dépendent des conditions de la morphogénèse et qui portent donc les marques de la zonalité. Néanmoins, ils dépendent aussi des propriétés du continent attaqué : élévation, structure, mais aussi formes initiales. Ces reliefs, dont les falaises et les plages comptent parmi les plus caractéristiques, sont d'une variété qui justifie une part spéciale de la géomor- 
phologie. Leur typologie morphologique déborde évidemment d'une simple présentation des façades océaniques. La géomorphologie littorale s'inscrit néanmoins à l'intérieur de la géomorphologie des façades. À un niveau d'échelle inférieur, l'influence des eaux marines et surtout des masses d'air océanique sur les reliefs proches des côtes se traduit par des processus particuliers, comme l'haloclastie, la dissolution par l'eau de mer ou la déflation, dont les effets s'estompent cependant non loin des côtes. En revanche, l'humidité des masses d'air en question favorise la météorisation et le ruissellement. À une dimension très supérieure, le niveau des océans influence l'encaissement des réseaux hydrographiques et l'abaissement des interfluves. Il règle théoriquement le terme de l'érosion des continents et sert de niveau de référence aux aplanissements dans les domaines exoréïques : les aplanissements se réalisent en premier lieu à partir des littoraux, donc des façades océaniques. Le niveau des mers est un des facteurs qui agissent sur les séquences d'érosion des continents, en particulier au cours des régressions marines. Le phénomène est universel. Néanmoins, il existe des façades à partir desquelles les aplanissements sont largement accomplis et dont l'arrière-pays s'élève progressivement vers des lignes de partage des eaux éloignées; ce sont celles où les effets de la morphogenèse l'emportent, comme dans le cas des façades atlantiques. Il existe par ailleurs des façades à partir desquelles les aplanissements ne font que s'amorcer; ce sont celles où les effets de l'orogenèse actuelle l'emportent, comme dans le cas des façades pacifiques.

La proximité des océans et des continents a également de multiples implications biogéographiques. Les premières formes de vie furent en effet aquatiques, parce que les conditions thermiques étaient moins contrastées dans les océans que dans l'atmosphère et parce que le potentiel nutritif y était supérieur (Vanney, 2002a, 2002b). L'océan a été le foyer de la diffusion de la vie terrestre, à partir des littoraux, donc des façades océaniques; les premières classes de vertébrés sont les poissons et les amphibiens. Les façades océaniques continuent d'être fréquentées par la faune marine, notamment par les oiseaux pélagiques qui nidifient sur les côtes (albatros, pingouins, frégates, fous), les tortues de mer qui débarquent sur les plages tropicales pour la ponte, les mammifères marins qui sont des habi- tués des littoraux (phoques, otaries, morses), les oiseaux marins qui suivent les fleuves (cormorans, mouettes rieuses présents jusqu'au lac Léman), les espèces de poissons anadromes (saumons, aloses) ou catadromes (anguilles). Elles enregistrent aussi les apports floristiques accomplis par l'intermédiaire des oiseaux et des courants.

Dans cette perspective, les façades océaniques se présentent comme un écotone entre les océans et les continents (Godet, comm. pers). Elles se présenteraient ainsi, dans une certaine mesure, comme des interfaces quadruples, impliquant la biosphère, comme la lithospère, l'hydrosphère et l'atmosphère.

L'océanité détermine, également, des conditions écologiques particulières sur les façades océaniques des continents et d'abord près des littoraux. L'humidité, supérieure à celle des espaces continentaux voisins, la fraîcheur des étés et la modération des hivers, déterminent une végétation océanique et des cortèges floristiques spécifiques. L'océanité implique une biomasse plus importante, une biodiversité plus élevée, une végétation plus verte, sauf cas particuliers, dont celui des déserts côtiers, mais aussi celui de landes océaniques des domaines tempérés. Elle s'exprime aussi par des formations végétales particulières, comme la lande océanique, la mangrove, les franges littorales d'arécacées. L'exposition aux influences océaniques implique en revanche des contraintes météorologiques dues à l'excès d'humidité, à la fraîcheur des étés et au vent, qui entrave, par endroits, la végétation arborescente.

\section{3/ Les dynamiques climatiques et leurs influences sur les continents et sur les océans}

Ce registre est plus restreint en raison de l'ordre suivi pour présenter les multiples relations réciproques qui unissent les océans, les terres et les masses d'air le long des façades. Les influences des climats sur les façades s'expriment en premier lieu à travers la zonation des processus, des formes, des héritages et, finalement, des paysages.

Les influences de la zonation climatique sur les océans s'expriment avant tout par des facteurs thermiques dont les effets directeurs et les principales manifestations sur les océans et sur les façades océaniques ont été déjà évoqués. Ces facteurs 
constituent, notamment, l'un des moteurs de la circulation océanique et de l'organisation des courants de surface. Ils ont de multiples relations sur les autres agents climatiques, biogéographiques et morphogéniques des continents.

Par ailleurs, la zonation des climats détermine les conditions de fonctionnement du cycle de l'eau audessus des océans et sur les façades : l'évaporation à partir des surfaces océaniques, la teneur des masses d'air océanique ou océanisé en humidité, ainsi que leur degré de saturation, les processus de condensation, les quantités et les régimes des précipitations et, par conséquent, les modalités de l'écoulement. Il existe, ainsi, des façades humides, arrosées, recoupées par d'immenses embouchures, près de l'équateur, et des façades arides le long desquelles les cours d'eau allochtones demeurent rares, aux abords des tropiques. Il existe aussi des façades, dans les hautes latitudes, où le cycle de l'eau se trouve restreint à tous les niveaux. Le froid entrave l'évaporation, engendre la banquise (qui réduit encore les possibilités d'évaporation), limite les précipitations, entraine la rétention nivale, provoque la capitalisation glaciaire et occasionne, finalement, un écoulement saisonnier.

Le vent, dernier agent climatique à considérer, détermine la puissance des houles par son orientation, sa course et sa puissance. L'agitation des eaux marines présente donc elle aussi des propriétés zonales, des variations saisonnières ou accidentelles, des effets contrastés selon les orientations des façades (Davies, 1964; Lageat et Miossec, 2003). Les domaines tempérés et subpolaires, soumis aux flux d'ouest, connaissent des houles puissantes, notamment à l'occasion des tempêtes, qui sévissent le plus souvent en hiver (Tonnerre, 2001). Les domaines tropicaux et subtropicaux sont moins agités en dehors des passages des cyclones. Les houles constituent les principaux agents de l'érosion littorale.

La zonation climatique exerce une influence fondamentale sur les conditions de la morphogenèse actuelle, ainsi que sur les phytocénoses et zoocénoses qui contribuent à l'environnement biogéographique des modelés littoraux. Les façades s'inscrivent de ce fait à l'intérieur de milieux variés depuis les régions polaires jusqu'aux tropiques. Les caractères généraux de trois d'entre eux méritent d'être résumés.

En dépit d'une répartition inverse des espaces continentaux et océaniques entre l'Arctique et l'An- tarctique, les façades des milieux froids sont contrôlées par le gel permanent ou saisonnier des eaux continentales et des sols (gélisols et glaciers, shelf en Antarctique, embâcle des grands fleuves et de leurs embouchures dans l'Arctique) et par la congélation des eaux marines (banquise permanente et saisonnière). L'état solide des eaux remet en cause les mécanismes ordinaires de la morphogenèse, sur les côtes et espaces proches encore assimilables aux façades. En revanche, leur retour saisonnier à l'état liquide crée des processus singuliers : érosion glaciaire et constructions fluvio-glaciaires, arrachement des berges au cours des débâcles, actions des glaces riveraines et des pieds de glace sur les littoraux, mais aussi effondrement des glaciers à front marin, velage et érosion glacielle, qui composent ensemble un système d'érosion littorale responsable d'une action mécanique dont les effets varient encore en fonction de l'exposition des façades pour des raisons analogues à celles qui entraînent les phénomènes de dissymétries bioclimatiques ou morphoclimatiques.

Les façades de domaines tempérés s'étendent, pour leur part, entre les limites des glaces et celles des récifs coralliens, dans des proportions rendues elles aussi inégales par la répartition déséquilibrée des terres et des mers selon les hémisphères et par la circulation atmosphérique d'ouest aux latitudes concernées. Elles se caractérisent par une forte agitation marine et par une grande énergie des houles sur les côtes, propices à une abrasion efficace. Celle-ci se traduit par la formation de côtes rocheuses : côtes à dénudation, mais surtout falaises et mégafalaises, dont la forme dépend en partie des roches et dont l'élévation dépend du relief de l'arrière-pays, mais dont le profil continue souvent d'intégrer des segments de versants continentaux (Guilcher, 1966, 1979; Pinot, 1998). La force de l'érosion littorale se traduit aussi par la fourniture de galets et la construction de cordons de matériaux grossiers. La formation de cordons dunaires relativement étendus est une manifestation supplémentaire de l'action du vent aux latitudes considérées.

Les façades des domaines intertropicaux, où les effets de l'érosion mécanique sont en partie relayés par ceux de l'érosion chimique, sont normalement moins exposées. Les côtes à falaises y sont moins présentes. En contrepartie, les vasières, alimentées par les argiles corrélatives de l'altération des roches, puis dispersées à partir des deltas des grands fleuves, 
forment l'un des principaux types de modelés littoraux et supportent des formations végétales amphibies comme les mangroves. Les dunes sont peu communes, en réponse au manque de sable quartzeux. Les constructions coralliennes correspondent donc à l'autre type de modelés caractéristiques des littoraux tropicaux. Leur répartition est limitée par les températures des eaux océaniques (en principe 25 à $30^{\circ}$ ) et par leur transparence. Elle est donc incompatible avec la proximité des embouchures de fleuves chargés et des vasières responsables d'une turbidité impropre au développement des coraux. Malgré des caractères azonaux, les littoraux actuels témoignent donc des effets de systèmes morphogéniques zonaux (Lageat et Miossec, 2003).

Les témoignages de cette zonalité s'appliquent également aux héritages. Les reliefs littoraux ont la singularité d'enregistrer doublement les effets des fluctuations des climats, à travers les empreintes des systèmes morphogéniques actuels ou passés (comme les reliefs continentaux), mais aussi - directement - à travers les effets de l'eustatisme. Il en ressort de rapides transformations des formes, associées à la mobilité du trait de côte, mais aussi une profonde originalité des héritages, qui débordent des espaces littoraux actuels et qui s'étendent parfois à l'arrière-pays et à l'avant-pays des façades.

Ces héritages sont spécialement répandus et variés dans les domaines froids et tempérés, où les fluctuations des climats ont connu le plus d'impacts au cours des séquences successives du Quaternaire. Ils appartiennent à trois catégories : les héritages des processus morphogéniques directement déterminés par les paléoclimats, les héritages des transgressions et régressions marines consécutives à ces derniers (glacio-eustatisme) et les héritages des compensations isostatiques des englacements et déglaciations (glacio-isostasie).

Les héritages de périodes froides, pour ne traiter que d'eux, appartiennent eux-mêmes à deux catégories, qui ne se différencient pas toujours d'emblée des effets de processus actuels. Ils présentent de multiples combinaisons de formes glaciaires héritées, sinon, par endroits, fonctionnelles, et de formes périglaciaires héritées, entretenues ou actives, dont les résultats varient encore selon les milieux (glaciaires actuels, périglaciaires actuels mais précédemment englacés, périglaciaires actuels épargnés des englacements pléistocènes, enfin tempérés à héritages périglaciaires) (Sellier, 2009a). Les héritages des processus glaciaires comprennent des modelés rocheux d'abandon, souvent peu retouchés par l'érosion littorale en raison d'une durée insuffisante depuis la fusion des inlandsis et d'une résistance particulière des formes glaciaires à l'érosion, à l'exception des grandes falaises qui font souvent partie des « rivages retrouvés » au terme de plusieurs séquences interglaciaires transgressives (Guilcher, 1954). Ils comprennent par ailleurs des épandages morainiques retaillés par des falaises basses, quand ils ne sont pas remaniés par des écoulements proglaciaires et/ou postglaciaires, et éventuellement bordés de cordons littoraux. Les héritages des processus périglaciaires comprennent également des formes rocheuses, comme les versants composites associant des segments de versants continentaux réglés au sommet et des falaises à leur base (Sellier, 2009b). Ils comprennent surtout des falaises en roches tendres, qui recoupent les dépôts périglaciaires pléistocènes, notamment les matériaux soliflués entrecoupés de paléosols ou de dépôts éoliens, dont le remaniement fournit les sables et galets accumulés par ailleurs.

Les héritages des mécanismes glacio-eustatiques, liés à la rétention des précipitations en période de refroidissement (impliquant une régression) et à la fusion des glaces en période de réchauffement (impliquant une transgression), sont de portée universelle puisqu'ils agissent sur le niveau de l'océan mondial, mais dépendent des conditions de leur enregistrement et de leur conservation (Pirazzoli, 1991, 1996). Ils se rangent eux aussi en plusieurs groupes. Le premier concerne les littoraux perchés généralement significatifs de niveaux transgressifs supérieurs à l'actuel : platiers, plages, parfois grottes et éventuellement paléofalaises. Le deuxième concerne les côtes de submersion de relief fluviaux ennoyés (côtes à rias) ou de reliefs glaciaires d'abandon (côtes à fjords prolongées parfois sur plusieurs centaines de kilomètres vers l'intérieur et côtes à skjär, ou archipels de roches moutonnées qui poursuivent en mer les paysages de knobs and lochans présents à terre). Le dernier concerne les éléments de reliefs continentaux submergés, comme les paléo-vallées sous-marines, mais aussi les paléokarsts, constructions coralliennes ou paléoreliefs granitiques (tors et taffonis ennoyés), les stocks de 
matériaux grossiers et constructions sédimentaires abandonnés sur les précontinents.

À la différence des précédents, les héritages des mécanismes glacio-isostatiques ne s'expriment que dans les régions qui ont été périodiquement recouvertes par les inlandsis et qui ont ainsi enregistré une surcharge responsable d'une subsidence temporaire de la croûte (Scandinavie, Canada). La fusion de ces inlandsis entraîne une décharge de grande ampleur, mais différée dans le temps en raison de l'inertie qui s'applique aux déformations de la croûte, alors que transgression et fusion des glaces sont simultanées. Il en résulte des littoraux soulevés, façonnés à différents stades de la transgression et rehaussés ensuite dans des proportions impressionnantes, compte tenu des délais concernés : 200 m en baie d'Hudson, $300 \mathrm{~m}$ au nord du golfe de Botnie, à l'emplacement du centre d'inlandsis, mais encore quelques dizaines de mètres sur les marges continentales adjacentes, en quelques milliers d'années seulement. Le phénomène affecte donc profondément les paysages des façades et de leur arrière-pays.

L'examen des influences de la zonation climatique sur les continents et sur les océans conduit à évoquer, pour finir, quelques-uns des échanges méridiens qui se produisent le long des façades en perturbant ses effets. Ces transferts se produisent à partir des océans, de l'atmosphère et des continents. Ils proviennent certes des courants océaniques, chauds ou froids, dont les trajets méridiens généralement parallèles aux façades provoquent les anomalies thermiques déjà évoquées, dont l'une des principales concerne les effets du Gulf Stream sur la façade atlantique européenne. Ils proviennent aussi des perturbations qui affectent les fronts, notamment sur les marges des zones subpolaires, tempérées et subtropicales, dont les déplacements permettent le transfert d'air chaud vers les hautes latitudes et d'air froid vers les basses altitudes (Vigneau, 2000). Ils proviennent enfin des reliefs continentaux (chaînes bordières ou bourrelets marginaux), responsables de l'extension des climats froids vers les latitudes tempérées en raison des altitudes et, subsidiairement, de celle des climats arides en raison de la création de déserts d'abri qui contribuent à interrompre plus brusquement les effets de façade. Il est clair que ces transferts peuvent cumuler ou opposer leurs effets. Ainsi, la façade atlantique européenne connaît un réchauffement transzonal de l'océan dû au Gulf Stream jusqu'au-delà du cap Nord et parallèlement, un refroidissement transzonal du continent dû à la présence des montagnes atlantiques jusqu’au Portugal (Sellier, 2006).

\section{2/ LES FAÇADES OCÉANIQUES : IDENTIFICATION, COMPARAISON ET SEGMENTATION RÉGIONALE}

Les façades sont présentées ici dans une perspective systémique, comme les espaces qui tiennent leurs propriétés fondamentales de la confrontation des océans et des continents. Leur identification et leur segmentation soulèvent des difficultés indéniables, qui ne sont cependant pas sans participer à l'intérêt du sujet. Elles peuvent être fondées sur les critères proposés ci-dessus $(\$ 12)$, considérés dans l'ordre suivant : les types de marge (donc les manifestations de la tectonique globale), l'orientation (donc l'exposition aux flux), la latitude (donc l'ensoleillement, facteur cosmique responsable de la zonalité), la circulation générale (constante ou saisonnière) et les courants (responsables de modifications thermiques). Chacun de ces critères se singularise par une tendance ou une alternative : tectonique de compression ou de distension, exposition vers l'ouest ou vers l'est, latitude haute ou basse, circulation associée aux Westerlies, aux alizés ou aux moussons, courant chaud ou froid. Une façade s'identifie donc à partir d'une association de critères distincts, homogènes et hiérarchisés, qui soulève implicitement des problèmes d'articulation et de subdivision. Les limites longitudinales des façades s'établissent à partir d'inversions de tendances, ce qui soulève cette fois des problèmes de gradations et de coïncidences éventuelles. Leurs limites latérales, vers l'avant-pays et vers l'arrière-pays, sont à déterminer pour chaque cas. Enfin, la réalité d'une façade impose, par définition, l'existence d'un avantpays océanique, d'un arrière-pays continental, mais aussi de flux (figure 3). Ces conditions ne sont pas partout réunies, notamment lorsque le premier s'accompagne d'arcs insulaires, le second se réduit à un isthme et les derniers longent les côtes.

\section{1/ Les façades atlantiques (figure 4)}

La configuration des façades atlantiques tient à quatre propriétés morphologiques fondamentales. 


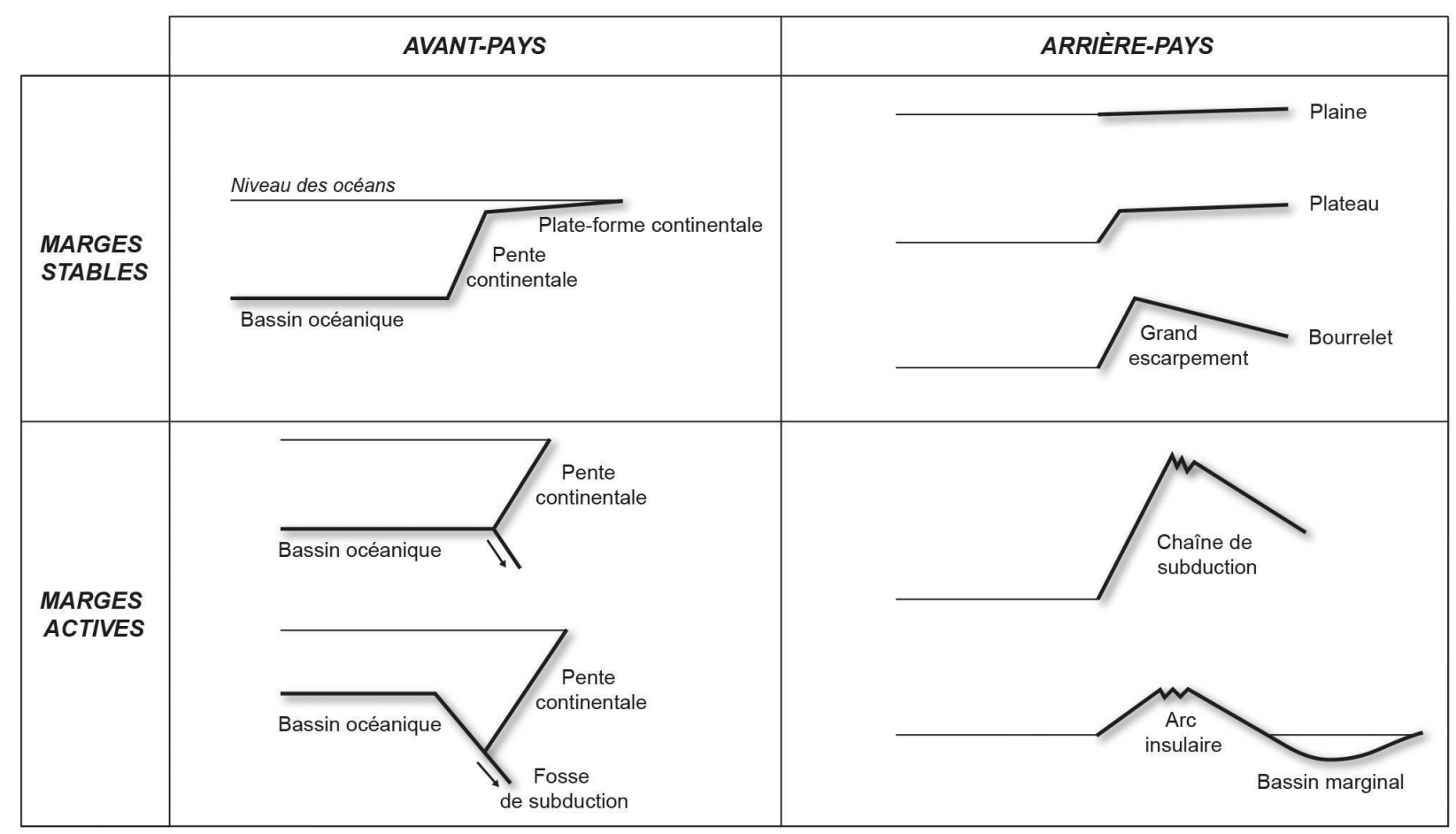

Figure 3 : Les éléments de l'avant-pays et de l'arrière-pays des façades océaniques (légende des coupes schématiques) The main components of foreland and hinterland oceanic façades (captions of schematic sections)

Ces façades sont d'abord très longues. Celle du continent américain s'étend du $83^{\circ} \mathrm{N}$ (Terre de Peary) au $55^{\circ} \mathrm{S}$ (cap Horn), soit sur $138^{\circ}$ de latitude. Celle de l'Ancien Monde, un peu plus courte, s'étend du $81^{\circ} \mathrm{N}$, au Spitsberg, au $35^{\circ} \mathrm{S}$, au cap des Aiguilles, soit sur $116^{\circ}$. Mais ces façades sont discontinues, contrairement aux façades américaines de l'océan Pacifique, sans être fragmentées comme celles de l'océan Indien, ni compartimentées par des arcs et des bassins marginaux, comme celle de l'Extrême-Orient asiatique. La façade atlantique américaine est recoupée par le détroit de Davis, à l'entrée de la mer de Baffin, et par l'arc insulaire des Antilles, en avant de la mer des Caraïbes; celle de l'Ancien Monde est recoupée par le détroit de Gibraltar et par les chaînes de collision qui l'encadrent, à l'entrée de la Méditerranée; la mer de Barents, la mer du Nord et la Manche ne sont que des mers épicontinentales. Les façades de l'océan Atlantique sont subméridiennes et symétriques, ce qui a été constaté très tôt, mais n’a été expliqué que récemment par l'ouverture de l'océan Atlantique à partir d'une dorsale médio-océanique. Elles sont sinueuses, en raison des multiples cisaillements transversaux de cette dernière (en particulier par la faille transformante Guyane-Guinée). En revanche, elles sont déséquilibrées dans le sens des latitudes, en conséquence de la répartition des terres et des mers entre hémisphères. Les propriétés générales des façades atlantiques dérivent ensuite de deux facteurs : leur symétrie morphostructurale longitudinale à partir de la dorsale médio-atlantique (due à la tectonique des plaques), responsable de leurs principaux points communs, et leur symétrie climatique latitudinale à partir de l'équateur (due à l'énergie solaire), responsable de leurs principales différences.

\section{$211 /$ Les caractères originaux des façades atlantiques}

- Les points communs des façades atlantiques sont d'ordre géomorphologique

Ils sont dus, pour l'essentiel, à une dynamique de divergence, à un océan en expansion et à des marges stables. Deux ensembles de plaques sont en jeu : d'une part la plaque d'Amérique du Nord et la 


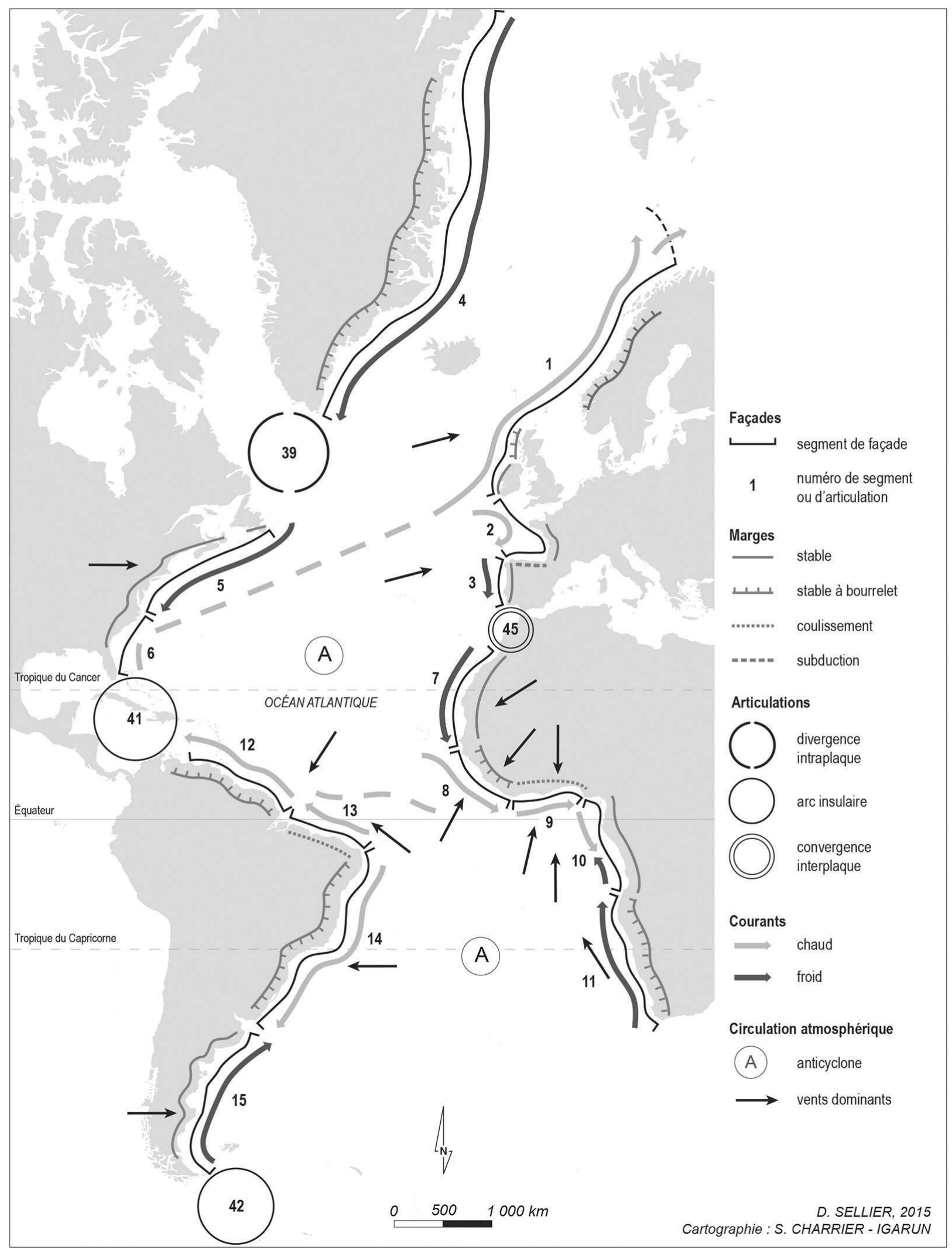

Figure 4 : La répartition des façades atlantiques The Atlantic façade distribution 
plaque d'Amérique du Sud, séparées par l'Amérique centrale et par l'arc insulaire des Antilles, d'autre part la plaque eurasiatique et la plaque africaine, séparées par une chaîne de collision et une faille transformante (faille des Açores).

Les façades atlantiques témoignent d'abord d'une organisation symétrique à partir de la dorsale médioatlantique. Le réservoir océanique et ses marges continentales doivent leur existence et leur relief à la déchirure initiale de la Pangée, à une divergence de plaques lithosphériques à partir d'une dorsale et à un mécanisme d'ouverture océanique solidaire d'un soulèvement localisé des marges des continents sous forme de bourrelets marginaux. Le fond de l'océan doit son recouvrement sédimentaire aux dépôts corrélatifs de l'érosion des continents encaissants. L'érosion de ces continents et la sédimentation océanique sont elles aussi solidaires.

Cette situation résulte de trois étapes majeures à partir d'une réunion momentanée de tous les continents entre la fin du Primaire (orogenèse hercynienne) et le Jurassique (Debelmas et Mascle, 2000). Cette réunion résulte de convergences successives de plaques continentales au Précambrien et au Primaire (Gondwana, Laurentia...), dont les vestiges demeurent actuellement de part et d'autre de l'océan : des chaînes de collision ont occupé le centre et l'ouest de l'Europe, ainsi que les Appalaches, qui représentent leur prolongement. Ces montagnes, aplanies, ont laissé place aux massifs anciens hercyniens actuels (Irlande, Sud-Ouest anglais, Armorique, Ibérie de l'ouest, Appalaches). La déchirure de la Pangée s'annonce au Trias à partir d'un axe qui occupe le centre de l'océan actuel. Une intumescence assortie d'un bombement et d'un amincissement de la croûte continentale se produit entre les latitudes du Sénégal et de Gibraltar. C'est le stade "pré-rift ». Il entraîne une déchirure de la croûte continentale et de premières distensions (rifting). Ces distensions engendrent des fossés à fond de croûte continentale (rifts continentaux), encadrés par des reliefs demeurés soulevés depuis le bombement initial (aux emplacements des actuels bourrelets marginaux). Ces fossés sont envahis par la mer et recouverts de sédiments provenant de l'érosion des reliefs adjacents (sédiments synrift). À partir du Jurassique, l'expansion des fonds océaniques provoque l'apparition de croûte océanique à partir d'une dorsale (dorsale médio-atlantique) et d'un rift central (rift océanique) sous l'impulsion d'une remontée du manteau. Cette croûte provient d'épanchements successifs de basalte qui élargissent les portions de plaques océaniques en formation de part et d'autre du rift océanique et qui écartent corrélativement les marges des continents encadrants. C'est le mécanisme de l'accrétion océanique (spreading). La dorsale sert d'axe de symétrie par rapport auquel s'organise progressivement l'ensemble du relief océanique et marginal. Les distensions provoquent d'abord la formation d'un océan initial, qui s'étend de la Guinée à Gibraltar («stade océanique »). L'Amérique du Nord (Laurasia) est séparée de l'Afrique de l'Ouest (Gondwana), mais l'Europe demeure soudée à l'Amérique et l'Amérique du Sud au golfe de Guinée. L'océan Atlantique ne s'ouvre donc au Jurassique qu'entre Gibraltar et la Guinée. Au Crétacé supérieur, il s'étend vers l'Afrique et l'Amérique du Sud, en se cisaillant le long de la fracture de Guyane-Guinée, qui détermine son tracé sinueux. Il se ramifie au nord de Gibraltar (cisaillement des Açores), en formant trois branches : vers la future mer de Baffin (entre le Groenland et le Labrador), vers les futures îles Britanniques et vers le golfe de Gascogne, qui commence à s'ouvrir entre la France et l'Espagne. Au Paléogène, l'Atlantique continue de s'élargir entre l'Afrique et l'Amérique du Sud à partir de la dorsale. Le Labrador commence à se séparer du Groenland au nord-est par le détroit de Davis. L'Atlantique s'élargit désormais plus vite le long de la Norvège qu'à partir du détroit de Davis, mais demeure encore étroit et peu profond. Par ailleurs, la plaque africaine commence à entrer en collision avec la plaque européenne, en engendrant les Pyrénées. Au Néogène, la dorsale médio-atlantique gagne le nord de l'Atlantique et provoque la dérive du Spitsberg par rapport au Groenland. L'Islande émerge à partir d'un point chaud centré sur cette dorsale (en formant la dorsale de Reykjaness à partir du Miocène).

Cette évolution a trois implications océaniques principales. La première concerne la largeur inégale du réservoir océanique : $6200 \mathrm{~km}$ entre la Mauritanie et la Floride, $4000 \mathrm{~km}$ entre la Galice et Terre-Neuve (séparées au Crétacé), 2500 km entre la Norvège et le Groenland (séparés au Néogène), $1000 \mathrm{~km}$ entre le Spitsberg et le Groenland. La deuxième concerne les disparités morphologiques du réservoir océanique. Le centre, ouvert dès le 
Jurassique entre la fracture de Guyane-Guinée et le plateau du Télégraphe (à la latitude des îles Britanniques), est le plus symétrique. Le Sud est également symétrique. Le Nord, dont l'ouverture est tardive, est resserré, encombré de bancs et de fossés, ponctué de points chauds (Islande, Jan Mayen); au nord du plateau du Télégraphe, l'Atlantique forme un assemblage de plateaux sous-marins (banc de Porcupine, plateau de Rockall) et de bassins (bassin de Norvège, bassin du Groenland). La troisième implication concerne la disparité des reliefs sousmarins. Ces reliefs, entièrement formés de croûte océanique, sont tous postérieurs au Jurassique, de plus en plus jeunes vers le large, mais de plus en plus couverts de sédiments vers les marges.

Au centre, la dorsale médio-atlantique est longue (près de 15000 km des abords du Spitsberg à l'île Bouvet) et large (100 à $250 \mathrm{~km}$ ). Elle est continue, malgré ses cisaillements par les failles transformantes. Elle se sonde généralement vers $2000 \mathrm{~m}$ et connaît des émersions insulaires à l'aplomb de points chauds (Jan Mayen et Islande, mais aussi Açores, Saint-Paul, Ascension, Tristan da Cunha, Gough, Bouvet). Elle est le siège d'un volcanisme sous-marin, mais peu sismique, puisqu'elle résulte d'une dynamique de divergence de matériaux très fluides. De part et d'autre, les bassins océaniques s'approfondissent vers les marges, en raison d'une densité croissante de la croûte et du poids croissant des sédiments, ce qui exprime aussi un phénomène de façade. Ils comprennent des secteurs particulièrement profonds : $6300 \mathrm{~m}$ au bassin des Canaries, $6250 \mathrm{~m}$ dans le bassin d'Argentine et $5540 \mathrm{~m}$ au sud du Cap, mais ne dépassent pas $3000 \mathrm{~m}$ au nord du plateau du Télégraphe, ouvert après le Crétacé. Ils sont ponctués de guyots et d'îles volcaniques, correspondant à des points chauds, qui résultent des émergences ponctuelles d'un panache ascendant de matériel mantellique. Ces îles océaniques se trouvent toutes au sud du plateau du Télégraphe (Bermudes, Trinidade, Madère, Cap Vert, SainteHélène) et sont parfois alignées (Canaries et São Tomé).

Dans cette perspective, les façades de l'Atlantique correspondent effectivement à des marges de divergence, donc à des marges stables, en dehors des cas localisés de coulissement ou de convergence. Du côté de l'avant-pays, le précontinent, d'étendue inégale selon les endroits, est très large au centre de la façade de l'Europe, entre la Norvège et le pays Basque, de même qu'à l'est du Groenland, entre le banc de Terre-Neuve et New York, ou encore au large des Guyanes. Il s'élargit vers le sud de l'Amérique du Sud, entre le Rio de la Plata et la Terre de Feu. Il est par ailleurs très étroit, notamment sur les façades africaines. Du côté de l'arrière-pays, le continent est essentiellement formé de platesformes antérieures à l'ouverture de l'Atlantique, formant des ensembles de dispositions symétriques par rapport à l'océan, mais de dimensions inégales. Des boucliers s'étendent dans les hautes latitudes boréales (boucliers canadien, groenlandais, scandinave, des Hébrides), éléments de socles précambriens partis à la dérive à partir du Jurassique (restes des cratons les plus vieux encadrant l'océan le plus jeune du monde). Des massifs anciens et des bassins sédimentaires les ceinturent vers les côtes et les moyennes latitudes des Scandes à l'Ibérie, ou à l'emplacement des Appalaches, héritages, pour leur part, d'orogènes primaires, calédonien ou hercynien. Des boucliers et des tables provenant de la déchirure du Gondwana arment à nouveau l'arrière-pays des façades aux latitudes tropicales (boucliers guyanais et brésilien, cuvette amazonienne, boucliers africains et cuvette congolaise).

Les façades dont il est question pour l'instant, conservent sur une grande partie de leur développement des bourrelets marginaux qui bordent les plates-formes de chaque côté de l'océan et qui rehaussent ainsi les marges considérées (Norvège-Irlande : 2458 m, Groenland oriental : 2940 m, Terre de Baffin-Labrador : 1676 m, nord des Appalaches : 1916 m, Brésil : 2820 m, SudOuest africain : $2200 \mathrm{~m}$ ). Les marges atlantiques ont connu par ailleurs un volcanisme tertiaire au Groenland, en Ecosse, en Irlande et, pour d'autres causes, au Cameroun. L'une de leurs dernières particularités tectoniques, par rapport aux autres, est d'être elles aussi peu sismiques (sauf aux Antilles, à cause d'un arc insulaire et, plus rarement, en Ibérie, à cause de la collision des plaques européenne et africaine).

Les façades proches de l'équateur correspondent à des marges de coulissement, qui représentent une première exception au schéma théorique des marges stables symétriques et des mécanismes de divergence simple qui leur sont appliqués. Elles 
concernent, d'un côté, la marge de l'Amérique latine située entre la mer des Caraïbes (Caracas) et le Nordeste brésilien (Natal) et, de l'autre, la marge africaine située entre la Guinée et l'est du golfe de Guinée. Le coulissement, réalisé selon une direction presque perpendiculaire à la dorsale, a débuté avec l'ouverture de l'Atlantique sud au Crétacé. Les deux marges, étroites et dépourvues de précontinent étendu, sont reliées par des zones de fractures profondes et resserrées qui cisaillent la dorsale médioatlantique et les bassins océaniques adjacents, ce qui explique le tracé sinueux de cette dorsale et des marges continentales autour de l'équateur jusqu'à conduire à l'alignement des côtes du nord du Brésil et du nord du golfe de Guinée à ce niveau.

La géomorphologie permet finalement d'effectuer une première segmentation des façades. Adossées à des plates-formes immenses, ces dernières sont en effet tronçonnées par des accidents majeurs, latéraux ou obliques qui témoignent de dynamiques et d'histoires différentes. Il existe ainsi quatre discontinuités majeures, qui constituent autant d'articulations, de part et d'autre de l'Atlantique. Le détroit de Davis représente une ramification de l'océan Atlantique entre le Groenland, le Labrador et l'archipel nord-canadien. Les suivantes correspondent à l'arc insulaire antillais, entre les plaques de l'Amérique du Nord et de l'Amérique du Sud, et à l'arc des Falkland, entre Terre de Feu et Terre de Graham, entre la plaque de l'Amérique du Sud et la plaque antarctique. De l'autre côté de l'Atlantique, le contact entre la plaque africaine et la plaque européenne, en mer et à terre, implique des accidents complexes, résultant d'un coulissement océanique (Açores), associé à une convergence continentale (golfe Ibéro-marocain) (\$24).

- Les facteurs de la diversité des façades atlantiques sont d'ordre climatique et océanique

Les façades de l'océan Atlantique enregistrent d'abord les effets de la zonation universelle des températures de l'air. Leurs différences résultent de bilans radiatifs excédentaires au centre et déficitaires aux pôles. Ces déséquilibres sont partiellement compensés par les échanges océaniques et atmosphériques méridiens qui s'établissent en priorité le long des façades. La circulation générale est conditionnée, autour de l'Atlantique comme ailleurs, par les centres d'action qui dépendent eux-mêmes de l'exposition au rayonnement solaire (anticyclones tropicaux des Açores et de Sainte-Hélène, dépressions boréales et australes). Il s'agit de la circulation générale d'ouest aux latitudes hautes ou moyennes boréales et australes (Westerlies, dans l'hémisphère nord, West wind drift au sud), déterminants sur la façade de l'Europe, et des alizés aux latitudes intertropicales, déterminants en Amérique centrale (car provenant de l'est), auxquels s'ajoutent une mousson sur la façade ouest de l'Afrique et des cyclones tropicaux sur la façade est de l'Amérique. La circulation zonale des masses d'air représente, par conséquent, un puissant agent de dissymétrie transversale. Les saisons sont rythmées par les températures liées au déplacement saisonnier des centres d'action et des masses d'air arctique, polaire et tropicale aux moyennes et hautes latitudes (saison chaude et saison froide), où les pluies, essentiellement frontales, se produisent en toutes saisons (surtout hors de la saison chaude sur les façades). Elles sont rythmées par les précipitations (saison humide, saison sèche), elles-mêmes conditionnées par l'exposition au rayonnement solaire, aux latitudes tropicales, où se produisent surtout des pluies convectives. L'effet de façade thermique se traduit par une diminution des amplitudes vers les côtes. L'effet de façade pluviométrique se marque presque partout par une augmentation des précipitations en arrière des côtes. Il se manifeste surtout en Europe et en Amérique centrale, de la Floride au Rio de la Plata.

La zonation thermique de l'océan est comparable à celle de l'air en surface, mais s'accompagne d'amplitudes encore plus réduites $\left(2{ }^{\circ} \mathrm{C}\right.$ à l'équateur, 6 à $10^{\circ} \mathrm{C}$ aux hautes latitudes). Les courants zonaux sont également un facteur majeur de différenciation des façades atlantiques. Le courant sud-équatorial circule du golfe de Guinée vers le Brésil le long de l'équateur, en bifurquant vers le nord (courant des Caraïbes) et vers le sud (courant du Brésil), sous les effets de l'anticyclone des Açores sur le tropique du Cancer et de l'anticyclone de l'Atlantique sud sur le tropique du Capricorne. Il est prolongé par des courants longeant l'Amérique vers le nord (Gulf Stream) et vers le sud (courant du Brésil), en induisant des contre-courants ouest-est, le long des $40^{\mathrm{e}}$ parallèles nord et sud, puis des courants côtiers méridiens dirigés vers l'équateur (courants des Canaries au nord, de Benguela au sud). L'ensemble forme donc deux grandes cellules circulaires de mouvements complé- 
mentaires, conformes aux grands centres d'action barométriques des zones intertropicales, en même temps qu'aux alizés. Le courant circumpolaire austral relie le cap Horn au cap de Bonne-Espérance. Il est associé à la dépression qui règne sur l'Antarctique et au West wind drift. Il pousse une branche le long des côtes argentines (courant des Falkland) et rejoint le courant de Benguela au sud-ouest de l'Afrique. Les courants zonaux sont remplacés par des courants méridiens ou diagonaux au-delà de $40^{\circ} \mathrm{N}$ : courants froids issus de la mer de Baffin et de l'océan glacial arctique : courants du Labrador et du Groenland oriental, qui conditionnent les limites de la banquise permanente, de la banquise saisonnière et des glaces flottantes; ces dernières s'étendent jusqu'au nord de l'Islande et jusqu'au $40^{\circ} \mathrm{N}$ au large de la Nouvelle-Ecosse, exceptionnellement jusqu'aux Açores et aux Bermudes, ce qui prouve toutefois l'ampleur des échanges hydrologiques dans l'Atlantique nord. Parallèlement, les glaces flottantes s'observent jusqu'au Cap et au large de Buenos Aires dans l'Atlantique sud.

Dans ce domaine, le Gulf Stream est un phénomène extraordinaire à plusieurs titres. Il provient des côtes occidentales de l'Afrique sous l'impulsion des alizés, passe devant le golfe du Mexique, avant de traverser l'Atlantique et d'atteindre les côtes européennes entre la Galice et le cap Nord, sous l'effet de la force de Coriolis et des Westerlies. Il est rapide (1 à $1,5 \mathrm{~m} / \mathrm{s}$ dans la mer des Sargasses). Il est entretenu par la circulation des vents, la forme du vase océanique, rétréci vers le nord, et l'accroissement de la force de Coriolis avec la latitude. De ce fait, il atteint la côte occidentale du Spitsberg jusqu’à $80^{\circ} \mathrm{N}$. Le Gulf Stream est responsable de la plus puissante anomalie thermique des eaux de surface au monde. Ses eaux, originaires des régions intertropicales, provoquent une surélévation des températures océaniques moyennes de plusieurs degrés par rapport aux latitudes concernées : 1 à $3{ }^{\circ} \mathrm{C}$ aux abords de la Galice et du Portugal, $4{ }^{\circ} \mathrm{C}$ dans le golfe de Gascogne, plus de $5^{\circ} \mathrm{C}$ entre le Finistère et le Cap Nord. Le Gulf Stream est également responsable d'une amplitude thermique annuelle des eaux de surface extrêmement faible : 6 à $8{ }^{\circ} \mathrm{C}$ pendant toute l'année et sur toute la façade (ce qui est exceptionnel, compte tenu de la distance : plus de $30^{\circ}$ de latitude), contre 10 à $14^{\circ} \mathrm{C}$ en mer du Nord et plus de $14^{\circ} \mathrm{C}$ en mer Baltique. Cette anomalie thermique explique l'absence d'englacement sur les côtes pendant toute l'année jusqu'à des latitudes inégalées dans le monde, à savoir jusqu'au cap Nord et à Mourmansk. La côte occidentale du Spitsberg est libre de glace en été, à $80^{\circ} \mathrm{N}$ (à comparer à l'englacement saisonnier de la Baltique à $60^{\circ} \mathrm{N}$, ou des côtes canadiennes à $45^{\circ} \mathrm{N}$ ). Le Gulf Stream contribue largement, avec la circulation atmosphérique, à la dilatation latitudinale des milieux tempérés sur la façade occidentale de l'Europe. Il est responsable de l'homogénéisation des températures dans le sens latitudinal.

Les ceintures biogéographiques continentales comprennent des zones tropicales à forêt équatoriale, forêt tropicale claire, savane, steppe, une zone tempérée à forêts de feuillus, très défrichée, des zones froides à toundra et forêt boréale, qui s'étendent jusqu'aux côtes quand elles n'y sont pas remplacées par les formations de façade ellesmêmes déterminées par les écosystèmes atlantiques (lande atlantique, végétation ouverte des déserts littoraux brumeux, mangrove en Afrique et aux Antilles). La dissymétrie ouest-est est extrêmement marquée aux moyennes latitudes boréales par la dilatation latitudinale des milieux tempérés sur la façade européenne et par sa rétraction sur la façade nord-américaine. Les ceintures biogéographiques marines se caractérisent par des espèces d'eau froide peu nombreuses aux latitudes arctiques et antarctiques $\left(0-5^{\circ} \mathrm{C}\right)$, des espèces d'eau chaude très nombreuses et des massifs coralliens développés à l'écart des vasières à mangrove aux latitudes intertropicales et par des espèces tempérées et boréales ou australes à cycles saisonniers au centre. La dissymétrie ouest-est de ces ceintures biogéographiques marines est également soulignée aux latitudes moyennes et boréales par la dilatation de la zone biogéographique marine tempérée sur la façade de l'Europe; elle résulte en grande partie des effets des courants.

L'Atlantique ne représente que $29 \%$ de la surface de l'océan mondial, mais draine $67 \%$ de la surface des continents. Les façades ne composent évidemment qu'une partie de cet espace. Elles comportent des types de drainage différents, qui participent à leur environnement : bassins des fleuves labradoriens et norvégiens au nord, cours inférieurs des fleuves tempérés (Saint-Laurent et fleuves appalachiens, fleuves européens de l'Elbe au Guadalquivir), domaine endoréíque en Afrique de l'Ouest, puis Sénégal et Niger, à régimes contras- 
tés, grands fleuves équatoriaux à débits massifs et à régimes réguliers (Orénoque, Amazone, Congo) qui échappent en majeure partie à la façade atlantique, Rio São Francisco (au Brésil), Rio Uruguay et Rio Paraná (aboutissant au Rio de la Plata), Orange dans le Sud-Ouest africain.

La zonation morphogénique associée aux précédentes présente des caractères propres aux façades atlantiques. Ainsi, les systèmes d'érosion et modelés froids, glaciaires et périglaciaires, à pergélisol ou à gel saisonnier des sols, sont exceptionnellement développés en latitude du côté européen (du Spistberg aux Highlands d'Ecosse le long des montagnes) et surtout du côté américain (du nord du Groenland à Terre-Neuve et au-delà), mais peu présents au sud. Les systèmes tempérés sont eux aussi très représentés, mais cette fois surtout en Europe, du Portugal jusqu'aux côtes de Norvège. Parmi eux, les milieux qualifiés d'océanisés, connaissent leur extension maximale sur la façade européenne, à l'échelle mondiale, en témoignant d'actions modérées de l'écoulement fluvial et de la météorisation, ainsi que de la conservation corrélative des héritages dans le relief. Les systèmes tropicaux, soumis aux effets fonctionnels ou hérités de l'aridité, de l'écoulement aréolaire, ou de l'écoulement concentré et de l'altération chimique, souvent au-delà des limites actuelles du fonctionnement des processus en cause, sont eux aussi très représentés en raison de l'allongement des façades aux latitudes concernées, en particulier en Afrique. Les bilans morphogéniques de ces systèmes successifs sont évidemment inégaux, comme le signalent les quantités de matériaux solides fournis à l'océan : Yukon 60 millions de tonnes par an, Mississipi 210, Amazone 900, Gange et Brahmapoutre 1670... (Vanney, 1991).

Une dernière spécificité des façades atlantiques a trait aux échanges, non pas seulement à travers l'océan (comme dans le cas des masses d'air), ni le long des façades (comme dans le cas des courants), mais entre les façades, en raison de la forme et des dimensions propres de l'Atlantique. Le Gulf Stream en est un des exemples majeurs. Les trajets des poissons, comme ceux des anguilles entre la mer des Sargasses et l'Europe, ou de grands cétacés, comme les cachalots à partir des tropiques, sont connus. Les migrations saisonnières des oiseaux, d'une façade à l'autre, sinon d'un hémisphère à l'autre, comme celles de la Sterne arctique, qui passe des terres australes aux régions boréales en suivant les façades, se pratiquent sur des distances immenses (Tuck et Heinzel, 1985; Chadenas et Sellier, 2014).

\section{2/ Les caractères régionaux des façades océaniques atlantiques}

La caractérisation des façades atlantiques repose sur les critères exposés en deuxième partie. Ils prennent ici en considération les types de marges (stables, sauf cas particuliers comme l'arc des Antilles, le Maroc, le sud du golfe de Gascogne), l'orientation des façades (vers l'ouest ou vers l'est), leur situation latitudinale (et ses effets climatiques, hydrologiques, biogéographiques et morphogéniques), le sens de la circulation atmosphérique d'ouest (Westerlies) ou d'est (alizés), la nature des courants (froids ou chauds provenant respectivement des hautes et des basses latitudes). Leur subdivision consiste d'abord à opposer la façade atlantique européenne (façade tempérée est) à la façade atlantique nord-américaine (tempérée ouest), puis la façade atlantique africaine (tropicale est) à la façade atlantique sud-américaine (tropicale ouest). Elle consiste ensuite à prendre en compte des phénomènes tectoniques (rifting latéral comme dans le détroit de Davis, arc et subduction comme aux Antilles, faille transformante et collision comme dans l'axe Açores-Gibraltar), la circulation des vents, zonaux ou méridiens et les changements de direction des courants, divergence (Nordeste brésilien, Galice), ou convergence (golfe de Guinée). Le tout conduit à distinguer une quinzaine de segments le long des façades de l'Atlantique.

La façade atlantique européenne représente une référence à l'échelle mondiale pour plusieurs raisons. Elle s'étend du Spistberg, au nord de la Norvège, jusqu'au cap Saint-Vincent, au sud du Portugal, soit sur $45^{\circ}$ de latitude, le quart d'un méridien. C'est donc l'une des plus longues, mais paradoxalement l'une des plus homogènes, en raison de facteurs situationnels et océanographiques. C'est aussi la plus étendue vers l'arrière-pays, en raison de facteurs climatiques et géomorphologiques, ainsi que de son orientation. C'est encore l'une des plus étendues vers l'avant-pays à cause de son large précontinent. C'est, en fait, celle qui témoigne de l'océanicité maximale au monde. 
Elle se caractérise effectivement par son climat océanisé, marqué conjointement par ses précipitations abondantes, ses vents violents, ses amplitudes réduites et son temps instable. Elle tient ces propriétés de sa situation aux latitudes tempérées et de son exposition aux « grands vents d'ouest » qui naissent à partir de dépressions le long d'un front polaire souvent perturbé, qui soufflent du cap Nord à la Galice et qui véhiculent des masses d'air saturées d'humidité jusqu'à l'intérieur des terres, mais qui entraînent aussi l'agitation des eaux océaniques (Vanney, 1991). Elle tient son exceptionnelle homogénéité en latitude non seulement au rôle de régulateur thermique de la mer, qui vaut pour toutes les façades, mais aussi au Gulf Stream qui remonte des eaux chaudes jusqu'en mer de Barents, mais qui rabat des eaux relativement fraîches le long des côtes du Portugal en créant ainsi l'anomalie thermique méridienne la plus considérable du monde (Guilcher, 1953; Godard et Tabeaud, 2004; Le Cœur et al., 1996). Par ailleurs, elle tire son exceptionnelle extension transversale de son relief de marge stable, qui favorise les effets de la circulation générale d'ouest. Ce relief est celui d'un pays de surfaces, basses et étendues, en dépit de l'alignement des montagnes Atlantiques qui proviennent de leur rehaussement près de la mer et qui se succèdent de façon discontinue à travers la Norvège, les îles Britanniques, les massifs anciens français et l'ouest de la péninsule Ibérique. Ces montagnes s'accompagnent d'une dégradation effective des conditions morphoclimatiques et bioclimatiques avec l'altitude, mais dépassent rarement 2000 m et culminent souvent vers $1000 \mathrm{~m}$ (Sellier, 2006). Toutes les conditions sont ainsi réunies pour assurer une large pénétration des influences océaniques, surtout au centre, à travers une succession de grandes plaines.

La façade atlantique européenne peut être néanmoins subdivisée à partir de critères géomorphologiques (marge à bourrelets étendus au nord de la mer Celtique, ou à bourrelets localisés, au sud), climatiques (influence d'un climat océanisé entre la Galice et Trondheim, océanisé chaud vers le sud, subpolaire océanisé vers le nord) et océaniques (passage du Gulf Stream au nord de la Galice, du contre-courant du Portugal au sud). Elle peut être subdivisée en trois segments inégaux, qui justifieraient des découpes plus détaillées en dehors d'une présentation aussi générale (figure 5).

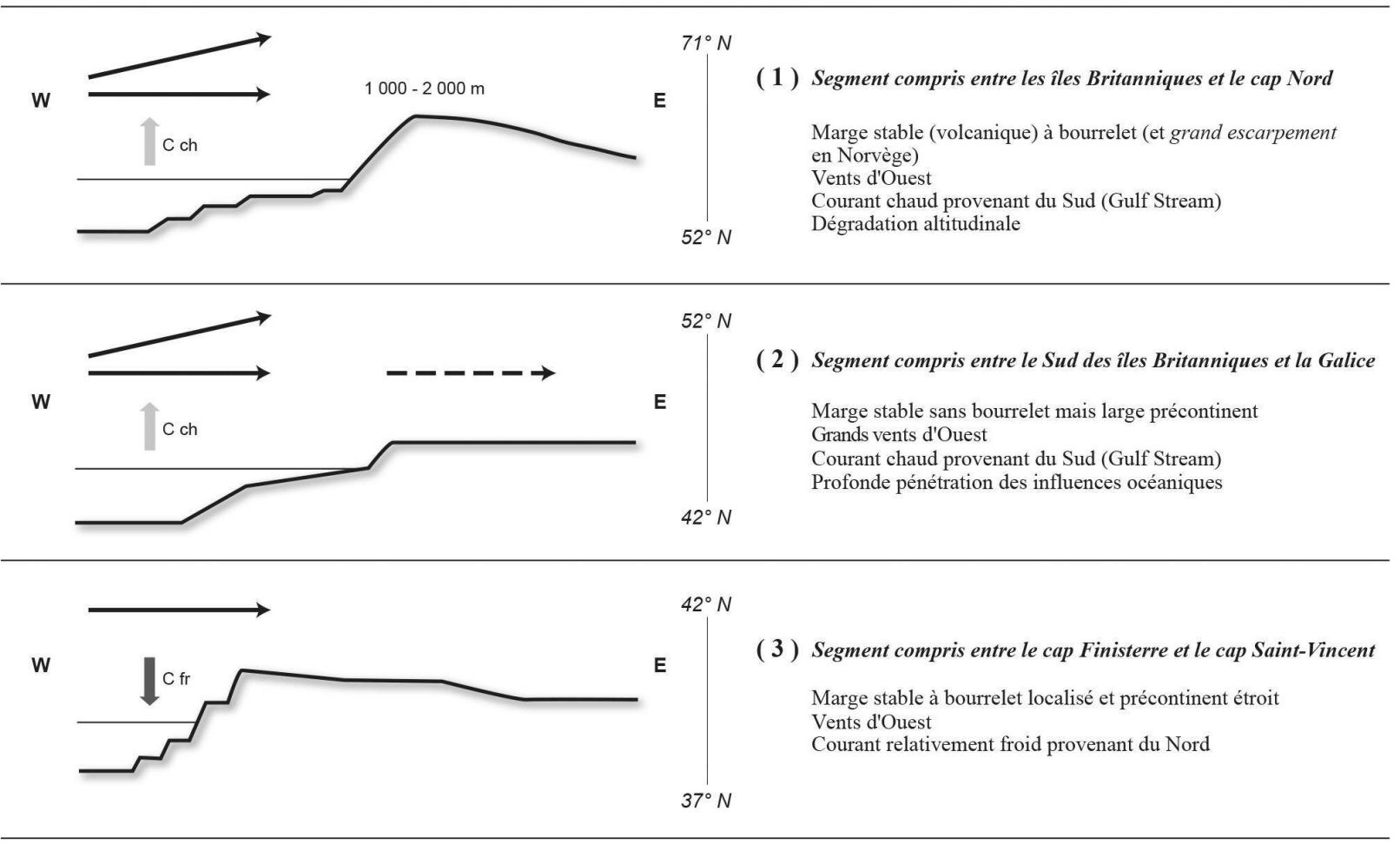

Figure 5 : La façade atlantique européenne The European Atlantic façade 
(1) Le segment compris entre les îles Britanniques $\left(52^{\circ} \mathrm{N}\right)$ et le cap Nord $\left(71^{\circ} \mathrm{N}\right)$, recoupé par la mer du Nord, fait face à une cuvette océanique qui, pour ne s'être ouverte qu'à partir de l'Eocène, a été soumise à une divergence rapide. Il en résulte une marge stable avec bourrelet qui a connu un volcanisme tertiaire puissant en Irlande et en Ecosse. Le relief continental formé, en l'occurrence, de massifs anciens d'origine calédonienne (Irlande, Ecosse, Norvège), côtoyant des éléments de boucliers (bouclier des Hébrides et bouclier Baltique), a été surélevé jusqu'à plus de 1000 m (îles Britanniques) et de 2000 m (Norvège) lors de l'ouverture de l'océan Atlantique. Il se distingue aussi par les héritages d'englacements pléistocènes, présents à tous les niveaux d'échelle, notamment par des fjords, firths et lochs. Ce relief, actuellement peu englacé (quelques massifs en Norvège), gêne la pénétration des influences océaniques à la mesure de son élévation. En revanche, le secteur est sous l'influence déterminante d'un climat tempéré océanisé exemplaire dans sa partie sud. C'est en effet en Irlande et en Écosse occidentale que se placent les stations de référence à un climat qualifié d'hyperocéanique par Birot (1965), caractérisé par des totaux annuels de précipitations de 1000 à 2000 mm, 220 à 250 jours de précipitations par an, des étés frais et un ensoleillement réduit. Ce climat évolue vers un climat subpolaire océanisé le long des côtes de Norvège, épargnées de tout englacement hivernal par le Gulf Stream, à la différence des côtes de la Baltique. La limite entre climat tempéré océanisé et subpolaire océanisé (qui se marque par l'existence de moins de quatre mois de moyenne thermique égale ou supérieure à $+10^{\circ} \mathrm{C}$ et qui coïncide souvent avec l'isotherme annuelle $+4{ }^{\circ} \mathrm{C}$, elle-même soulignée par l'écotone forêt tempérée-forêt boréale), suit les côtes de Norvège et s'en rapproche progressivement au nord de Trondheim (Péguy, 1970). L'espace situé au-delà du cap Nord, en direction du Svalbard et de la mer de Barents, fait partie de ceux qui se trouvent aux limites du sujet en dépit de la continuité et de la largeur de la plate-forme continentale intégrée à la plaque européenne. L'océan continue de bénéficier des terminaisons du Gulf Stream, qui valent encore aux côtes occidentales du Spitsberg de ne connaître qu'une banquise saisonnière, en dépit de leur climat polaire océanique.
(2) Le segment compris entre le sud des îles Britanniques (mer Celtique, $52^{\circ} \mathrm{N}$ ) et la Galice (cap Finisterre, $42^{\circ} \mathrm{N}$ ) a été soumis dans son ensemble à une divergence lente, associée à l'ouverture de l'Atlantique à partir du Crétacé et à la création d'une marge stable non volcanique et sans bourrelet, caractérisée par un relief plus modéré, un précontinent particulièrement large, des blocs crustaux étendus, un relief continental formé de massifs anciens et de bassins sédimentaires rapportés au domaine hercynien. Il intègre une courte chaîne de subduction au sud du golfe de Gascogne (chaîne Cantabrique) et l'extrémité d'une chaîne intracratonique (à l'emplacement des Pyrénées). Le golfe de Gascogne s'ouvre vers l'océan Atlantique à partir de l'estuaire de l'Adour, entre l'éperon de Goban $\left(49^{\circ} \mathrm{N}\right)$, au large de la mer Celtique, et le banc de Galice $\left(43^{\circ} \mathrm{N}\right)$. Il constitue une échancrure océanique singulière à l'intérieur de la façade atlantique européenne par sa profondeur (5 $476 \mathrm{~m}$ au sud-ouest) et son plancher de croûte océanique, recouvert de sédiments pélagiques. Son ouverture à partir du Crétacé moyen est contemporaine de celle de l'océan Atlantique aux mêmes latitudes et procède de la divergence des éléments armoricains et ibériques d'un même socle. Cependant, le golfe de Gascogne subit dès la fin du Crétacé les effets de la convergence des plaques africaine et européenne, qui crée les Pyrénées, ainsi que la chaîne Cantabrique, par plongement du fond océanique de la plaine abyssale de Gascogne sous la croûte continentale ibérique. En conséquence, le golfe de Gascogne se caractérise par sa dissymétrie morphostructurale. Le rebord nord (côtes armoricaines et aquitaines) s'apparente à une marge stable; il comprend un large précontinent assorti de blocs crustaux basculés et un relief continental modéré (384 m dans les monts d'Arrée). Le rebord méridional s'apparente à une marge active dans sa situation actuelle; il comprend un plateau continental rétréci et faillé (Mar Cantabrico) et une chaîne plissée (monts Cantabriques), au centre de laquelle le Picos de Europa (2665 m) constitue le point culminant de l'ensemble de la façade atlantique européenne. Ces différences impliquent les modalités de l'érosion continentale : aux marges maigres de l'Armorique, où les recouvrements sédimentaires sont inférieurs à 3000 m d'épaisseur, s'opposent les marges grasses du Pays basque, où ils dépassent $10000 \mathrm{~m}$. L'exposition à une circu- 
lation d'ouest, ajoutée à la présence d'une enfilade de larges plates-formes, assure une pénétration maximale des influences océaniques et l'existence d'un arrière-pays étendu jusqu'aux Vosges, si l'on se réfère aux critères de continentalisation usuels tel que le tracé de l'isoamplitude annuelle $20{ }^{\circ} \mathrm{C}$ (Péguy, 1970). Le Gulf Stream, qui aborde les côtes européennes en s'introduisant vers le nord par la mer d'Irlande, la Manche et la mer du Nord, exerce ici une influence maximale.

(3) Le segment compris entre le cap Finisterre $\left(42^{\circ} \mathrm{N}\right)$ et le cap Saint-Vincent $\left(37^{\circ} \mathrm{N}\right)$, qui ne mesure que $800 \mathrm{~km}$ de long, s'est trouvé rehaussé à l'ouest de la cordillère Cantabrique par la subduction de la plaine abyssale de Gascogne sous l'Ibérie et culmine encore à plus de $2400 \mathrm{~m}$ aux abords de la Galice. Il correspond surtout à une marge stable sans bourrelet, ou à bourrelet réduit, bordée d'un plateau continental relativement étroit, accidenté de horsts et d'escaliers de failles (Peulvast et Vanney, 2002). Son relief continental est à nouveau formé de massifs anciens qui appartiennent au domaine hercynien et qui approchent $2000 \mathrm{~m}$ dans la Serra da Estrela. Les principales différences entre ce segment de la façade européenne et ses voisins sont d'origine océanique et climatique. Une partie des eaux poussées par le Gulf Stream se rabat vers le sud à partir du golfe de Gascogne et longe les côtes du Portugal avant de rejoindre le courant des Canaries. Il s'agit d'un apport en eaux relativement froides qui ralentissent le passage vers un climat océanisé chaud, même si la limite septentrionale de l'olivier, qui marque traditionnellement celle du domaine méditerranéen, passe en plaine à l'extrême nord du Portugal (où elle résulte d'une humidité estivale excessive plus que du froid hivernal). Ce climat est principalement marqué par le réchauffement progressif des températures vers le sud, l'augmentation de la sécheresse estivale et un maximum hivernal des précipitations. Des traits océaniques persistent néanmoins le long des côtes, où les amplitudes demeurent inférieures à $12{ }^{\circ} \mathrm{C}$ et les précipitations supérieures à $700 \mathrm{~mm}$.

La façade atlantique de l'Amérique du Nord représente le symétrique de la précédente, ce qui explique analogies et différences. Elle s'étend du nord du Groenland au sud de la Floride, sur une longueur encore supérieure. Elle correspond aussi à une marge stable, avec ou sans bourrelet, mais subit les influences d'une circulation océanique différente. Son orientation vers l'est ne l'expose plus aux effets prépondérants des grands vents d'ouest. Les influences océaniques sont maintenues aux abords des côtes, mais l'arrière-pays est étroit et les contrastes entre le nord et le sud s'expriment à travers chaque propriété climatique et biogéographique. La zonalité reprend ses droits. La façade atlantique nord-américaine peut être également subdivisée en trois segments selon des critères géomorphologiques (la coupure produite par le détroit de Davis), climatiques (l'affrontement des masses d'air arctique, polaire et tropicale) et océaniques (la descente de courants froids qui repoussent les influences du Gulf Stream au sud) (figure 6).

(4) La façade orientale du Groenland, du cap Morris $\left(83^{\circ} \mathrm{N}\right)$ au cap Farewell $\left(60^{\circ} \mathrm{N}\right)$, correspond à une marge stable volcanique, avec bourrelet, à retombée océanique faillée, comme le segment compris entre les îles Britanniques et le cap Nord, avec lequel elle partage une histoire et des propriétés structurales communes. En revanche, il s'agit de l'une des façades les moins océanisées du monde. Du côté de l'arrière-pays, le bourrelet marginal, qui a subi un rehaussement supplémentaire à l'Holocène par compensation de la subsidence glacio-isostatique enregistrée au centre du Groenland au Pléistocène, culmine en effet autour de $3000 \mathrm{~m}$ à proximité des côtes. Le relief est entièrement soumis aux systèmes morphogéniques glaciaire et périglaciaire fonctionnels. Partout, le froid, intense et persistant, exerce une influence zonale des plus puissantes. Il provoque des températures propres aux climats polaires d'inlandsis à l'intérieur et polaire océanique sur les côtes (impliquant des moyennes annuelles inférieures à $0{ }^{\circ} \mathrm{C}$ ). Il engendre des anticyclones thermiques pelliculaires qui entravent les ascendances et réduisent les précipitations en dessous de $250 \mathrm{~mm}$ par an vers le nord. Il bloque l'écoulement (l'inlandsis recouvre $90 \%$ du Groenland et parvient aux côtes ou à leurs abords). Il engendre des vents catabatiques qui soufflent de l'inlandsis vers les côtes et qui s'imposent aux vents parallèles aux côtes, animés, pour leur part, par la dépression d'Islande. La côte à fjords, très découpée, comme en Norvège, comprend des glaciers à front marin, impliquant vêlage et icebergs. La faune littorale est essentiellement d'origine marine (pinnipèdes, 


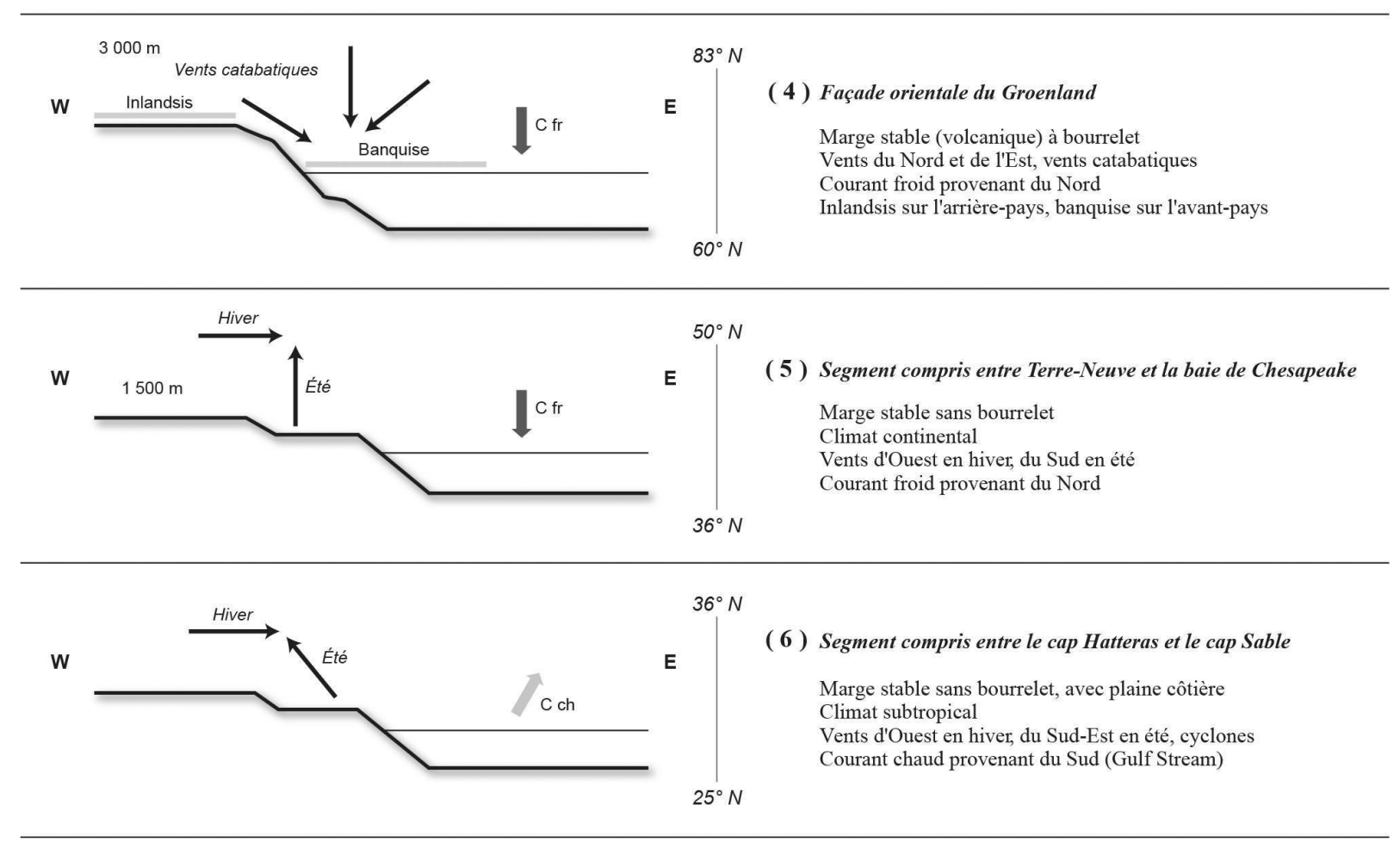

Figure 6 : La façade atlantique de l'Amérique du Nord The North America Atlantic façade

oiseaux). Du côté de l'avant-pays, la banquise saisonnière (plus développée près des côtes, car plus froides), s'étend jusqu'au cap Farewell. Le courant du Groenland oriental, venant du nord, aggrave le froid. Pour l'ensemble de ces faits, l'océanisation est extrêmement faible au nord, et demeure réduite au sud. Il s'agit donc d'un cas limite, pour des causes climatiques.

(5) Le segment compris entre Terre-Neuve $\left(50^{\circ} \mathrm{N}\right)$ et la baie de Chesapeake $\left(36^{\circ} \mathrm{N}\right)$ s'étend du détroit de Davis aux environs de la baie de Chesapeake (au sud du $40^{\mathrm{e}}$ parallèle). Il représente le cas d'une façade orientale de continent aux latitudes moyennes, établie là encore sur une marge stable, en l'occurrence sans bourrelet, dont l'océanicité, demeure ici relativement limitée. Cette situation tient à deux causes. La première concerne son environnement, notamment les dimensions et la disposition de l'arrièrepays. La plaine côtière demeure étroite sur cette partie de la façade nord-américaine; elle commence au sud de l'embouchure du Saint-Laurent, qui est, pour sa part, l'une des plus vastes du monde; elle est bordée par une côte à fjords au nord (Hudson) et par de grandes baies au sud (Delaware, Chesapeake). Les
Appalaches et leurs prolongements correspondent à un massif ancien dont le relief, marqué par sa structure caractéristique comme par les héritages d'une érosion glaciaire pléistocène, demeure peu élevé (moins de $1500 \mathrm{~m}$ ), mais suffisant pour contribuer à s'opposer aux éventuelles influences océaniques. Le climat demeure de toute façon de type continental, en raison d'une circulation dominante d'ouest en hiver, qui repousse les influences océaniques vers l'est, alors que le courant du Labrador qui termine sa course aux latitudes concernées écarte le Gulf Stream. Les hivers sont donc rigoureux, surtout au nord, où le Saint-Laurent est pris par les glaces. Les étés sont chauds, surtout au sud, où la remontée de l'anticyclone des Açores entraîne une circulation temporaire des vents depuis le sud et où le climat tempéré continental est rapidement remplacé par un climat tempéré humide à été chaud. Ce segment de façade orientale se présente comme l'un de ceux où la zone tempérée est la plus rétractée en latitude.

(6) Le segment compris entre le cap Hatteras (au sud de la baie de Chesapeake) et le cap Sable (an sud de la Floride, $25^{\circ} \mathrm{N}$ ), appartient au «Sud » des ÉtatsUnis. Il obéit au même dispositif structural que le 
précédent (marge stable sans bourrelet, suite des Appalaches), mais comporte une large plaine côtière subsidente, bordée de côtes sableuses à cordons de la Virginie à la Floride et influencée par le trajet du Gulf Stream qui contourne la mer des Sargasses vers le nord-est. Le climat tempéré humide à été chaud au nord passe au climat sub-tropical, de type chinois, vers le sud (Godard et Tabeaud, 2004). La circulation d'ouest qui continue de régner en hiver, en provoquant des amplitudes annuelles et des coups de froid significatifs de la persistance des influences continentales (jusqu'en Floride), passe à une circulation qui provient du sud-est en été, sous l'influence des déplacements, éloignés, de l'anticyclone des Açores en provoquant la pénétration des masses d'air tropical. La façade n'est que modérément soumise aux alizés. En revanche, elle est épisodiquement dévastée par les cyclones tropicaux qui se forment au-dessus de la mer entre l'équateur et le tropique et qui peuvent remonter jusqu'à la baie de Chesapeake. Les influences océaniques provoquent des précipitations abondantes, en toutes saisons, et s'avèrent, finalement, plus déterminantes que sur les segments situés plus au nord.

La façade atlantique de l'Afrique soulève un problème à propos de son contact avec la façade atlantique européenne. Ce contact, différent de tous les segments de façade identifiés précédemment, mérite d'être examiné d'abord dans le sens ouestest, du cap Saint Vincent à Agadir. Le littoral, interrompu entre Gibraltar et Tanger, présente un tracé général arqué qui s'ouvre sur $750 \mathrm{~km}$ et qui borde un golfe Ibéro-marocain l.s. (Vanney et Ménanteau, 2004). Assorti de cordons sableux et d'estuaires, il se trouve en avant de plaines côtières étendues, en Espagne comme au Maroc. Il est rafraîchi sur toute sa longueur par le courant des Canaries, qui provient du nord, et longé, toute l'année, par des vents dominants du nord-ouest et du nord. L'arrièrepays demeure soumis, en plaine, au climat méditerranéen au nord (Algarve et Andalousie), méditerranéen subaride au sud (plaines marocaines). Ce golfe, organisé autour du détroit de Gibraltar, passe cependant au droit des chaînes diagonales (Sierra de Tolox à l'extrémité de la cordillère Bétique, Rif, Muen et surtout Haut Atlas) qui montrent qu'il se rapporte prioritairement à un type de marge active, lié à la convergence des plaques continentales afri- caine et européenne. Considéré dans le sens sudnord, l'ensemble se compose en effet de chaînes de collision tertiaires, perpendiculaires à la façade atlantique de l'Ancien Monde, qui culmine au-delà de $4000 \mathrm{~m}$ du côté marocain (Atlas) et de $3000 \mathrm{~m}$ du côté ibérique (cordillère Bétique). Il se range donc parmi les articulations entre deux plaques et, par là, entre deux façades (\$24).

(7) Le segment de façade compris entre l'Anti-Atlas (Maroc, $31^{\circ} \mathrm{N}$ ) et la Casamance (Sénégal, $12^{\circ} \mathrm{N}$ ) reproduit une partie des caractères des façades intégrées à une marge stable sans bourrelet (Peulvast et Vanney, 2001) (figure 7). L'avant-pays comprend un précontinent étroit, comme le long de la plupart des côtes atlantiques de l'Afrique, précédé par l'archipel des Canaries, îles océaniques associées à un point chaud et à des édifices volcaniques élevés, en partie actifs (le Teide culmine à $3707 \mathrm{~m}$ ). Le littoral est bas, sableux, sans embouchure notable jusqu'au Sénégal. L'arrière-pays appartient aux plates-formes indifférenciées du vieux socle africain, en l'occurrence des cuvettes de subsidence marginales, dont les surfaces s'étendent sans limite vers l'intérieur, de la Mauritanie à la Guinée-Bissau. Les alizés du nord-est (animés par l'anticyclone des Açores) et les vents nord-sud, dont le Simoun, repoussent les masses d'air océanique et expulsent les sables sahariens vers le large, au-delà des plages. Par ailleurs, le courant des Canaries, termine sa course en provenance du nord et rafraîchit l'atmosphère, en contrariant les ascendances. Un phénomène d'upwelling engendre, par conséquent, un désert littoral brumeux le long de la Mauritanie, qui ajoute ses effets à l'aridité zonale. Ce segment de façade, situé en bordure du Sahara et du Sahel, encore soumis au nord au climat méditerranéen subaride (à maximum de précipitations d'hiver), passe au sud à un climat aride puis à un climat sahélien (à maximum de précipitations d'été). Les influences océaniques ne conduisent qu'à renforcer l'aridité de ce dernier.

(8) Le segment compris entre la Casamance $\left(12^{\circ} \mathrm{N}\right)$ et le Libéria (cap des Palmes, $4^{\circ} \mathrm{N}$ ) suit une direction nord ouest-sud est et appartient à une marge stable à bourrelet marginal réduit (Birot, 1970). L'arrièrepays appartient au bouclier Guinéen, basculé vers l'intérieur. Il est dominé par les plateaux étagés du Fouta Djalon en Guinée (1527 m) et des monts Loma en Sierra Leone (1948 m), disséqués par des vallées rectilignes, encaissées, dirigées vers l'inté- 


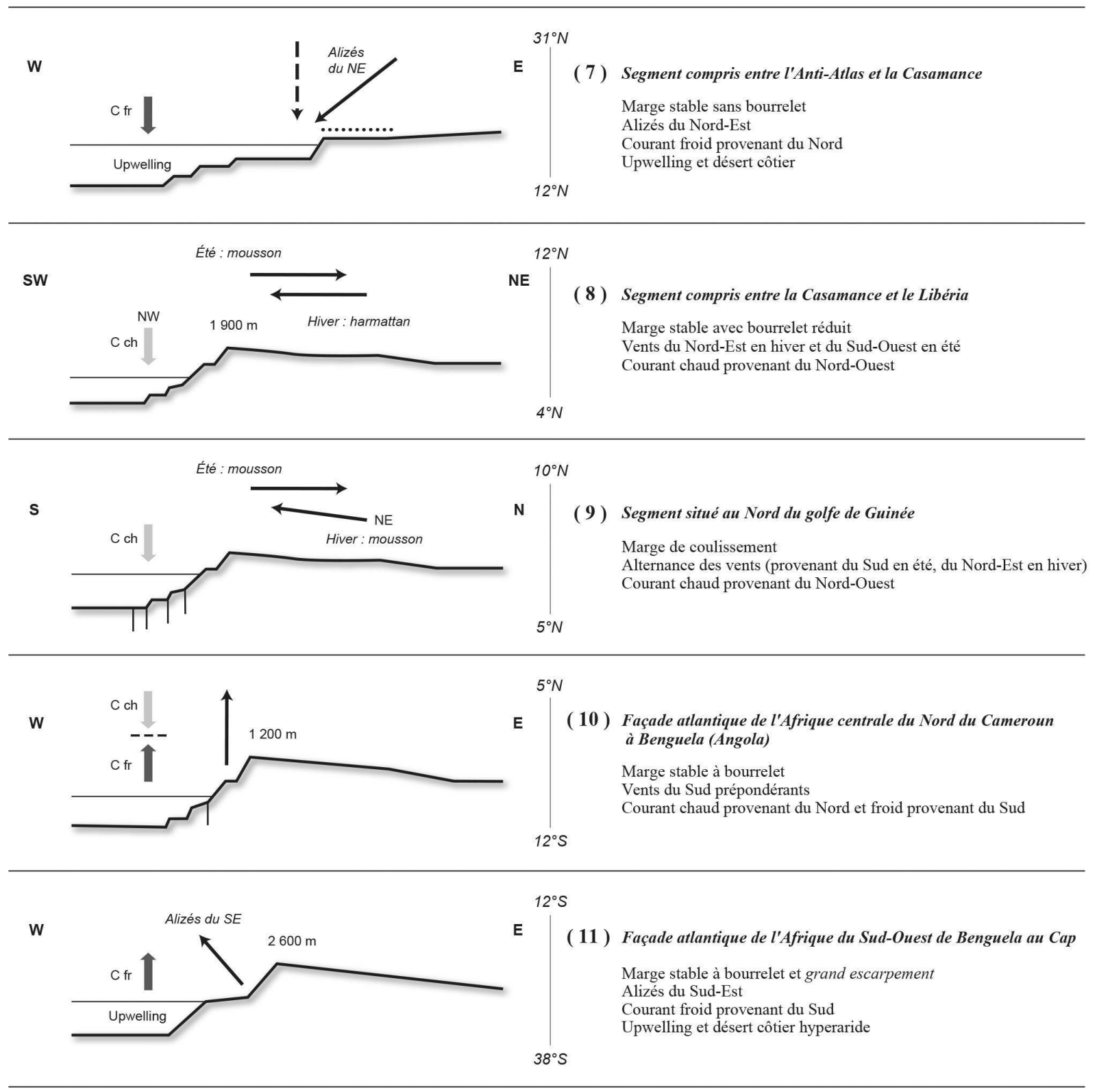

Figure 7 : La façade atlantique de l'Afrique

The African Atlantic façade

rieur, dont celles du Sénégal et du Niger. L'avantpays océanique est parcouru par le contre-courant de Guinée, venant du nord-ouest qui apporte des eaux chaudes, propices au développement des coraux, quoique la côte commence à être occupée aussi par la mangrove. Le climat tropical au nord (savane) à climat équatorial au sud (forêt) est soumis à une alternance saisonnière des vents : l'Harmattan souffle du nord-est en hiver, mais la mousson atlantique apporte en été un supplément de précipitations estivales (2 000 à plus de 4000 mm par an sur les côtes), donc une influence océanique effective, rapidement réduite par les reliefs intérieurs.

(9) Le segment situé au nord du golfe de Guinée s'étend, parallèlement à l'équateur, de la Guinée au Cameroun, entre $10^{\circ}$ et $5^{\circ}$ de latitude nord. Il correspond au symétrique de la côte des Guyanes et du nord du Brésil par rapport à l'Atlantique. Il en représente aussi l'homologue, par son appartenance à une marge de coulissement (ou marge de cisaillement), associée aux grandes failles transformantes transatlantiques Guyane-Guinée, et constitue, de 
ce fait, un nouveau cas particulier de façade du côté africain de l'Atlantique. Le type de divergence en cause a entraîné le cisaillement des bordures du bouclier Guinéen et le relief, dans son ensemble, se rapporte à des surfaces basses, plaines côtières et pédiplaines surmontées par quelques lambeaux de plateaux résiduels (Peulvast et Vanney, 2002). La côte, encore longée par le contre-courant de Guinée dirigé vers l'est, est bordée de plages sableuses, cordons, lagunes et marais littoraux à mangrove. Elle est recoupée à l'est par l'embouchure du Niger, analogue à celle de l'Amazone, qui forme un delta de plus de $300 \mathrm{~km}$ de largeur. Le climat, équatorial, est caractérisé par des pluies tropicales à maximum zénithal, donc à deux saisons pluvieuses, ainsi que par une circulation saisonnière méridienne inversée des vents : une mousson d'été, provenant de l'hémisphère sud alterne avec des alizés venant du nordest. Les incidences des flux d'origine océanique sur l'arrière-pays, effectives dans le cas de cette façade, sont cependant atténuées par des influences zonales prépondérantes.

(10) La façade atlantique de l'Afrique centrale du nord du Cameroun à Benguela (Angola) retrouve une direction méridienne de part et d'autre de l'équateur $\left(5^{\circ} \mathrm{N}-12^{\circ} \mathrm{S}\right)$. Elle correspond à une marge stable à bourrelet large. Elle comporte un relief de platesformes surélevées jusqu'à plus de $1200 \mathrm{~m}$, bordées de plaines côtières plus étroites qu'au nord, sauf à l'embouchure des grands cours d'eau comme l'Ogoué et le Congo, second fleuve du monde par l'étendue de son bassin versant et par son débit (plus de $40000 \mathrm{~m}$ 3/s). Au nord, cette façade est limitée par le rift transversal de la basse Bénoué au Cameroun, ouvert dans le prolongement du rift transversal du Sertão du Brésil et responsable d'un volcanisme fonctionnel depuis le Crétacé sur l'avant-pays (îles de São Tomé et de Fernando Pó, 3106 m) comme sur l'arrière-pays (stratovolcan du mont Cameroun, $4070 \mathrm{~m}$ ). Cette façade est celle des convergences méridiennes : des courants d'abord, avec l'affrontement des eaux du contre-courant, chaud, de Guinée et du courant, relativement frais, de Benguela, des masses d'air ensuite, en fonction des déplacements du front intertropical. Elle reste, toutefois, principalement conditionnée par une circulation du sud ou du sud-ouest, animée par l'anticyclone sud-atlantique, qui produit les derniers effets de la mousson atlantique à partir des côtes. La façade atlantique de
l'Afrique centrale comprend des milieux équatoriaux ou tropicaux humides, essentiellement caractérisés par la forêt. Elle est l'une des plus pluvieuses du monde avec son homologue d'Amérique du Sud.

(11) La façade atlantique de l'Afrique du SudOnest de Benguela au Cap s'étend le long du sud de l'Angola, de la Namibie et de l'Afrique du Sud, entre 12 et $38^{\circ}$ de latitude sud. Elle apparaît d'abord comme le symétrique de la façade de l'Afrique de l'Ouest comprise entre l'Anti-Atlas et la Casamance (7), mais s'en distingue par plusieurs caractères physiques fondamentaux. Elle se rapporte d'abord à une marge stable à bourrelet marginal qui s'élève jusqu'à 2600 m, en avant de hautes plates-formes précambriennes inclinées vers l'intérieur. Elle s'accompagne d'un relief de grand escarpement à blocs faillés, recoupés par des vallées encaissées, comme celle du fleuve Orange. Cet escarpement presque continu domine une plaine côtière étroite, bordée de dunes littorales, longée par le courant de Benguela qui circule du sud vers le nord. Ce courant provient directement des eaux froides de l'océan Austral, en s'échappant du courant circumpolaire et non d'une dérivation d'un courant initialement chaud, comme le courant des Canaries (Vanney, 1991). Associé aux effets des alizés du sud-est, il engendre un courant d'upwellling qui bloque les ascendances et qui explique la présence du désert côtier hyperaride à été chaud du Namib (10 à $20 \mathrm{~mm}$ de précipitations en moyenne par an). L'aridité « de façade» s'ajoute en l'occurrence à l'aridité zonale déterminée par la ceinture anticyclonique tropicale et explique l'étirement du désert vers le nord, en direction de Benguela. Au nord, la façade atlantique de l'Afrique du Sud passe ainsi rapidement à la façade tropicale de l'Afrique centrale. Au sud, près du Cap, elle passe aussi brusquement à un climat tempéré, moins étendu que sur la façade orientale de l'Afrique du Sud. Finalement, ce segment, comme le précédent, demeure partout longé plus que traversé par les flux.

\section{La façade atlantique de l'Amérique du} Sud provient, elle aussi, de la fragmentation du Gondwana à partir du Secondaire. Elle s'étend des bouches de l'Orénoque au cap Horn, mais se trouve décalée en latitude vers le sud $\left(10^{\circ} \mathrm{N}-55^{\circ} \mathrm{S}\right)$. Elle s'appuie sur de vastes plates-formes, boucliers et tables, symétriques de celles de l'Afrique. Elle est soumise aux influences de la circulation des cou- 
rants et des masses d'air propres aux façades orientales de l'hémisphère sud. Elle est recoupée par de gigantesques embouchures (Orénoque, Amazone, Rio de la Plata) et peut être découpée en quatre segments, si l'on écarte pour l'instant l'articulation correspondant à l'arc Antillais (figure 8).

(12) Le segment situé entre les embouchures de l'Orénoque et de l'Amazone, entre le $10^{\circ}$ parallèle nord et l'équateur, représente le symétrique de la façade de l'Afrique de l'Ouest comprise entre la Casamance et le Libéria (8). Elle correspond, en effet, à une marge de distension, à bourrelet marginal, en avant du bouclier des Guyanes (2810 m au Venezuela), homologue du bouclier Guinéen par sa formation et par sa composition, où les plateaux de roches endogènes et de grès s'élèvent au-dessus de $2000 \mathrm{~m}$. Elle est longée par le courant sud-équatorial chaud venant du sud-est et continuellement exposée aux alizés du nord-est, propices à la pénétration des influences maritimes vers l'intérieur. Elle est soumise à un climat tropical humide, chaud toute l'année, à amplitudes thermiques dérisoires (inférieures à $1{ }^{\circ} \mathrm{C}$ ) et à pluies zénithales, qui justifie l'étendue de la mangrove sur les côtes et de la forêt sempervirente sur l'arrière-pays. Elle appartient, en partie, aux régions sévèrement touchées par les cyclones tropicaux. L'embouchure de l'Orénoque correspond à un immense delta. L'estuaire de l'Amazone, le fleuve le plus puissant du monde $\left(90000 \mathrm{~m}^{3} / \mathrm{s}\right.$ de débit moyen), commence à $400 \mathrm{~km}$ des côtes et émet des eaux fluviales à plusieurs dizaines de kilomètres en mer. L'effet de façade est ici l'un des plus marqués au monde.

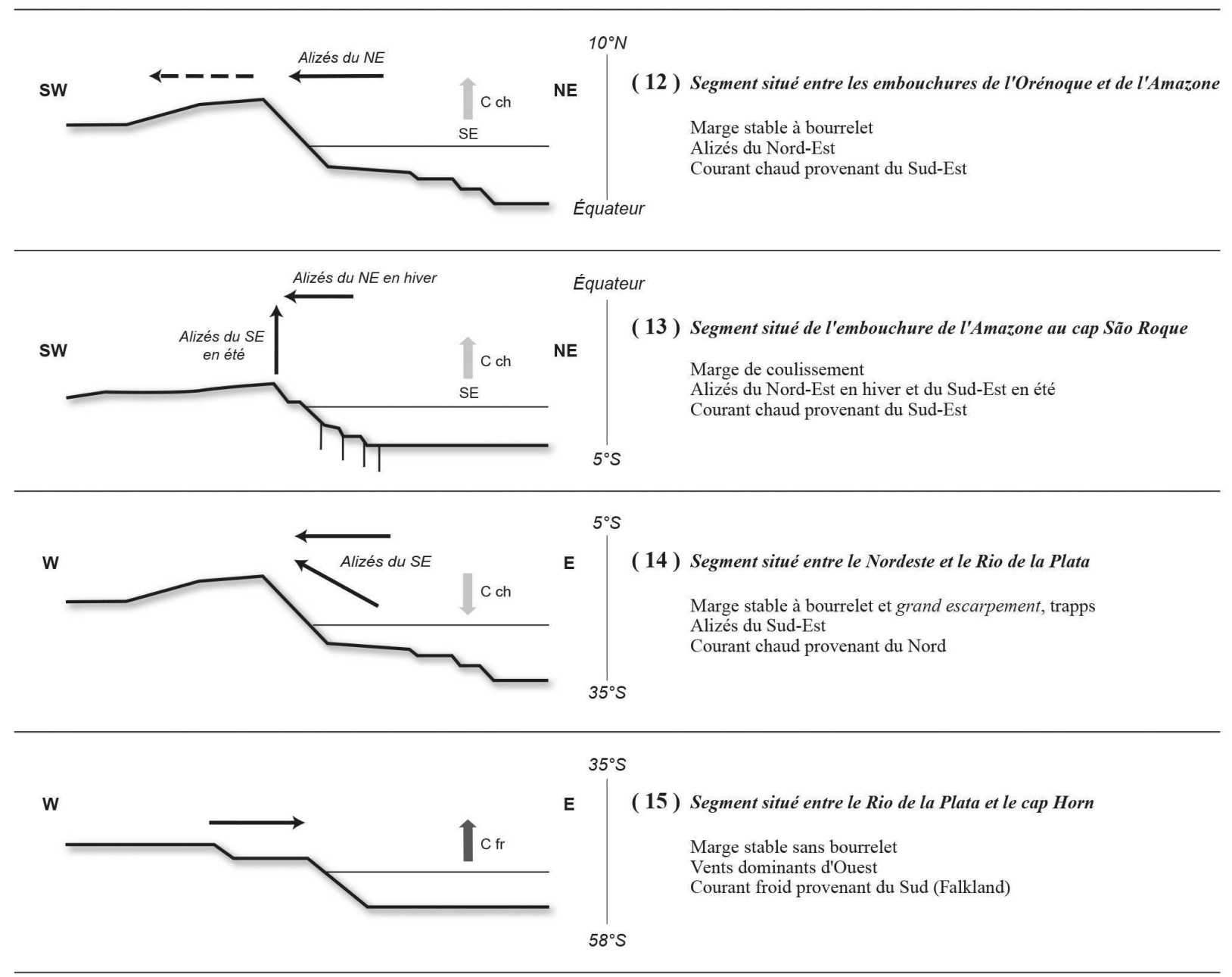

Figure 8: La façade atlantique de l'Amérique du Sud The South America Atlantic façade 
(13) Le segment situé entre l'embouchure de l'Amazone et le cap São Roque (Natal) est subparallèle à l'équateur et s'allonge sur près de $2000 \mathrm{~km}$ au nord du Brésil (équateur $-5^{\circ} \mathrm{S}$ ). Sa principale singularité est de correspondre à une marge de coulissement, symétrique, pour sa part, du segment de la façade africaine située au nord du golfe de Guinée, donc d'orientation opposée. Elle continue d'être exposée aux influences océaniques véhiculées par les alizés du nord-est en hiver et facilitées par un relief très bas (composé de la bordure de la cuvette amazonienne, de vastes plaines côtières et de bas plateaux). Elle reçoit les alizés du sud-est en été. La forêt dense passe progressivement à la forêt claire, puis à une végétation semi-désertique en direction du Nordeste brésilien. L'avant-pays océanique appartient au domaine des calmes équatoriaux.

(14) Le segment situé entre le Nordeste $\left(5^{\circ} \mathrm{S}\right)$ et le Rio de la Plata $\left(35^{\circ} \mathrm{S}\right)$ tient d'abord son unité de sa structure. Il correspond sur toute sa longueur à une marge stable à bourrelet marginal qui borde le bouclier Brésilien et ses grands trapps volcaniques d'âge crétacé. Ce bourrelet culmine à $2820 \mathrm{~m}$ immédiatement en arrière de Rio de Janeiro, dans le secteur où le grand escarpement témoigne d'un redressement exemplaire. Son unité est également d'ordre océanique, puisque l'ensemble de son littoral est longé par le courant du Brésil, qui dérive, vers le sud, du courant sud-équatorial et qui entraîne un réchauffement supplémentaire des masses d'air. Pour le reste, les influences océaniques sont inégales et cette façade pourrait être découpée en plusieurs secteurs. Les vents dominants proviennent toujours de l'océan, en l'occurrence de l'est ou du sud-est (alizés) dans la partie nord, de l'est et du nord-est dans la partie sud, en fonction de la place de l'anticyclone de l'Atlantique sud. En revanche, le bourrelet bloque rapidement la circulation des masses d'air tropical océanique. La conséquence la plus notoire de cette conjoncture se manifeste à l'emplacement du Nordeste brésilien, qui est présenté comme un désert d'abri, en raison des effets de son bourrelet marginal, dont l'exposition vers l'est et les altitudes, pourtant inférieures à 1000 m, s'opposent à l'intervention des alizés dans l'arrière-pays. Ce « désert », présent à l'écart des côtes, et paradoxalement proche de l'équateur tire sa singularité de ses crises de sécheresse (qui sévissent lorsque le défaut des pluies d'été tropicales associées au passage du front intertropical n'est pas compensé par les apports de pluies cycloniques provenant des secteurs tempérés situés plus au sud), plus que par ses totaux moyens annuels de précipitations, encore supérieurs à 500 mm (Demangeot et Bernus, 2001).

(15) Le segment situé entre le rio de la Plata et le cap Horn n'a pas de symétrique en Afrique aux latitudes concernées $\left(35^{\circ}-58^{\circ} \mathrm{S}\right)$ et se trouve borné par deux grandes coupures maritimes : le rio de la Plata, large de près de $200 \mathrm{~km}$ à l'embouchure, et le cap Horn, au sud de la Terre de Feu. Il s'oppose au précédent par chacun de ses caractères. Il correspond à une marge stable sans bourrelet, qui comprend un précontinent élargi du côté de l'avant-pays et des plaines côtières étendues, coïncidant avec les immenses bassins tertiaires de l'Uruguay et du nord de l'Argentine, du côté de l'arrière-pays. Elle est côtoyée sur toute sa longueur par le courant froid des Falkland, qui provient du sud. Elle est conditionnée par un climat tempéré à été chaud au nord, un climat «patagonien » au sud du golfe de San Matias, rattaché à la diagonale aride formée à l'abri des Andes, et un climat tempéré océanique en Terre de Feu. Du fait de la latitude, les vents d'ouest sont déjà dominants et contrarient l'influence des masses d'air atlantiques, sauf dans l'extrême Sud, où la nébulosité et l'instabilité du temps ne sont pas sans rappeler certains des aspects de l'Atlantique nord.

\section{2/ Les façades péripacifiques (figure 9)}

Il convient de poursuivre par elles pour leurs analogies avec les façades atlantiques du fait de leur extension en latitude, de leurs expositions, des mécanismes de la circulation atmosphérique et océanique. Ces façades sont un peu plus courtes que celles de l'Atlantique. Celle de l'Amérique part du cap Horn et ne s'étend que jusqu'au cercle polaire boréal, qui recoupe le détroit de Béring, soit sur $121^{\circ}$ de latitude. Celle de l'autre rive, s'étend sur $108^{\circ}$ si on l'allonge jusqu'en Tasmanie, au-delà de l'articulation indonésienne et de l'Australie. La première est, à l'évidence, la plus continue du monde, alors que la seconde est assortie d'une succession de six bassins marginaux. L'une et l'autre sont subméridiennes, donc elles aussi transzonales, et font preuve sur ce plan d'une certaine symétrie. En revanche, ces deux façades sont très éloignées l'une de l'autre : plus de $15000 \mathrm{~km}$ au niveau de l'équateur. L'océan Pacifique est en effet 


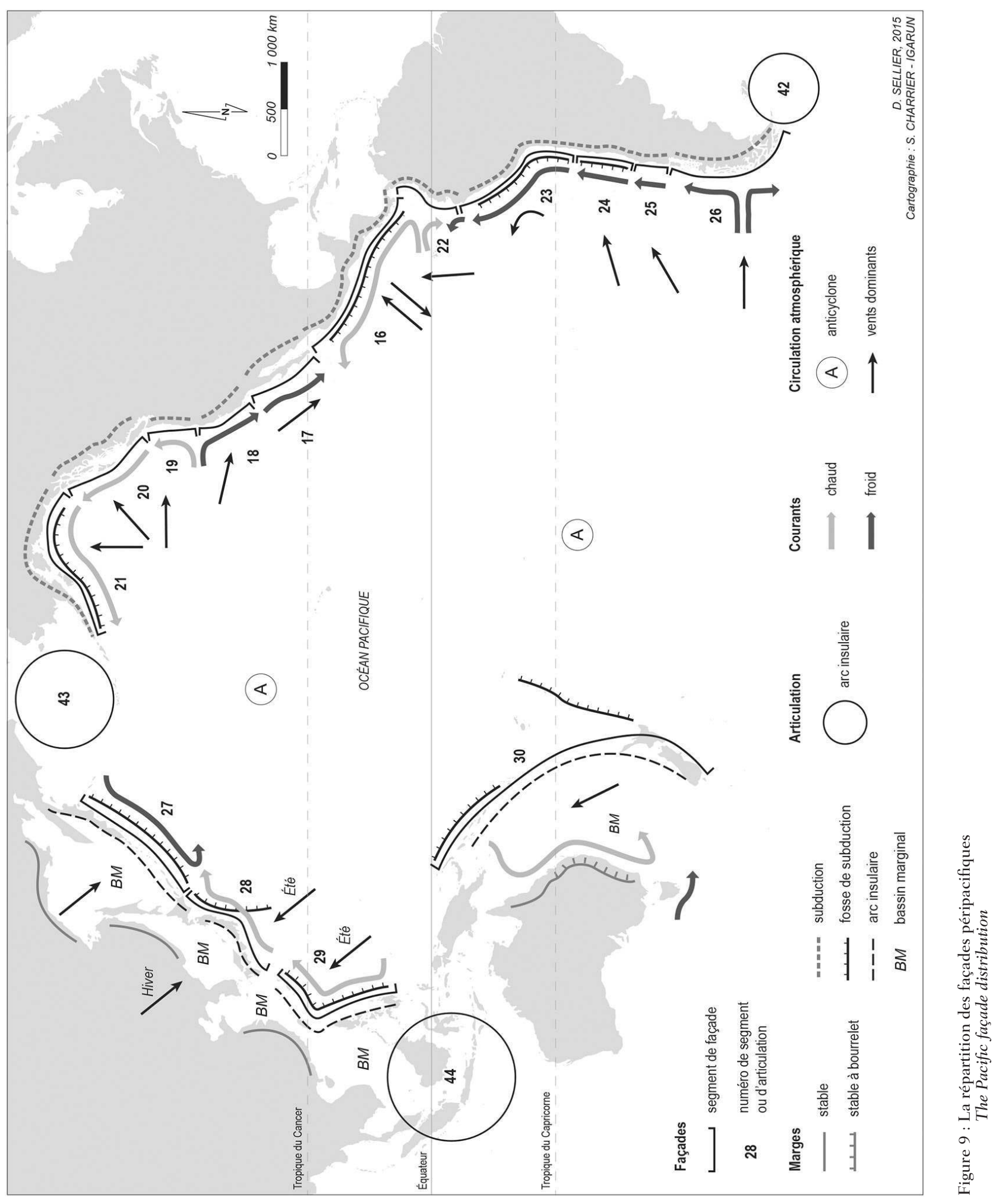


beaucoup plus vaste que l'Atlantique et a fortiori que l'océan Indien; sa superficie est supérieure à celle de l'ensemble des terres émergées, ce qui exclut ici toute possibilité d'échanges transversaux (Vanney, 1991). Par ailleurs, l'appartenance de ces façades à une même catégorie de marges, en l'occurrence actives, n’implique ni leur symétrie, ni leurs similitudes dans le sens est-ouest.

\section{$221 /$ Les propriétés générales des façades océaniques péripacifiques}

- Les caractères morphostructuraux des façades péripacifiques

Ils s'opposent à ceux des façades atlantiques. Ils se rapportent, en effet, pour l'essentiel à une dynamique de convergence et à des marges actives. Cette dynamique implique les deux plaques américaines, la plaque eurasiatique, la partie orientale de la plaque indo-australienne, qui occupent la périphérie de deux plaques océaniques : la plaque pacifique et la plaque de Nazca (ou plaque de l'île de Pâques) (Vanney, 1991; Debelmas et Mascle, 2000). L'existence de la dorsale du Pacifique oriental, qui passe à l'ouest de l'île de Pâques, donc très au large de l'Amérique du Sud, et qui rejoint l'Amérique centrale vers l'entrée du golfe de Californie est l'unique point commun de l'agencement tectonique du Pacifique et de l'Atlantique. Cette dorsale sépare la plaque Pacifique de la plaque de Nazca, attenante à la façade de l'Amérique du Sud, et la sous-plaque de Cocos (ou plaque des Galapagos), adjacente à la façade de l'Amérique centrale. Pour le reste, les façades pacifiques, américaines ou australasiatiques, sont marquées sur l'essentiel de leur tracé par des chaînes plissées généralement élevées, précédées de fosses sous-marines profondes. Elles sont conjointement significatives de phénomènes de subduction des plaques océaniques sous les plaques continentales, assortis de leurs corollaires : sismicité active, volcanisme de type andésitique, éventuellement explosif, dont les édifices ceinturent le Pacifique. Lầge de la croûte océanique indique que le déplacement des plaques considérées a débuté ici aussi au Jurassique, mais, contrairement à l'Atlantique, à l'emplacement d'un océan initial qui existait avant le morcellement de la Pangée (Vanney, 1991). De ce fait, les marges du Pacifique correspondent partout à des marges de convergence, en dehors de phénomènes localisés de coulissement, sinon de collage. Les relations entre les façades pacifiques, américaines ou australasiatiques, s'établissent selon des dynamiques différentes de celles qui valent pour les façades atlantiques : le moteur des dynamiques en cause se trouve immédiatement à l'avant des façades. Il est relativement autonome, en tout cas opposé à celui qui fonctionne de façon symétrique et solidaire à partir de l'océan Atlantique. Les façades pacifiques présentent des propriétés qui nécessitent donc des développements pour chacune d'entre elles.

- La circulation des eaux océaniques le long des façades péripacifiques

La circulation des eaux de surface relève de mécanismes équivalents à ceux qui fonctionnent dans l'Atlantique. Néanmoins, la cuvette océanique du Pacifique, plus vaste que celle de l'Atlantique, mais presque totalement fermée au nord, au niveau du détroit de Béring, est encore plus ouverte sur l'océan Austral. Dans l'hémisphère sud, le tracé des courants forme une cellule animée par les anticyclones sud-pacifiques, encore plus grande que celle qui concerne l'Atlantique sud. Le courant sud-équatorial circule dans la même direction (vers l'ouest) et à la même latitude (celle de l'équateur) que son homologue atlantique. Il se prolonge, le long de la façade pacifique de l'Australie par le courant d'Australie oriental (de tracé nord-sud), dont les eaux rejoignent celles de la dérive Antarctique. Une partie de celles-ci remonte vers le nord jusqu'à l'équateur en formant le courant de Humboldt le long de la façade pacifique de l'Amérique du Sud. Dans l'hémisphère boréal, au nord du contre-courant équatorial (de direction ouest-est) s'observe une double cellule, plus réduite, animée par l'anticyclone de Californie au sud et, en partie, par celui de Sibérie. Le courant nord-équatorial (de direction est-ouest) circule au nord du précédent, s'incurve au droit des Philippines, suit la façade pacifique de l'Asie et atteint le sud du Japon (Kouro Shivo). Les eaux de ce dernier traversent le Pacifique nord en franchissant le $40^{\mathrm{e}}$ parallèle (dérive nord-Pacifique). Elles se répartissent en deux branches en atteignant la façade pacifique de l'Amérique du Nord (comme celles du Gulf Stream au large du golfe de Gascogne); l'une se dirige vers le sud (courant de Californie, relativement froid) et rejoint le courant 
nord-équatorial; l'autre s'oriente vers le nord (courant de l'Alaska, relativement chaud) et se prolonge vers le Japon (Oya Chivo). Les courants méridiens qui longent les façades sous l'effet de cette circulation sont à l'origine d'anomalies thermiques de même nature, sinon du même ordre, que dans l'Atlantique.

- Les effets des climats le long des façades péripacifiques

Les façades pacifiques recoupent les mêmes zones climatiques que leurs homologues atlantiques, mais sont moins étendues vers les hautes latitudes boréales. Les mécanismes qui commandent la circulation atmosphérique sont analogues à ceux qui fonctionnent à l'emplacement de l'Atlantique, mais engendrent des situations différentes selon les façades, les saisons et les hémisphères. Au sud, la ceinture d'anticyclones qui stationnent autour du tropique du Capricorne (anticyclone australien, anticyclone du Pacifique sud, ou de l'île de Pâques) participe à la mise en route des vents d'ouest qui soufflent au-dessus de l'océan Austral. Elle anime également les vents d'ouest ou de sud-ouest qui atteignent la façade pacifique de l'Amérique du Sud pendant toute l'année et qui engendrent un phénomène d'alizé transéquatorial dévié sur les côtes du Mexique pendant l'été boréal; elle provoque surtout une mousson d'été très prononcée sur la façade de l'Asie du Sud-Est, en relation avec la dilatation de l'anticyclone d'Australie, la remontée du front intertropical et, corrélativement, celle des alizés équatoriaux jusqu'au sud du Japon. Au nord, l'anticyclone de Californie étend son influence sur la majeure partie du Pacifique nord pendant l'été, en créant une circulation des vents dans le sens anticyclonique de l'hémisphère nord, donc de grands vents d'ouest vers la façade pacifique de l'Amérique du Nord et des vents de sud-est vers la façade pacifique de l'Asie. Il se rétracte au cours de l'hiver boréal, alors que l'anticyclone sibérien s'étend, en provoquant une inversion saisonnière de la circulation des vents, qui soufflent alors du continent vers l'océan, entre la mer de Béring et le nord de la Chine. Les façades pacifiques sont également concernées par les cyclones tropicaux sur les côtes du nord-est de l'Australie au cours de l'été austral, sur les côtes du Mexique et surtout sur celles de l'Asie, des Philippines au sud du Japon, au cours de l'été boréal. L'organisation climatique des façades du Pacifique obéit donc à une dissymétrie est-ouest, à une dissymétrie nordsud et à des inversions saisonnières corrélatives du déplacement du front intertropical.

L'ordonnance bioclimatique et morphoclimatique des façades pacifiques devrait répondre, en principe, aux mêmes influences de la zonalité que les façades atlantiques, en raison d'une même ouverture en latitude. Plusieurs facteurs majeurs modifient cependant cette ordonnance. Le premier tient à la répartition des terres et des mers selon les façades et les hémisphères. C'est ici la façade située à l'est de l'océan, donc du côté américain, qui est la plus continue et qui recoupe le plus grand nombre de zones; la façade située à l'ouest est fractionnée par les bassins et arcs insulaires qui se succèdent du détroit de Béring à celui de Malacca, puis fragmentée en archipels et en grandes îles entre ce dernier et la NouvelleZélande. Le deuxième facteur tient à l'orographie. Les façades océaniques pacifiques sont principalement des façades montagneuses, alors que celles de l'Atlantique sont formées de plates-formes, avec ou sans bourrelets marginaux. Les chaînes de subduction qui bordent l'Amérique forment une montagne continue qui culmine à plus de $6000 \mathrm{~m}$ en Alaska et à près de $7000 \mathrm{~m}$ dans les Andes, encore à plus de $4000 \mathrm{~m}$ dans certains des secteurs les plus étroits de l'Amérique centrale. Leur élévation entraîne la dégradation des climats et l'étagement de la végétation avec l'altitude, qui restreignent les effets de la zonalité, sans jamais les abolir complètement. Leur proximité des côtes en fait des barrières qui arrêtent brusquement la pénétration des masses d'air océanique aux latitudes où, comme en Europe, elles pourraient s'étendre à travers l'arrière-pays; l'isoamplitude annuelle $20{ }^{\circ} \mathrm{C}$ demeure proche des côtes tout le long de l'Amérique du Nord et ne s'en écarte progressivement qu'en Californie. Les reliefs sont moins gigantesques du côté australasiatique, quoiqu'ils dépassent $3500 \mathrm{~m}$ au Kamchatka, au Japon, à Taïwan, en Indonésie et en Nouvelle-Zélande. Mais de ce côté, l'originalité provient de la mousson, qui fait sentir ses effets jusqu'à Honshū, alors qu'Hokkaidō connaît des hivers sibériens. La dissymétrie entre les deux façades est et ouest du Pacifique est donc encore plus marquée qu'autour de l'Atlantique et le contraste climatique qui s'exprime dans le sens 
méridien aux dépens du domaine tempéré est encore plus prononcé sur la façade est de l'Asie que sur celle de l'Amérique du Nord.

Les systèmes morphogéniques en action sur les façades pacifiques se conforment à ces circonstances. Les bassins versants sont extrêmement étroits et restreints le long de la façade pacifique de l'Amérique du Sud, en réponse à la proximité de la ligne de crêtes des Andes par rapport aux côtes. Ils sont plus étendus le long de celle de l'Amérique du Nord, où les Rocheuses sont plus aérées (bassins versants du Colorado, de la Columbia et du Yukon) et de celle de l'Asie (bassins de l'Amour, du Houang Ho, du Yangzi Jiang et du Mékong), où le relief est aussi plus étagé et où les précipitations sont particulièrement abondantes jusqu'à la latitude du Japon. Quoi qu'il en soit, l'inégale étendue des bassins versants vers l'arrière-pays, conforme, pour sa part, à la configuration morphostructurale des marges concernées est compensée ici par l'élévation des reliefs livrés à l'érosion $(\$ 131)$. Les fleuves qui parviennent aux façades du Pacifique participent au drainage des reliefs qui comptent parmi les plus élevés du monde. La morphogenèse associée à l'écoulement linéaire est par conséquent très agressive et les tonnages de sédiments qui aboutissent aux embouchures sont parmi les plus forts au monde.

Les façades pacifiques, quelles qu'elles soient, sont par ailleurs celles qui présentent les plus grands risques naturels pour les populations riveraines, par leur multiplicité, leur fréquence et leur intensité (volcanisme, séismes, tsunamis, décalage du passage de la mousson dans le temps, cyclones tropicaux, irrégularités des courants méridiens, comme dans le cas d'El Niño).

\section{2/ Les caractères régionaux des façades océaniques péripacifiques}

La caractérisation des façades pacifiques peut reposer sur les mêmes critères que ceux qui s'appliquent aux façades atlantiques : type de marges (en principe convergentes, hormis quelques secteurs le long de l'Amérique du Nord), orientation (donc exposition), situation par rapport aux zones climatiques, circulation atmosphérique et océanique. Partant de là, de profondes différences existent entre les façades américaines et australasiatiques.
Les façades pacifiques américaines sont les plus simples, en raison de leur continuité, de leur orientation méridienne, de leur exposition vers l'ouest et de leur structure de marges actives, qui associe presque partout des reliefs montagneux (Rocheuses, Andes) et des fosses de subduction (Mexique, Atacama...). Ce sont les plus élevées au monde par leur relief, mais aussi les plus étroites par leur arrière-pays et par leur précontinent. En contrepartie, ce sont celles qui s'ouvrent sur les espaces océaniques les plus vastes et les plus vides. Les façades pacifiques américaines correspondent, en fait, à l'une des principales coupures du monde. Elles aboutissent à deux détroits : le détroit de Béring et le détroit de Drake qui, dans les circonstances actuelles, demeurent les moins fréquentés. Leur éloignement des façades australasiatiques et leurs propriétés tectoniques privent de toute correspondance structurale avec celles-ci. En revanche, leurs dimensions leur valent de connaître tous les climats qui se succèdent sur les façades occidentales des continents, jusqu'aux domaines subpolaires, et leur situation relativement équilibrée en latitude conduit à s'appuyer sur leur symétrie par rapport à l'équateur pour la segmenter. Trois segments majeurs se présentent alors à l'évidence : les façades de l'Amérique centrale, de l'Amérique du Nord et de l'Amérique du Sud. Dans la suite, celle de l'Amérique du Nord peut être subdivisée en deux segments principaux en fonction des courants et des climats, de part et d'autre du $40^{\mathrm{e}}$ parallèle, proche des limites entre Californie et Orégon. Celle de l'Amérique du Sud peut être subdivisée en deux autres segments principaux, dont la séparation, située vers le centre du Chili, serait plus climatique qu'océanique, puisque le courant de Humboldt remonte jusqu'aux abords des Galápagos. Cinq segments peuvent être finalement distingués vers le détroit de Béring, puis vers le détroit de Drake à partir de l'Amérique centrale, en fonction de la zonalité (figure 10).

(16) En partant ainsi, de l'équateur, la façade pacifique de l'Amérique centrale s'étend du sud du golfe de Panama $\left(4^{\circ} \mathrm{N}\right)$ à l'entrée du golfe de Californie (recoupée par le tropique du Cancer). Il s'agit d'une marge active, qui tire d'abord son unité des traits de son climat et de son avant-pays océanique. Il s'agit d'une façade tropicale exposée vers l'ouest, bénéficiant d'un climat continuellement chaud, équatorial ou tropical humide, à pluies zénithales, 


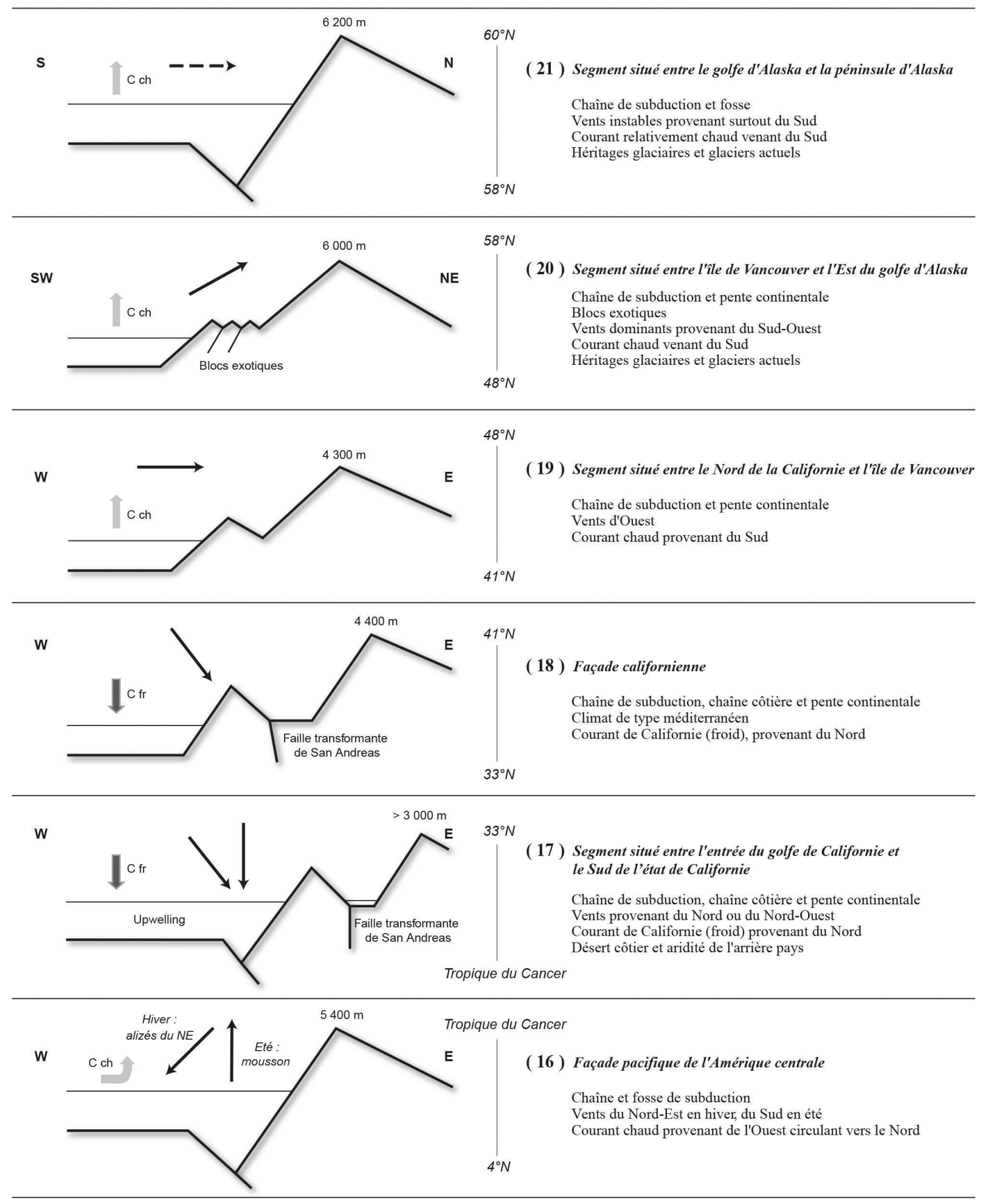

Figure 10 : Les façades pacifiques de l'Amérique du Nord

The North America Pacific façades 
au moins près des côtes, qui entretient la forêt à l'intérieur de l'arrière-pays, alors que la mangrove ou les récifs coralliens occupent une partie des côtes. En dehors des calmes équatoriaux qui règnent sur l'avant-pays, la circulation des masses d'air est soumise à l'alternance des alizés du nord-est en hiver et d'alizés transéquatoriaux déviés (mousson) qui franchissent l'équateur et atteignent les côtes de l'Amérique centrale en été. Ces dernières sont également exposées au contre-courant équatorial, chaud, provenant de l'ouest, qui disperse une partie de ses eaux vers le nord et qui n'est pas sans analogie avec le contre-courant de Guinée. Cette façade pacifique de l'Amérique centrale ressemble au segment Casamance-cap des Palmes en Afrique occidentale tropicale (8). Elle s'en démarque toutefois par son appartenance à une marge active à chaîne et fosse de subduction. Les chaînes plissées dominent directement le Pacifique (Sierra Madre del Sur, cordillère de Talamanca), en provoquant une forte dissymétrie du relief dans le sens ouest-est. Elles sont ininterrompues jusqu'à l'isthme de Panama, en dépit du rétrécissement continuel de l'arrière-pays vers le sud. Elles dépassent $5400 \mathrm{~m}$ près de Mexico, $4200 \mathrm{~m}$ près des côtes du Guatemala et encore $3800 \mathrm{~m}$ au Costa-Rica. Cette façade se rapporte à la plaque continentale de l'Amérique du Nord, qui surmonte la plaque océanique des Cocos à l'est de la fosse d'Amérique centrale, dont la profondeur atteint $6662 \mathrm{~m}$ à proximité des côtes du Mexique. À l'absence de plaine côtière correspond celle de plate-forme continentale le long d'une façade d'autant plus exemplaire d'une marge active qu'elle est le lieu d'une puissante activité sismique et volcanique.

(17) Vers le nord, le segment situé entre l'entrée du golfe de Californie (tropique du Cancer) et le sud de l'état de Californie, près du désert Mohave $\left(33^{\circ} \mathrm{N}\right)$, se distingue, certes, par ses tendances climatiques à l'aridité, mais d'abord par une configuration qui annonce celle des segments situés jusqu'à l'île de Vancouver : la présence d'une chaîne côtière qui dépasse 3000 m vers San Diego, à la frontière entre le Mexique et les Etats-Unis, parallèle au corps principal des montagnes continentales (en l'occurrence la Sierra Madre occidentale et les plateaux du Colorado, d'altitude un peu supérieure). Ici la chaîne côtière se trouve réduite à une péninsule longiligne, remarquablement étroite, qui s'étire sur près de $1000 \mathrm{~km}$ de long : la presqu'île de Basse-
Californie. L'espace intermédiaire, affaissé, se trouve immergé et occupé par le golfe de Californie. L'avant-pays océanique présente une pente continentale redressée et une fosse de subduction encaissée (fosse de Cedros, 6275 m), mais la spécificité structurale de cette façade tient à la terminaison de la dorsale du Pacifique oriental, tronçonnée et décalée par des failles transformantes, qui aborde les côtes pacifiques du Mexique et qui suit le golfe de Californie, en «transformant » ainsi un processus d'accrétion en processus de subduction; la plus septentrionale, en même temps que la plus remarquable, est la faille de San Andreas, qui relie le fond du golfe de Californie à Tomales Bay, au nord de San Francisco (Debelmas et Mascle, 1997). En dehors des risques sismiques, ce dispositif tectonique implique la disparition des fosses péricontinentales le long des segments de façades situés plus au nord, de la Californie au golfe d'Alaska, où la pente continentale, proche des côtes et redressée, aboutit directement à des plaines abyssales (Vanney, 1991). Pour le reste, les vents dominants sont de secteur nord ou nord-ouest en fonction des déplacements de l'anticyclone de Californie au large et les côtes sont longées par le courant de Californie, qui émane de la dérive du Pacifique nord, qui circule vers le sud et qui s'accompagne de la remontée d'eaux froides. L'une des principales originalités de ce segment de façade provient aussi de l'aridité de son arrière-pays, qui tient des déserts côtiers, en raison du blocage des ascendances par le courant de Californie, mais aussi des déserts d'abri, en raison du compartimentage du relief (Demangeot et Bernus, 2001).

(18) La façade californienne, qui s'étend des environs de l'archipel de Santa Barbara $\left(33^{\circ} \mathrm{N}\right)$ à ceux du cap Mendocino $\left(41^{\circ} \mathrm{N}\right)$, ne se distingue guère du segment précédent par les trajets des vents et des courants de surface. Elle est surtout connue pour l'ordonnance tripartite de son relief, pour ses singularités tectoniques et pour l'attractivité de son climat. Le relief comprend d'abord les Coast Ranges, qui culminent à $2466 \mathrm{~m}$ au nord, ne s'écartent du littoral qu'au sud, au niveau de la plaine de Los Angeles, et ne s'interrompent qu'au centre, à l'emplacement de la baie de San Francisco, au débouché des eaux du Sacramento et du San Joaquin, mais aussi au passage de la faille de San Andreas. Il comprend ensuite la grande vallée de Californie, qui s'étire en arrière sur plus de 600 km et la Sierra 
Nevada, qui culmine pour sa part à $4418 \mathrm{~m}$ au mont Whitney. Le climat est de type méditerranéen, chaud et sec en été, plus humide en hiver, tout au moins en plaine, car les Coast Ranges et surtout la Sierra Nevada provoquent des pluies orographiques sur leur versant ouest, qui dessèchent les masses d'air rabattues sur leur versant est. De ce point de vue, la haute barrière de la Sierra Nevada, dont la ligne de crête ne s'écarte guère de plus de 250 km des côtes, confère à la façade californienne un arrière-pays étroit doté d'une limite interne remarquablement précise, au-delà de laquelle s'étendent les plateaux désertiques du Nevada et ses annexes.

(19) Un segment situé entre le nord de la Californie $\left(41^{\circ} \mathrm{N}\right)$ et l'extrémité de l'île de Vancouver $\left(48^{\circ} \mathrm{N}\right)$ est à distinguer de ses voisins pour tenir compte, comme en Europe, de la dilatation de la zone tempérée et de la juxtaposition de domaines bioclimatiques variés le long des façades occidentales des continents. Ce segment suit le littoral des États de l'Orégon et de Washington. Il se caractérise par un climat de type tempéré océanisé, frais et pluvieux, par un drainage dense et par des forêts étendues. La côte, rectiligne, est dominée par une chaîne côtière qui ne se trouve séparée ici de la chaîne intérieure que par les vallées du réseau inférieur de la Columbia. Cette chaîne, au relief raviné et au nom significatif (chaîne des Cascades), culmine à 4392 m au mont Rainier. Par ailleurs, la façade est soumise à une circulation de « grands vents d'ouest », qui véhiculent des masses d'air maritime saturé d'humidité par leur passage au dessus du Pacifique nord. Elle est soumise aux influences adoucissantes de la dérive du Pacifique nord, qui circule vers le nord, en apportant des eaux relativement chaudes. Elle présenterait donc des similitudes avec les segments compris entre le cap Finisterre et le cap Nord, si elle ne s'en distinguait pas fondamentalement par un relief de montagne jeune, qui limite rapidement les influences océaniques vers l'arrière-pays et qui impose corrélativement, comme plus au sud, les marques caractéristiques de la continentalité.

(20) Le segment de la façade pacifique boréale situé entre l'île de Vancouver $\left(48^{\circ} \mathrm{N}\right)$ et l'est du golfe d'Alaska (méridien de Juneau, $58^{\circ} \mathrm{N}$ ) mérite également d'être différencié de celui qui lui succède jusqu'à l'extrémité de la péninsule de l'Alaska, en dépit de points communs. Le climat subit les effets progressifs de la latitude, malgré une exposition vers le sud-ouest, face aux vents dominants, et une remontée de la dérive du Pacifique nord. On demeure cependant à l'intérieur d'un domaine à climat tempéré océanisé, pluvieux (plus de $2000 \mathrm{~mm}$ par an) et venté sur les côtes, où les températures moyennes mensuelles demeurent positives, mais se dégradent rapidement vers l'intérieur du fait des altitudes. La forêt boréale succède à la forêt tempérée, comme en Norvège. Le relief connaît, pour sa part, plusieurs particularités. La chaîne côtière de Colombie britannique s'adosse ici directement au corps des Rocheuses, qui se rétrécissent en largeur, mais qui gagnent rapidement en altitudes (le mont Logan, $6050 \mathrm{~m}$ se situe à moins de $100 \mathrm{~km}$ des côtes). La structure est surtout compliquée par la présence de «blocs exotiques », ou suspect terranes, restes d'un ancien arc insulaire, dissociés actuellement en trois éléments principaux, empilés et décrochés contre la marge de la plaque continentale de l'Amérique du Nord (îles de Vancouver et de la Reine Charlotte en Colombie, monts Wrangel au Yukon et en Alaska) (Birot, 1970; Debelmas et Mascle, 1997). En contrepartie de cette dynamique spécifique, l'avant-pays ne comprend que des plaines abyssales, comme le long de toutes les façades pacifiques qui se succèdent depuis le tropique du Cancer. L'une des principales propriétés géomorphologiques de cette façade provient, par ailleurs, de sa paléogéographie. Les inlandsis pléistocènes nord-américains ont atteint le Puget Sound. Ils ont profondément marqué le relief entre Seattle et l'Alaska en façonnant des réseaux de vallées glaciaires denses et encaissées, qui forment des couloirs responsables d'un profond découpage des côtes par des fjords et par des îles parallèles à la chaîne côtière. Ces glaciers, explorés et décrits par John Muir dès la fin du XIX ${ }^{\mathrm{e}}$ siècle, continuent par endroits d'atteindre la mer, en dépit de leur retrait actuel (Glacier Bay, près des monts Saint-Helias). Ainsi, certains vêlent, ce qui ne se produit qu'au Spitsberg du côté européen de l'Atlantique.

(21) Le segment de la façade pacifique boréale situé entre le golfe d'Alaska (à partir du mont Logan) et la péninsule d'Alaska ressemble au précédent par son isolement et le froid hivernal qui s'abat sur l'arrièrepays dès qu'on s'éloigne des côtes. Il appartient en fait à une entité géographique différente. Il suit un tracé arqué qui lui vaut d'être exposé vers le sud et entièrement situé entre les $58^{\mathrm{e}}$ et $60^{\mathrm{e}}$ parallèles. Son inflexion suit celle de la chaîne de l'Alaska, qui 
se rétrécit, s'étire à travers la péninsule de l'Alaska et se poursuit par les îles Aléoutiennes, mais qui atteint $6194 \mathrm{~m}$ au mont McKinley, à moins de $200 \mathrm{~km}$ d'Anchorage. Ce relief retrouve les propriétés d'une chaîne de subduction, étroite et proche des côtes, précédée d'une fosse qui naît au fond du golfe d'Alaska et qui atteint plus de $7000 \mathrm{~m}$ de profondeur le long des Aléoutiennes. Le relief de l'arrière-pays, plus cloisonné qu'au sud, est drainé par le réseau du Yukon. Il a été affecté au Pléistocène par un englacement de montagne, épais et continu, mais limité à la chaîne de l'Alaska et à ses abords. Des glaciers de plateau et des glaciers de vallée demeurent sur les reliefs les plus proches des côtes et les plus élevés sous l'effet d'enneigements résultant des masses d'air maritime poussées depuis le Pacifique par des vents instables, surtout de secteur sud. Certains composent des glaciers de piedmont, dont l'exemplarité leur vaut le synonyme de glaciers alaskiens. Ces glaciers produisent eux aussi des icebergs. En revanche, la banquise est absente, comme en Europe du Nord, en raison du passage du courant de l'Alaska qui prolonge la dérive du Pacifique nord et qui réchauffe ainsi les côtes (alors que la mer de Béring connaît un engel saisonnier). L'océanité du milieu, qui se traduit notamment par des totaux pluviométriques supérieurs à $1500 \mathrm{~mm}$ par an, un tracé des isothermes parallèles aux côtes et le maintien de la forêt boréale jusqu'à la péninsule d'Alaska et l'île de Kodiak, n'empêche pas les hivers rigoureux (cinq mois de moyennes thermiques négatives à Anchorage, au fond du Cook Inlet), l'apparition du pergélisol sporadique et l'installation progressive d'un climat subpolaire jusqu'à l'océan. La côte est moins découpée que celle du secteur précédent, mais comprend des baies profondes et appartient également aux côtes à fjords.

(22) En repartant de l'équateur vers le sud (figure 9 et 11), le segment situé entre le golfe de Panama $\left(4^{\circ} \mathrm{N}\right)$ et le cap Parinas (près de la frontière $d u$ Pérou, vers $5^{\circ} \mathrm{S}$ ), correspond à la façade pacifique de la Colombie et de l'Équateur. Elle appartient à la plaque de l'Amérique du Sud qui chevauche la plaque océanique de Nazca suivant une direction nord est-sud ouest. L'arrière-pays continental est formé par les Cordillères colombiennes qui culminent déjà à $5750 \mathrm{~m}$ et qui se réunissent pour constituer les Andes, longues et étroites, qui atteignent $6371 \mathrm{~m}$ au nord-est du golfe de Guayaquil. Cette partie des Andes se distingue du reste par une chaîne de collision liminaire, qui correspond dans le relief actuel à la cordillère occidentale de la Colombie et de l'Équateur et qui provient de l'affrontement d'un ancien arc insulaire contre la marge continentale sud-américaine (Peulvast et Vanney, 2002). Les montagnes dominent des plaines côtières larges d'une centaine de kilomètres qui n'auront plus d'équivalent vers le sud. L'avant-pays est formé de bassins océaniques profonds (4000 m), mais ne présente pas de véritable fosse de subduction. La circulation des eaux de surface dépend principalement du contre-courant équatorial, bifide, dont la branche descendante est rapidement bloquée par les eaux moins chaudes du courant de Humboldt. Le littoral comprend principalement des côtes de construction, dont le tracé est déformé par les deltas de fleuves andins, courts, mais très chargés. Le climat tropical humide est propice à la mangrove ou aux récifs coralliens selon les endroits, comme le long du segment situé immédiatement plus au nord (16). Il est marqué par des pluies abondantes, à maximum zénithal et par une végétation forestière, par endroit très dense. Les masses d'air océanique ont une influence réduite sur l'arrièrepays parce que les vents, de secteur sud du fait de la position des centres d'action du Pacifique sud, longent les côtes et parce que le relief constitue ici une barrière proche des côtes. Vers l'intérieur, les étagements bioclimatiques conduisent rapidement à des climats de montagne. Vers le sud, les pluies tropicales laissent place à l'aridité. Cette façade fait partie, finalement, de celles qui connaissent les flux climatiques les plus limités.

(23) Le segment situé entre le nord du Pérou $\left(5^{\circ} \mathrm{S}\right)$ et le nord du Chili (vers $28^{\circ} \mathrm{S}$ ), long et coudé, présente une forte unité par ses propriétés géomorphologiques, climatiques et océaniques. Il représente un modèle de marge de subduction. Du côté du continent, la cordillère des Andes, continue et étroite, représente la façade la plus élevée au monde (près de $7000 \mathrm{~m}$ ); elle surmonte, sans plate-forme continentale, des fosses profondes de 7000 à $8000 \mathrm{~m}$ (fosse du Pérou et fosse du Chili); elle intègre des reliefs volcaniques ponctuels ou des coulées laviques et compte parmi les secteurs les plus sismiques du globe. Du côté de l'océan, la circulation des eaux de 

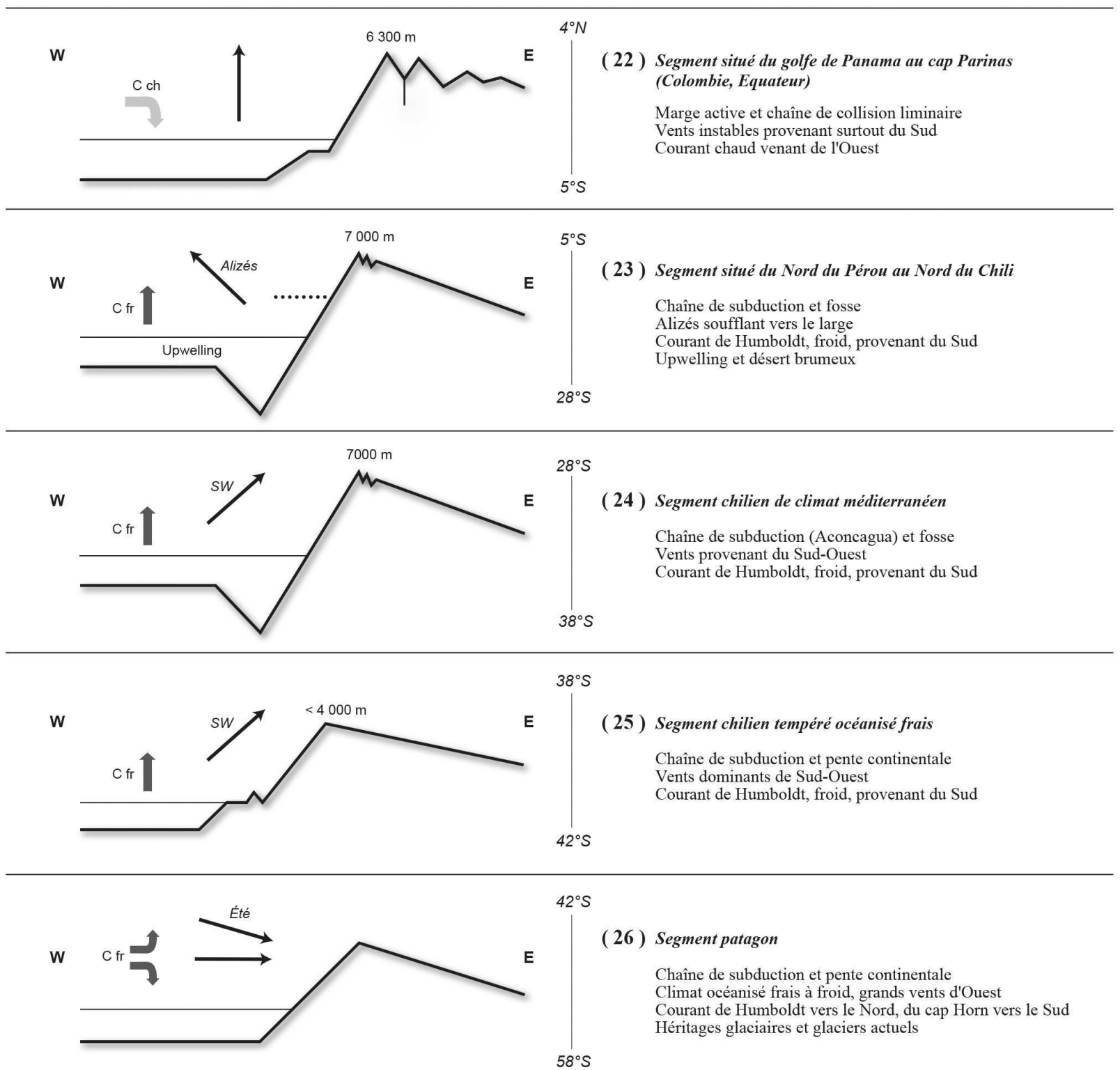

(26) Segment patagon

Chaîne de subduction et pente continentale Climat océanisé frais à froid, grands vents d'Ouest

Courant de Humboldt vers le Nord, du cap Horn vers le Sud Héritages glaciaires et glaciers actuels

Figure 11 : Les façades pacifiques de l'Amérique du Sud The South America Pacific façades

surface est contrôlée par le courant de Humboldt, l'un des plus grands courants méridiens au monde, responsable d'anomalies thermiques négatives de plusieurs degrés sur toutes les côtes qu'il parcourt (l'isotherme annuelle $20^{\circ} \mathrm{C}$ passe vers $22^{\circ} \mathrm{S}$ sur les côtes du Pérou, alors qu'elle descend jusqu'à $35^{\circ} \mathrm{S}$ le long de celles de l'Uruguay). Ajouté aux effets des alizés, animés par l'anticyclone du Pacifique sud, et à ceux de l'obstacle crée par les Andes, ce courant participe également à l'un des mécanismes d'upwelling les plus exemplaires, au point que ses dérèglements momentanés (El Niño), eux-mêmes produits par ceux du contre-courant équatorial qui fonctionne plus au nord, suscitent souvent plus d'attention que ses mécanismes ( $\$ 131)$. Il est rare que la conjonction du relief, du trajet des vents et de la circulation des eaux de surface provoque un tel "effet de façade ", sous la forme d'une remontée d'eaux profondes vers la surface et, corrélativement, d'un refroidissement des eaux superficielles, des 
masses d'air et des domaines côtiers adjacents. Le blocage des ascendances à l'approche des côtes, déjà engendré par les centres de hautes pressions dynamiques du Pacifique sud, se trouve ainsi renforcé par une subsidence thermique qui explique l'aridité des littoraux. Les « déserts brumeux » qui occupent les plaines côtières et une partie des versants andins du Pérou et du nord du Chili se caractérisent par l'indigence des précipitations (et de l'écoulement) comme par le stationnement de leur couvert nuageux pendant une grande partie de l'année. Cette aridité littorale s'ajoute à une aridité zonale et à une aridité d'abri en contribuant à la grande « diagonale aréique » qui débute au nord de Lima, se poursuit par le désert d'Atacama, de part et d'autre du tropique du Capricorne, et franchit les Andes pour rejoindre la façade atlantique de l'Amérique du Sud vers le golfe de San Matias (15).

(24) Le segment chilien de climat méditerranéen situé entre $28^{\circ} \mathrm{S}$ et les environs de $38^{\circ} \mathrm{S}$, ressemble au précédent par son relief continental et sousmarin. L'arrière-pays est encore plus étroit et plus élevé qu'au nord; l'Aconcagua, volcan actif et point culminant de la façade pacifique américaine, atteint $6959 \mathrm{~m}$ à une centaine de kilomètres seulement de l'océan. Le contact avec celui-ci s'établit par le débouché de vallées plus que par des plaines littorales. La fosse du Chili se poursuit aux abords des côtes. Le courant de Humboldt apporte des eaux moins attiédies qu'au nord et les alizés proviennent progressivement du sud-ouest, en raison des latitudes. Dans ces circonstances, cette partie de la façade chilienne tire sa principale singularité de ses caractères bioclimatiques. Le climat, chaud à pluies d'hiver, est rapporté au type méditerranéen des façades occidentales de continents aux latitudes subtropicales et tempérées. Il connaît néanmoins des transitions entre le Nord, subdésertique, où la durée de la sécheresse est supérieure à 200 jours par an et le Sud, subméditerranéen, où elle est inférieure à 40 jours par an, en passant par le centre, vers Santiago, où elle varie autour de 150 jours par an. Ce segment représente donc le symétrique de la façade californienne (18) par son climat, en dépit d'une situation un peu plus rapprochée du tropique. Finalement, le fait zonal l'emporte ici sur les effets de façade; les flux, quels qu'ils soient, entre avant-pays et arrière-pays, sont particulièrement réduits.
(25) Un segment tempéré océanisé frais propre aux façades occidentales des moyennes latitudes, se rencontre au Chili entre les $38^{\mathrm{e}}$ et $42^{\mathrm{e}}$ parallèles, au sud de Conception. Il représente ainsi le symétrique du segment situé entre le nord de la Californie et l'extrémité de lî̀le de Vancouver (19) et de celui situé entre la mer Celtique et la Galice (2), mais se trouve réduit sur la façade pacifique de l'Amérique du Sud par la configuration des reliefs. L'armature de la marge diffère de la précédente par le passage direct de la cordillère aux bassins océaniques par une simple pente continentale. Les Andes n'atteignent plus que $4000 \mathrm{~m}$ et sont localement précédées de plaines ou de chaînes côtières. Mais la discontinuité la plus marquée est d'ordre climatique : les vents dominants de secteur sud-ouest se renforcent, les températures hivernales varient de 10 à $5^{\circ} \mathrm{C}$, les totaux annuels de précipitations qui ont lieu principalement pendant l'hiver austral passent rapidement de 500 à $2000 \mathrm{~mm}$. Le climat se détériore vers le sud.

(26) Le segment patagon, beaucoup plus long, s'étend de la «mer intérieure » de Chiloé $\left(42^{\circ} \mathrm{S}\right)$ au cap Horn $\left(58^{\circ} \mathrm{S}\right)$. Son climat évolue progressivement d'un type océanisé frais et humide à un type froid. Les précipitations sont supérieures à $2000 \mathrm{~mm}$ dès la côte. La circulation atmosphérique est de nouveau soumise au régime de grands vents d'ouest, principalement actifs au cours de l'hiver austral et fréquemment assortis de tempêtes, sinon de vents du nord-ouest au cours de l'été, l'ensemble apportant en permanence de l'air polaire maritime froid (Vanney, 1991). Les moyennes thermiques hivernales sont partout inférieures à $+5^{\circ} \mathrm{C}$ près de la mer. L'extrême Sud est recoupé par l'écotone forêtpelouse australe et présente des tendances subantarctiques aux environs du détroit de Magellan. Le temps est instable, la nébulosité élevée. Du côté de l'océan, la dérive Antarctique (vers l'est) se divise aux latitudes concernées, en créant le courant de Humboldt qui s'oriente vers le nord-ouest et le courant du cap Horn qui passe au sud-est. Le type de marge est la suite du précédent : le passage de la cordillère (3375 m au Fitzroy, 4058 m au San Valentin) aux bassins océaniques (profonds de $4000 \mathrm{~m}$ ) s'effectue par une simple pente continentale. La distance entre la ligne de crête et le littoral, donc la profondeur de l'arrière-pays montagneux, devient, par endroits, inférieure à $150 \mathrm{~km}$. Le relief porte des marques d'actions passées et présentes 
des glaciers qui s'expliquent à la fois par les latitudes, les altitudes et l'exposition à des masses d'air froid et humide venant de l'ouest et qui figurent ici encore un phénomène de façade. Les glaciers ont occupé l'Amérique du Sud au Pléistocène jusqu'au niveau des mers sur la façade pacifique, comme sur les façades occidentales d'Europe en Scandinavie, ou d'Amérique du Nord en Alaska, où l'abondance des précipitations et l'enneigement relèvent effectivement d'un phénomène de façade. Il en résulte un modelé glaciaire exemplaire sur les montagnes de l'arrière-pays et une côte à fjords, qui apparaît aussi découpée que celle qui existe au nord de Vancouver (20) et qui contraste de ce fait sur les cartes avec les côtes rectilignes qui bordent l'ensemble des façades situées plus au nord. Actuellement, les glaciers occupent une partie des montagnes entre les $45^{\mathrm{e}}$ et $50^{\mathrm{e}}$ parallèles, parfois jusqu'aux abords du littoral. Il existe parmi eux des glaciers de piedmont (San Rafael), caractéristiques de régions impropres au développement de glaciers de type polaire, mais suffisamment enneigées par l'arrivée de masses d'air froid et humide sur des reliefs relativement élevés qui émettent des lobes de glaces au-delà des montagnes. Les glaciers de piedmont (encore présents dans de grandes îles océaniques comme l'Islande ou les Kerguelen) pourraient représenter, par ce fait, des glaciers de façade. En revanche, le segment patagon ne connaît ni banquise, ni glaces dérivantes, comme ses homologues d'Amérique du Nord (20, 21 ) et d'Europe du Nord (2), avec lesquelles il présente finalement de nombreux points communs, si ce n'est que les premières sont longées par un courant venant comme ici du sud, relativement chaud, et que la seconde est longée par un courant venant du sud et également chaud, mais qu'elle appartient à une marge stable, ce qui indique déjà, après 26 exemples, qu'il n'existe pas deux façades véritablement identiques.

Au sud, la découpe des côtes devient telle que le détroit de Magellan relie les deux façades de l'Amérique du Sud, à près de $300 \mathrm{~km}$ de distance du cap Horn, lequel signale, au passage, que les finistères américains se croisent en franchissant des méridiens, alors que ceux de l'Ancien Monde, orientés vers l'ouest, se doublent en recoupant des parallèles.

Les façades pacifiques australasiatiques suivent le contact de la plaque continentale asia- tique et de la partie est de la plaque indo-australienne avec les plaques océaniques du Pacifique et des Philippines. Elles s'opposent aux précédentes par leur orientation vers l'est, leur profond découpage et leur armature structurale complexe, malgré leur appartenance commune à des marges actives, subordonnées à des dynamiques de convergence. Les façades pacifiques australasiatiques correspondent presque partout à des arcs insulaires et montagneux, volcaniques et sismiques, presquî̀les, archipels ou guirlandes d'îles, qui dépassent souvent 3000 m d'élévation (Kamtchatka, Japon, Taïwan, Philippines), mais qui se réduisent parfois à des alignements d'îles lorsque n'émergent que des sommets (Kouriles, Ryū Kȳ̄). Ces arcs sont différents des arcs intraocéaniques, comme celui des Antilles, par leurs origines et leur constitution; ils présentent pour la plupart un substratum granito-gneissique identique à celui des continents situés en arrière et se composent donc de lambeaux de croûte continentale (Debelmas et Mascle, 1991). Ils sont bordés du côté océanique par les fosses de subduction les plus profondes au monde (fosse des Kouriles, du Japon, des Bonins, des Mariannes, qui dépassent $10000 \mathrm{~m}$ ). Ils sont séparés du continent asiatique par des bassins marginaux (mers marginales de Béring, d'Okhotsk, du Japon, de Chine, de Chine méridionale, de Tasmanie), dont la largeur depuis le continent est souvent de l'ordre du millier de kilomètres, mais dont les profondeurs sont variables (plus de $4500 \mathrm{~m}$ en mer de Chine méridionale, $4000 \mathrm{~m}$ en mer du Japon et encore plus de $3000 \mathrm{~m}$ en mer d'Okhotsk, par contre moins de $200 \mathrm{~m}$ en mer de Chine). Ces bassins résultent d'une distension et d'un affaissement de la lithosphère, d'une fragmentation de la marge continentale et de l'apparition d'une croûte de type océanique parmi des restes de croûte continentale. Dans ces conditions, les façades sont à placer sur le bord externe des arcs insulaires, au-dessus des fosses de subduction, alors que les bassins intérieurs, accidentés, parfois ponctués de volcans, appartiennent déjà à l'arrière-pays. Les bordures du continent (littoraux russes, chinois, indochinois) se présentent ainsi comme des marges passives, souvent soulevées et bordées d'escarpements regardant vers la mer (Peulvast et Vanney, 2002). De fait, le continent se rapporte essentiellement à des plates-formes : socles et tables, localement déformés et rehaussés par des horsts et plisse- 
ments de différentes origines, rarement supérieurs à 2000 m d'altitude en dehors d'édifices volcaniques. L'ensemble est drainé par de grands fleuves d'origines lointaines, qui passent par des plaines alluviales et qui aboutissent à d'immenses constructions deltaïques (Vanney, 1991).

En excluant, pour l'instant, l'arc des Aléoutiennes et la mer de Béring (qui n'appartiennent pas vraiment à une façade, en raison de l'absence d'arrièrepays suffisant et de la coupure, au moins maritime, que représente le détroit de Béring entre l'Amérique et l'Asie), ainsi que l'Indonésie (qui est un archipel), les façades pacifiques australasiatiques comprendraient donc quatre ensembles d'arcs, fosses et bassins, du Kamchatka aux Philippines, auxquelles s'adjoindrait la façade pacifique de l'Australie, de même ordonnance, mais dans l'hémisphère sud (Vanney, 1991; Peulvast et Vanney, 2001). La circulation des eaux océaniques permettrait de retenir trois segments. Le premier est associé à l'Oya Shivo qui prolonge le courant de l'Alaska et dont les eaux froides descendent le long des côtes de Russie orientale jusqu'à Hokkaidō, le deuxième au Kouro Shivo, qui prolonge le courant nord-équatorial, dont les eaux chaudes remontent le long des Philippines jusqu'à Honshū, le troisième au courant d'Australie orientale, dont les eaux chaudes proviennent du courant sud-équatorial et se dirigent vers le sud jusqu'en Tasmanie. La circulation atmosphérique permettrait également d'en distinguer trois, en fonction des phénomènes de moussons, qui connaissent en Asie du Sud et du Sud-Est leurs manifestations les plus puissantes. Les alizés transéquatoriaux déviés, animés par l'anticyclone australien, parviennent en effet jusqu'au sud du Japon en été, en provoquant des précipitations élevées. Les vents continentaux de nord-ouest, animés quant à eux par l'anticyclone de Sibérie atteignent en hiver le nord du Japon et soufflent, en fait, jusqu'aux Philippines. La façade orientale de l'Australie, à l'écart de ces alternances, reçoit des vents du sud ou de l'est. Les climats fournissent ici les moyens les plus appropriés pour proposer une segmentation de la façade australiasiatiques, en s'appuyant, cette fois, sur la zonalité et les contrastes climatiques caractéristiques des façades est de continent (figure 12).
(27) Le segment de façade asiatique compris entre le Kamtchatka, en Extrême-Orient russe $\left(62^{\circ} \mathrm{N}\right)$, et Hokkaidō, au nord du Japon $\left(43^{\circ} \mathrm{N}\right)$, donne sur la mer de Béring et sur le Pacifique nord. Vers l'avant-pays, la fosse des Kouriles (effectivement profonde de plus de $10000 \mathrm{~m}$ ) s'incurve de l'île du Commandeur, à l'entrée de la mer de Béring, jusqu'aux abords d'Hokkaido. L'arc du Kamtchatka culmine à plus de $4700 \mathrm{~m}$, en raison de la présence de grands volcans. Il se poursuit vers le sud par les îles Kouriles. Presqu'île et îles cernent ainsi la mer d'Okhotsk à l'est. Le continent asiatique, précédé par l'île de Sakhaline à partir du $55^{\mathrm{e}}$ parallèle, la domine à l'ouest. Les montagnes qui la bordent jusqu'à Vladivostok, à l'ouest d'Hokkaidō, dépassent rarement $2500 \mathrm{~m}$. Cette façade appartient à un milieu froid, de type continental. Le froid vient de l'arrière-pays, en raison de la proximité des immenses espaces sibériens, dont il est l'aboutissement, et en raison des descentes d'air polaire ou d'air arctique provoquées par les vents de nord-ouest (la «mousson » du nord-ouest), eux-mêmes animés par l'anticyclone de Sibérie en hiver. Il est renforcé par l'expulsion des masses d'air maritime vers l'est, en dehors des tempêtes qui surviennent, comme ailleurs, à ces latitudes. Le pergélisol discontinu est présent sur une grande partie des côtes et passe au pergélisol continu vers l'intérieur. Le froid vient aussi de l'avant-pays, où l'Oya Shivo relaie le courant de l'Alaska et véhicule des glaces dérivantes jusqu'au nord du Japon en hiver, alors que la banquise saisonnière se forme le long des côtes jusqu'à Sakhaline, ce qui souligne la continentalité du climat. L'isotherme des eaux de surface $0{ }^{\circ} \mathrm{C}$ atteint les côtes d'Hokkaidō en janvier, ce qui reste sans équivalent à cette latitude dans le monde (celle de l'Aquitaine). La façade demeure toutefois en dehors du domaine polaire, qui ne concerne que les côtes de la mer de Béring (Godard et André, 1999). Elle demeure dans un domaine de type subpolaire qui tend vers le domaine tempéré (les températures moyennes estivales se situent entre 10 et $20^{\circ} \mathrm{C}$ ). En revanche, elle demeure très froide en hiver (les températures moyennes de janvier atteignent $-35^{\circ} \mathrm{C}$ sur les côtes septentrionales de la mer d'Okhotsk et $-20{ }^{\circ} \mathrm{C}$ au nord du Kamtchatka ou de Sakhaline). Les amplitudes moyennes annuelles sont supérieures à $40{ }^{\circ} \mathrm{C}$ sur ces dernières et à $30^{\circ} \mathrm{C}$ à Vladivostok, ce qui témoigne encore de la continentalité du climat. 


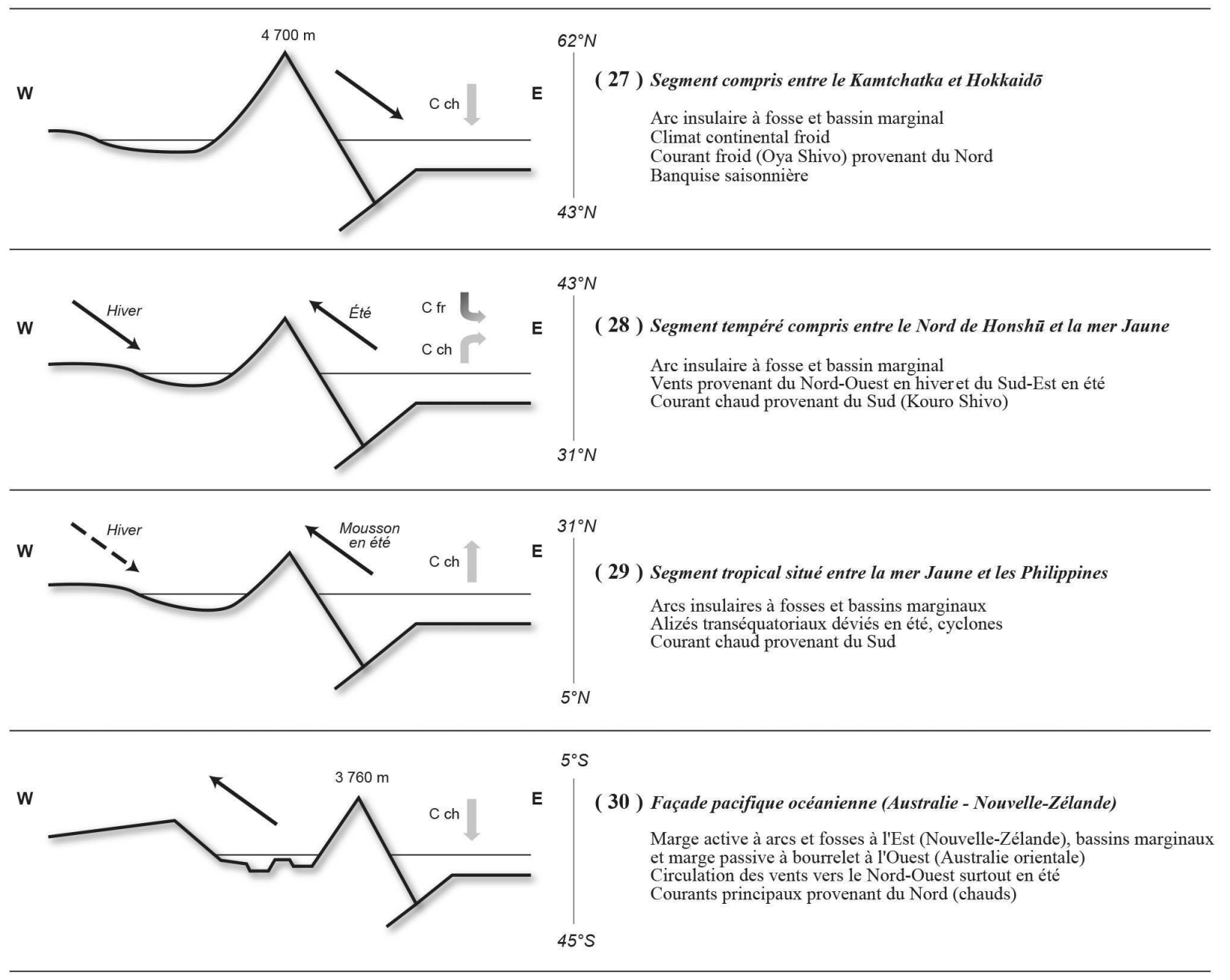

Figure 12 : Les façades pacifiques australasiatiques

The Asiatic and Australian Pacific façades

Les précipitations, qui se produisent principalement en été, restent inférieures à $1000 \mathrm{~mm}$, souvent à $500 \mathrm{~mm}$ par an, en dehors des montagnes, pour des raisons déjà exposées (circulation atmosphérique et océanique, continentalité du climat). Cette façade est donc un pays froid, qui ne connaît pas de glaciers dans le présent, par manque d'alimentation neigeuse, qui en a peu connu dans le passé, en dehors des hauts reliefs, et qui ne présente donc pas de côtes à fjords, comme du côté américain. Il s'agit de l'une des façades les plus continentalisées au monde.

(28) Le segment tempéré compris entre le nord de Honsh $\overline{\mathrm{u}}$, au Japon $\left(43^{\circ} \mathrm{N}\right)$, et la mer Jaune $\left(31^{\circ} \mathrm{N}\right)$, présente déjà de forts contrastes avec le précédent, mais ne correspond qu'à une transition avec le seg- ment tropical situé plus au sud. Ses limites, plus franches au nord qu'au sud, pourraient passer au large de Kiū Shū et de l'embouchure du Yangzi Jiang. Le cadre structural est comparable au précédent et enregistre les effets d'une dynamique convergente très active, comme la plupart des façades péripacifiques, mais comprend plusieurs relais. La fosse de subduction de Honshū (10542 m) limite la plaque Pacifique. Celles des Bonins et des Mariannes (11034 m), qui bordent la plaque des Philippines au large, en avant d'arcs insulaires intraocéaniques, vient s'y accrocher à la latitude de Tokyo, en augmentant la sismicité. L'arc insulaire du Japon, montagneux et volcanique, culmine à $3776 \mathrm{~m}$ au mont Fuji. Il participe, avec la Corée, à la fermeture des bassins marginaux occupés par la mer du 
Japon et par la mer Jaune. L'arrière-pays continental se compose des plaines et des plateaux de Corée, de Mandchourie et de Chine du Nord. Du côté de l'océan, cette façade est atteinte par le courant méridien chaud du Kouro Shivo qui bloque l'Oya Shivo à la latitude de Honshū et correspond à un contact thermique des eaux de surface spécialement contrasté. L'isotherme des eaux de surface $15{ }^{\circ} \mathrm{C}$ en janvier passe près de Tokyo alors que l'isotherme $0{ }^{\circ} \mathrm{C}$ atteint en même temps les côtes d'Hokkaidō. Le Japon et la Chine continuent de subir des hivers froids sous l'influence des vents continentaux venus du nord et l'embouchure du Yangzi Jiang peut enregistrer plus d'une centaine de jours avec gel par an. Le segment considéré appartient par conséquent au domaine de la forêt de feuillus. Il connaît par contre des étés chauds et pluvieux sous l'effet des alizés transéquatoriaux déviés et se trouve aux marges de "l'Asie des moussons", mais normalement en dehors des aires d'activité des cyclones tropicaux. Au contraire du précédent, il est donc traversé par des flux très puissants, notamment depuis l'avant-pays.

(29) Le segment tropical situé entre la mer Jaune $\left(31^{\circ} \mathrm{N}\right)$ et les Philippines $\left(5^{\circ} \mathrm{N}\right)$ comprend deux arcs insulaires successifs, celui de Ryū Kyū, au nord de Taïwan, et celui des Philippines, plus au sud, devancés, comme les autres, par une fosse de subduction à l'est. Le premier est situé en avant de la mer de Chine orientale, en face de la Chine du Sud (de Shanghaï à Hong Kong), elle-même constituée d'un socle fracturé et étagé. Le second se trouve en avant de la mer de Chine méridionale et de la cordillère du Viêt Nam (2500 m), qui correspond à une marge continentale soulevée à escarpement. L'arrière-pays apporte les eaux des grands fleuves, dont le Yangzi Jiang et le Fleuve Rouge, et les sédiments qui sont leurs corollaires. Des vents relativement froids parviennent encore jusqu'en Asie du Sud-Est en hiver. Mais les échanges principaux se réalisent sur cette façade à partir de l'avant-pays : plongement de la plaque des Philippines sous la plaque asiatique, eaux chaudes associées au courant équatorial ou à des terminaisons du courant sud-équatorial et surtout alizés transéquatoriaux déviés en été, parfois aussi cyclones, qualifiés en l'occurrence de typhons, qui rencontrent des conditions de formation particulièrement propices au sud-ouest du Pacifique. Cette façade appartient donc pleinement à «l'Asie des moussons », caractérisée par ses étés chauds et pluvieux. Au sud du Yangzi Jiang, les précipitations annuelles dépassent $2000 \mathrm{~mm}$. La forêt tropicale, sempervirente, et ses variétés, occupent les espaces les moins peuplés. Littoraux à mangroves et littoraux à coraux réapparaissent, selon les endroits.

(30) La façade pacifique océanienne $\left(5^{\circ}-45^{\circ} \mathrm{S}\right)$ correspond à une marge active ordonnée comme les précédentes, mais dépend de l'hémisphère sud, provient de la subduction de la plaque pacifique sous la plaque indo-australienne et présente une complexité proportionnelle à ses dimensions. Elle comprend d'abord une succession hétérogène d'îles et d'archipels disposés en arcs successifs ou concentriques, qui débute à l'extrémité orientale de la Nouvelle-Guinée, au nord-est, et qui comprend les îles Salomon, le Vanuatu, la Nouvelle-Calédonie, les Fidji et, au delà, les îles Samoa, Tonga, Kermadec et la Nouvelle-Zélande. Ces ensembles insulaires appartiennent à plusieurs types : arcs insulaires intra-océaniques, formés d'îles volcaniques, bordés de fosses de subduction profondes vers l'extérieur (Tonga, Kermadec) aux limites des plaques, arcs résiduels, associant une ride sous-marine inactive à un arc insulaire actif, séparés par un bassin intra-arc (Fidji). La Nouvelle-Zélande, au sud-est, comprend deux grandes îles formées de croûte continentale, plissée, fracturée et ponctuée de volcans; elle correspond à un « croisement et à un étagement de structures » à la fois interplaques Australie-Pacifique (arc et fosse de Kermadec, arc et fosse de Macquarie, plis en relais suivant l'axe des deux îles) et intraplaques (faille cisaillante, comparable à celle de San Andreas, qui traverse obliquement l'île du Sud) (Peulvast et Vanney, 2002). À l'ouest s'étendent des bassins marginaux (mers de Corail, mer de Tasmanie), encore accidentés de rides (rides de Lord Howe et de Norfolk) et de zones de divergence (Debelmas et Mascle, 1997). La Nouvelle-Zélande se trouve à 2000 km des côtes australiennes. Celles-ci correspondent à une marge stable à bourrelet (cordillère australienne) à grand escarpement de regard est, qui s'étend du cap York $\left(11^{\circ} \mathrm{S}\right)$ à Hobart en Tasmanie $\left(42^{\circ} \mathrm{S}\right)$ et qui culmine à plus de $2200 \mathrm{~m}$ en avant de plateaux intérieurs du "vieux bouclier australien » (Birot, 1970). En fait, cette façade fait pleinement partie de l'Océanie. La partie marine y occupe une plus grande étendue que partout ailleurs, en dehors de l'avant-pays océanique proprement dit. À cette ordonnance est-ouest déterminée par la structure, 
s'oppose une ordonnance nord-sud imposée par la zonalité en raison de l'ouverture de la façade pacifique océanienne en latitudes (environ $40^{\circ}$ ). La circulation atmosphérique est commandée par l'anticyclone d'Australie. Celui-ci participe activement au déplacement du front intertropical, qui descend en janvier jusqu'au milieu de la façade australienne (basses pressions), en s'accompagnant d'une convergence des vents depuis le nord (au nord) et depuis le sud (au sud), et qui remonte en juillet avec les alizés transéquatoriaux jusqu’à la mer de Chine orientale (29). Les côtes sont longées jusqu'au sud de l'Australie par le courant sud-équatorial, alors que les eaux plus froides qui suivent le parcours de la dérive antarctique vers l'est cernent les côtes de Tasmanie. Au nord du cap Byron $\left(27^{\circ} \mathrm{S}\right)$, les températures moyennes mensuelles de l'air dépassent $15^{\circ} \mathrm{C}$ tous les mois. La mangrove se développe sur les côtes et une savane s'étend vers l'intérieur; les eaux sont chaudes et la Grande Barrière de corail occupe une large plate-forme. Au sud, le climat devient progressivement plus tempéré; plusieurs espèces de manchots venant des mers australes accostent déjà en Tasmanie. Lî̂le du Sud de la Nouvelle-Zélande conserve des glaciers, des héritages d'englacements pléistocènes et, à nouveau, une côte à fjords, en raison de ses latitudes et surtout de ses altitudes (3760 m au mont Cook).

\section{3/ Les façades gondwaniennes de l'océan Indien (figure 13)}

Elles se différencient des précédentes par leur localisation en latitude et leur tracé. Essentiellement concentrées entre les tropiques, sur une soixantaine de degrés seulement, elles ne présentent guère de continuité qu'en Afrique. Elles sont, par ailleurs séparées par le golfe d'Aden et l'archipel indonésien. Elles comprennent donc plusieurs sections relativement courtes à l'échelle planétaire : façades occidentale et orientale de l'Inde, façades occidentales de la péninsule Indochinoise et de l'Australie. Cette situation procède évidemment de leur évolution à partir du paléo-continent de Gondwana, qui réunissait au Primaire, avant l'époque de la Pangée, les espaces correspondant à l'Amérique du Sud, l'Arabie, l'Inde, l'Australie et l'Antarctique autour de ce qui correspond aujourd'hui à la plaque africaine (Allègre, 1999).

\section{1/ Les caractères particuliers des façades de l'océan Indien}

- Les héritages de la dislocation du continent de Gondwana

Les façades de l'océan Indien résultent, effectivement, d'une dynamique de divergence impliquant la mise en place de marges stables, sauf au nordest (Indonésie). Les déchirures qui ont conduit au démembrement du Gondwana et à l'ouverture de l'océan Indien ont été initiées au Jurassique supérieur et au Crétacé, comme dans l'Atlantique sud. Le mécanisme en cause est cependant plus complexe du côté oriental de l'Afrique à cause de la divergence de trois plaques principales, à la fois continentales et océaniques : plaque africaine (ou somalienne) à l'ouest, plaque antarctique au sud et plaque indoaustralienne à l'est (Vanney, 1991). Cette dernière est la plus hétérogène; elle comprend la plaque arabique, le subcontinent Indien, l'Australie et présente des contacts variés, par subduction avec les plaques Asiatique et Pacifique (Indonésie, Australie), mais aussi par collision avec la plaque continentale asiatique au nord de l'Arabie (golfe Persique et chaînes iraniennes) et de l'Inde (Himalaya). Ces plaques divergent à partir de trois dorsales océaniques qui se séparent au point triple de Rodrigues, à environ $1000 \mathrm{~km}$ à l'est des Mascareignes, au centre de l'océan Indien (Lageat, 2014). La dorsale médioindienne se dirige d'abord vers le nord, puis vers le nord-ouest (dorsale de Carlsberg), vers l'ouest (où elle s'accompagne de l'ouverture du golfe d'Aden) et à nouveau vers le nord-ouest (où elle entraîne la séparation de la plaque africaine et de la plaque arabique à partir de la mer Rouge). Bifide au sud du tropique du Cancer, elle comprend une branche entre l'Afrique et l'Antarctique (dorsale sud-ouest indienne) et une autre entre l'Australie et l'Antarctique (dorsale sud-est indienne). Les marges continentales de l'océan Indien sont donc principalement stables, le plus souvent avec bourrelet, en conséquence des dynamiques de distension qui se poursuivent à partir des rifts et dorsales, comme à l'est de l'Afrique, à l'ouest et à l'est de l'Inde, à l'ouest de l'Australie. Ces dynamiques s'accompagnent néanmoins de situations particulières, en fonction des stades et de la vitesse de la dérive des fragments du Gondwana. La Corne de l'Afrique s'écarte progressivement du reste du continent à partir du rift est-afri- 


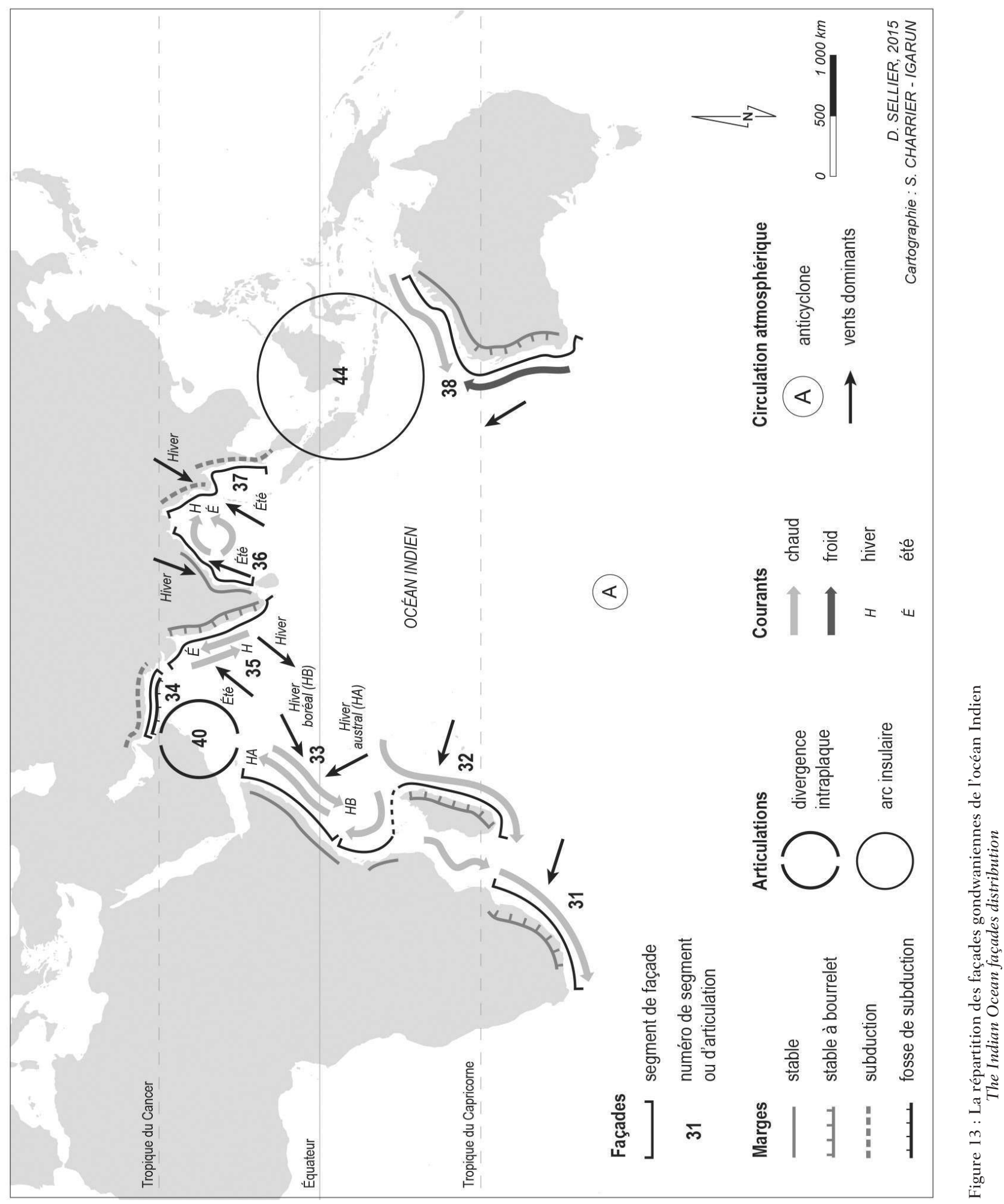


cain, en représentant, ainsi, le cas d'un arrière-pays soumis à une expansion. L'assemblage des marges de la plaque arabique résulte d'un double mouvement de divergence à partir de la mer Rouge et du golfe d'Aden, mais de convergence et de collision au niveau du golfe d'Oman. Il est à ranger parmi les articulations interplaques ( $\$ 24)$. Le poinçonnement de la plaque asiatique par la plaque indienne a entraîné la formation de la chaîne de collision la plus élevée du monde qui a des conséquences climatiques et océaniques en proportion sur les façades indiennes. La façade birmane du golfe du Bengale, qui tient ses caractères montagneux de la convergence de la plaque indo-australienne et de la plaque asiatique, s'accompagne d'un bassin marginal. Il reste que l'essentiel de l'arrière-pays des façades indiennes est constitué de plates-formes : boucliers et tables.

\section{- La tropicalité des façades}

Les façades de l'océan Indien sont intégralement soumises à la chaleur tropicale, sinon subtropicale à leurs terminaisons sud (Demangeot, 1999). Les moyennes thermiques des mois les moins chauds demeurent le plus souvent supérieures à $20^{\circ} \mathrm{C}$; les amplitudes sont inférieures à $10^{\circ} \mathrm{C}$, souvent à $5{ }^{\circ} \mathrm{C}$. Les rythmes saisonniers sont donc commandés par les pluies et par les vents, eux-mêmes déterminés par les déplacements des centres d'action tropicaux. Ils expriment l'influence d'une zonalité qui tend à estomper les dissymétries ordinaires entre façades ouest et façades est des continents. Cette zonalité contribue à expliquer la succession des domaines climatiques le long des façades africaines de l'océan Indien. Elle est elle-même perturbée par la mousson, les renversements saisonniers et les anomalies pluviométriques qui s'appliquent au nord du bassin indien plus que nulle part ailleurs. L'anticyclone positionné au sud de l'océan Indien, entre le tropique et le $40^{\mathrm{e}}$ parallèle (anticyclone sud-indien), se déplace en été vers le nord et anime les alizés du sud-est qui parcourent l'océan sur toute son étendue, en déplaçant des masses d'air tropical chargées d'humidité jusqu'aux versants himalayens et en provoquant des précipitations qui atteignent des records, en particulier au fond du golfe du Bengale. Toujours en été, les façades situées au nord de l'équateur entre la mer d'Oman et le golfe du Bengale, sont parmi celles qui sont les plus affec- tées par les cyclones. En hiver, ces mêmes façades reçoivent les vents froids venant du nord sous l'impulsion de l'anticyclone saisonnier de Sibérie.

\section{- La circulation des eaux océaniques}

Il est évident que l'océan Indien, certes plus réduit que les autres, est largement ouvert sur l'océan Austral. Il est surtout le seul à être complètement fermé au nord du tropique du Cancer. À l'écart des dorsales, son fond comprend des bassins océaniques accidentés de rides et ses bords comportent des plates-formes continentales généralement étroites. L'océan Indien est un océan uniformément chaud, dont les températures moyennes en surface dépassent $28^{\circ} \mathrm{C}$ à l'équateur et presque toujours $20^{\circ} \mathrm{C}$ jusqu'au sud de l'Afrique et de l'Australie. Au-delà, les températures chutent rapidement au niveau du front subtropical, vers le $40^{\mathrm{e}}$ parallèle, à la rencontre du courant austral, qui fonctionne continuellement d'ouest en est (Vanney, 1991). La circulation de ces eaux de surface se trouve compliquée par la situation, les dimensions et les contours de l'océan. Elle l'est également par les inversions saisonnières de la circulation des masses d'air et des vents, qui engagent celle des courants. Il convient de distinguer deux zones principales à ce sujet de part et d'autre des $15^{\mathrm{e}}$ à $10^{\mathrm{e}}$ parallèles sud (divergence sud-équatoriale). Ainsi, la partie de l'océan située au nord de ces parallèles est soumise à une circulation de sens anticyclonique lors de la mousson d'été (courant de la mousson du sudouest), qui a des implications régionales le long de chaque segment de façade. Elle est soumise à une circulation en sens cyclonique lors de la «mousson d'hiver» (courant de la mousson du nord-est), qui présente des implications régionales inverses. La partie de l'océan située plus au sud, connaît une rotation des eaux dans le sens anticyclonique de l'hémisphère austral pendant la majeure partie de l'année, sur le modèle de l'océan Atlantique sud (Lageat, 2014). La spécificité de l'océan Indien est toutefois de connaître des échanges réciproques entre les terres et les mers d'une puissance peu ordinaire. Ces échanges se produisent principalement dans le sens méridien et concernent donc sa partie nord. L'océan reçoit de grandes quantités d'eau douce issues des montagnes les plus élevées du monde, par l'intermédiaire de l'Indus, du Gange, du Brahmapoutre et des réseaux birmans. Il reçoit des sédiments en proportion, qui proviennent de l'érosion du Tibet et de l'Himalaya, 
justifient des transports fluviaux sans équivalent et construisent, bien au-delà, des deltas et des cônes alluviaux sous-marins jusqu'aux bassins océaniques, en mer d'Oman et dans le golfe du Bengale (cônes de l'Indus et du Bengale). Dans l'autre sens, le continent reçoit les pluies apportées en été par les vents. Ses côtes enregistrent aussi les effets dévastateurs d'une sismicité sous-marine propre aux dynamiques de convergence sur les bords de la plaque asiatique.

\section{2/ Les caractères régionaux des façades gondwaniennes}

Les marges de l'océan Indien ne présentent pas de symétries selon les méridiens ou les parallèles comme celles qui permettent d'opposer entre elles les façades atlantiques ou pacifiques. Leur caractérisation peut s'effectuer de leur jonction avec l'Atlantique, en Afrique du Sud vers l'Australie, élément du Gondwana isolé aux confins du Pacifique.

- Les façades africaines de l'océan Indien

Elles s'étendent du cap des Aiguilles $\left(35^{\circ} \mathrm{S}\right)$ à l'entrée du golfe d'Aden $\left(12^{\circ} \mathrm{N}\right)$, donc surtout dans l'hémisphère sud. Elles sont subméridiennes, appartiennent à une façade est de continent, suivent la principale déchirure du Gondwana, correspondent à des marges stables à bourrelet et appartiennent à des milieux tropicaux ou subtropicaux. Les facteurs climatiques et océaniques permettent d'y reconnaître trois segments principaux aux limites imprécises, en raison des « effets de façade » qui prolongent certains domaines climatiques au-delà des emplacements qui leur sont normalement dévolus par la zonalité (figure 14).

(31) La façade de l'Afrique du Sud-Est, entre le cap des Aiguilles $\left(35^{\circ} \mathrm{S}\right)$ et l'entrée du canal du Mozambique, aux abords du tropique du Capricorne $\left(24^{\circ} \mathrm{S}\right)$, correspond à un bourrelet marginal exemplaire en même temps qu'à l'un des reliefs les plus élevés de l'Afrique subsaharienne. Il culmine à près de 3500 m au Drakensberg, s'étend jusqu'à l'ensellement suivi par le cours du Limpopo (Transvaal) et entraîne une dissymétrie du relief dans le sens océan Indien-océan Atlantique, que souligne celle des réseaux hydrographiques (notamment le tracé du fleuve Orange). Il présente un grand escarpement à regard est, qui surmonte une étroite plaine

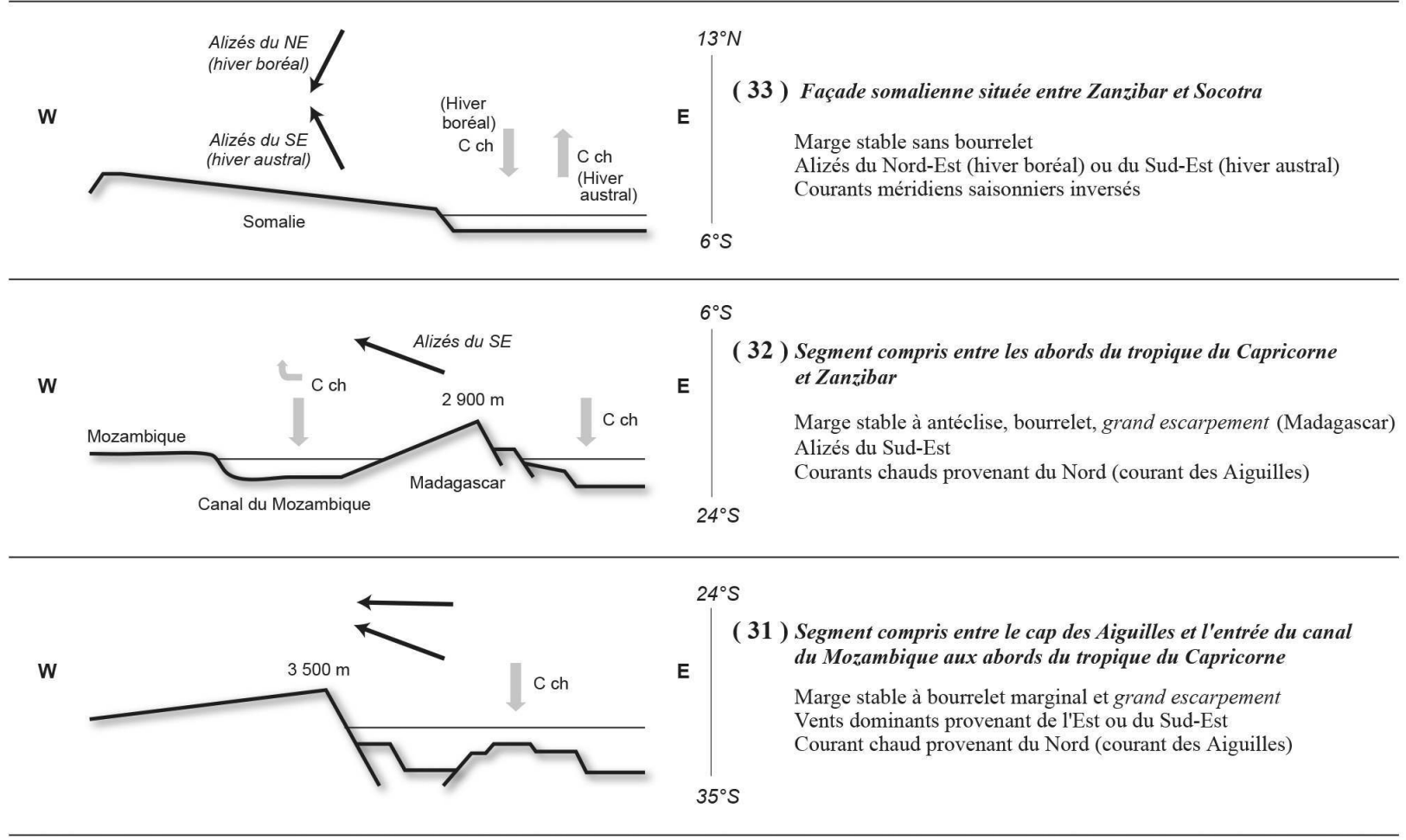

Figure 14 : Les façades africaines de l'océan Indien The African façades of the Indian Ocean 
côtière et une pente continentale redressée, fracturée, sans véritable plate-forme mais non dépourvu pour autant d'avant-pays. Cette pente est en effet précédée par des bassins d'effondrement et horsts encore formés de croûte continentale, qui se trouvent en dessous du niveau de la mer (plateau Vauban) et qui n'entrent en contact avec la croûte océanique qu'au large (Vanney, 1991; Peulvast et Vanney, 2002). Cette configuration morphostructurale limite évidemment l'arrière-pays et contrarie les effets des masses d'air océanique portées par les vents issus du centre de hautes pressions sudindien. Les vents dominants sont en effet d'est et de sud-est, sauf au Cap où prévalent déjà des vents d'ouest, comme au cap Horn et dans l'océan Austral. Les côtes sont longées par le courant des Aiguilles, circulant constamment du nord au sud, donc chaud, depuis le canal du Mozambique. Le climat est de type méditerranéen au sud de la province du Cap. Il devient de type tropical à saison sèche vers le tropique, en s'accompagnant du passage de la forêt de feuillus à la savane (Birot, 1970). Le type de marge en présence restreint en l'occurrence les flux qui se rapportent ordinairement à une façade.

(32) Les façades comprises entre les abords $d u$ tropique du Capricorne (24ㅇ) et Zanzibar ( $6^{\circ} \mathrm{S}$ ) s'ordonnent autour du canal du Mozambique, qui sépare la "grande île » de Madagascar des côtes de l'Afrique continentale. Elles occupent une marge stable à bourrelet marginal d'un style tectonique qui ressemble à celui du cas précédent. La marge et son bourrelet passent en l'occurrence par Madagascar, antéclise de croûte continentale à retombée océanique accidentée d'escaliers de failles, qui s'élève ici au-dessus du niveau de la mer. Le grand escarpement, orienté vers l'océan Indien, se situe donc sur la côte est de Madagascar. Il est presque rectiligne sur près de $1600 \mathrm{~km}$, dépasse fréquemment $2000 \mathrm{~m}$ d'altitude et atteint près de $2900 \mathrm{~m}$ au nord. Il domine une plaine côtière à cordons littoraux, là aussi très réduite et correspond à une façade océanique au vent, exposée toute l'année aux alizés du sud-est. Il implique une asymétrie topographique analogue à celle qui affecte la marge de l'Afrique du Sud-Est. Il s'oppose ainsi à une façade malgache interne, à regard ouest, donc sous le vent, qui borde le canal du Mozambique, comprend de vastes plaines côtières et se prolonge par un plateau continental élargi. Le canal du Mozambique demeure étroit (moins de $400 \mathrm{~km}$ au centre), peu profond (moins de $4000 \mathrm{~m}$ ), ponctué de reliefs sous-marins et d'îles (Comores, Îles éparses). Il est bordé à l'ouest par une troisième façade, véritablement continentale, exposée de nouveau au vent, qui limite les plaines et les plateaux du Mozambique et de Tanzanie formant l'arrière-pays. Ces façades appartiennent partout à des milieux tropicaux humides. Le courant des Aiguilles et ses ramifications qui pénètrent dans le canal du Mozambique par le nord, provient du courant sud-équatorial et maintient les eaux chaudes comme le révèle la répartition des coraux. Les masses d'air tropical qui stationnent dans cette zone s'accompagnent de températures moyennes continuellement supérieures à $20^{\circ} \mathrm{C}$. En revanche, la latitude, les saisons et l'exposition, donc l'effet de façade créent des différences. À Madagascar, les précipitations sont très supérieures à $2000 \mathrm{~mm}$ sur les sommets et la végétation varie en fonction de l'orientation et des altitudes. La façade au vent est évidemment la plus arrosée, toute l'année (et la plus exposée aux cyclones qui proviennent du nord-est au cours de l'été austral); elle connaît la forêt sempervirente. La façade sous le vent, celle de la savane, en partie arborée, connaît une saison sèche prolongée au cours de l'hiver austral, et une saison humide pendant l'été austral au terme de la trajectoire de la «mousson du nord-ouest ». Sur la façade continentale africaine, les pluies surviennent au cours de l'été austral et atteignent des totaux annuels compris entre 500 et $2000 \mathrm{~mm}$, un peu inférieurs, toutefois à ce qu'ils pourraient être aux latitudes concernées, en raison d'une " anomalie est-africaine ", qui trouve ses explications et ses manifestations les plus marquées plus au nord (33). Les paysages de cette façade, au-delà des littoraux occupés par les mangroves, sont ceux de la savane et de la forêt claire étendues à perte de vue, sur des surfaces immenses.

(33) La façade "somalienne ", située entre Zanzibar $\left(6^{\circ} \mathrm{S}\right)$ et Socotra, à l'entrée du golfe d'Aden $\left(13^{\circ} \mathrm{N}\right)$, appartient à un espace qu'il est commun d'appeler la corne de l'Afrique et de considérer à partir des bordures internes qui le séparent du reste de la plaque africaine (le rift intercontinental est-africain, situé à $1000 \mathrm{~km}$ vers l'intérieur, axé sur l'Abyssinie et encadré par des rebords soulevés à plus de 4000 m), ou à partir de l'ensemble golfe d'Aden-Afars-mer Rouge (qui s'inscrit dans la suite de la dorsale de Carlsberg et qui le sépare de la plaque arabique). Il s'agit d'une 
portion du vieux socle africain qui s'incline progressivement vers l'océan Indien, en formant une marge stable sans bourrelet, à plaines côtières étendues et à côtes basses, sans drainage autre que celui qui prolonge des cours d'eau allogènes issus des hauts plateaux intérieurs adjacents au rift. Cette façade est recoupée par l'équateur. Elle se trouve donc aux latitudes du Congo de l'autre côté de l'Afrique, et de l'Indonésie, de l'autre côté de l'océan Indien. Elle est effectivement très chaude $\left(25\right.$ à $30^{\circ} \mathrm{C}$ de moyennes mensuelles), mais subit un climat semiaride au sud (où les précipitations annuelles peuvent atteindre $500 \mathrm{~mm}$ ) et aride au nord (où les mêmes précipitations demeurent inférieures à $250 \mathrm{~mm}$ ), qui se traduit dans le paysage par la présence d'une steppe, éventuellement arbustive, à la place de la brousse à épineux qui occupe l'arrière-pays à partir de Zanzibar (Demangeot et Bernus, 2001). La façade somalienne comporte donc un semi-désert, sans équivalent dans le monde aux latitudes concernées. Cette " anomalie est-africaine » (Lageat, 2014), tient à une circulation alternée des vents, des masses d'air et des courants marins. Pendant l'hiver austral (juillet), qui s'avère la saison la plus sèche, circule l'alizé du sud-est, depuis l'anticyclone sudindien (situé au sud du tropique du Capricorne), en direction du nord, mais en se détournant de la façade somalienne. Pendant l'hiver boréal (janvier), circule un alizé du nord-est, depuis les pourtours de la mer d'Oman (la «mousson du nord ») qui transporte donc des masses d'air relativement peu humides en direction du sud, mais aussi en longeant la façade en question. Cette alternance climatique s'accompagne d'une inversion saisonnière des courants : vers le nord pendant l'hiver austral (en même temps qu'une remontée d'eaux profondes), vers le sud pendant l'hiver boréal (courant saisonnier de Somalie). Le déficit de précipitations tient aux influences cumulées de ces flux subméridiens, qui supplantent les flux transversaux d'ordinaire en action sur les façades.

\section{- Façades indiennes et adjacentes}

Elles s'étendent de l'entrée du golfe d'Oman à celle du golfe de Martaban. Elles se singularisent d'abord par une orientation générale vers le sud, à la différence de toutes les autres façades examinées, ce qui les expose aux flux majeurs en action sur cette rive septentrionale de l'océan Indien : flux tectoniques (avec la dérive de l'Inde vers le nord à partir de la dorsale médio-indienne, sa collision avec la plaque asiatique, la formation de l'orogène himalayen et les phénomènes de poinçonnement latéraux survenus du côté iranien et du côté birman), mais aussi flux climatiques (en raison des inversions saisonnières associées aux moussons). La tectonique des plaques compose un ensemble de quatre segments élémentaires, dont la symétrie est encore renforcée par celles des constructions sédimentaires (deltas et grands cônes sous-marins), mais dont les styles tectoniques sont hétérogènes (figure 15).

(34) Le segment situé entre le détroit d'Ormuz, au sud de l'Iran, et le delta de l'Indus, à l'est du Pakistan (24-2 $\left.1^{\circ} \mathrm{N}\right)$, est directement exposé vers le sud et correspond à une marge active qui résulte du plongement de la portion océanique de la plaque arabique sous la plaque asiatique. L'avant-pays comprend le bassin d'Arabie, formé de croûte océanique, et la fosse de subduction de Makran. L'arrière-pays est formé des monts du Baloutchistan, qui guident le tracé de la côte, suivant le $24^{\mathrm{e}}$ parallèle, avant de s'incurver vers le nord sous l'effet du poinçonnement de l'Asie au nord du Deccan. Le contact avec le segment suivant s'établit au delta de l'Indus, qui alimente en mer le grand cône sous-marin construit par les dépôts corrélatifs de l'érosion des massifs montagneux himalayens, forme spécialement représentative des flux sédimentaires qui s'accomplissent à l'emplacement d'une façade (Vanney, 1991). Ce segment de façade est soumis au rythme des moussons, quoique de façon marginale, avec moins d'effets qu'au niveau de ses voisins, et au mouvement alternatif des courants. Il s'inscrit dans un domaine tropical proche de l'aridité qui s'étend jusqu'à l'Indus et témoigne ainsi d'une persistance des influences zonales sur cette rive de l'océan.

(35) La façade occidentale du Deccan $\left(21^{\circ} \mathrm{N}-8^{\circ} \mathrm{N}\right)$ représente l'exemple d'une marge stable volcanisée à bourrelet et à retombée océanique faillée (Peulvast et Vanney, 2002). Elle s'étire sur $1600 \mathrm{~km}$ le long du bouclier Indien, suivant un tracé rectiligne. Elle est bordée par le Ghat occidental, héritage de l'intumescence initiale du rift intracontinental associé à la dorsale médio-indienne et aux puissants événements volcaniques survenus au cours de la migration de la plaque indienne vers le nord au Tertiaire. Ce volcanisme effusif a conduit à l'empilement des vastes coulées basaltiques qui occupent la partie nord- 


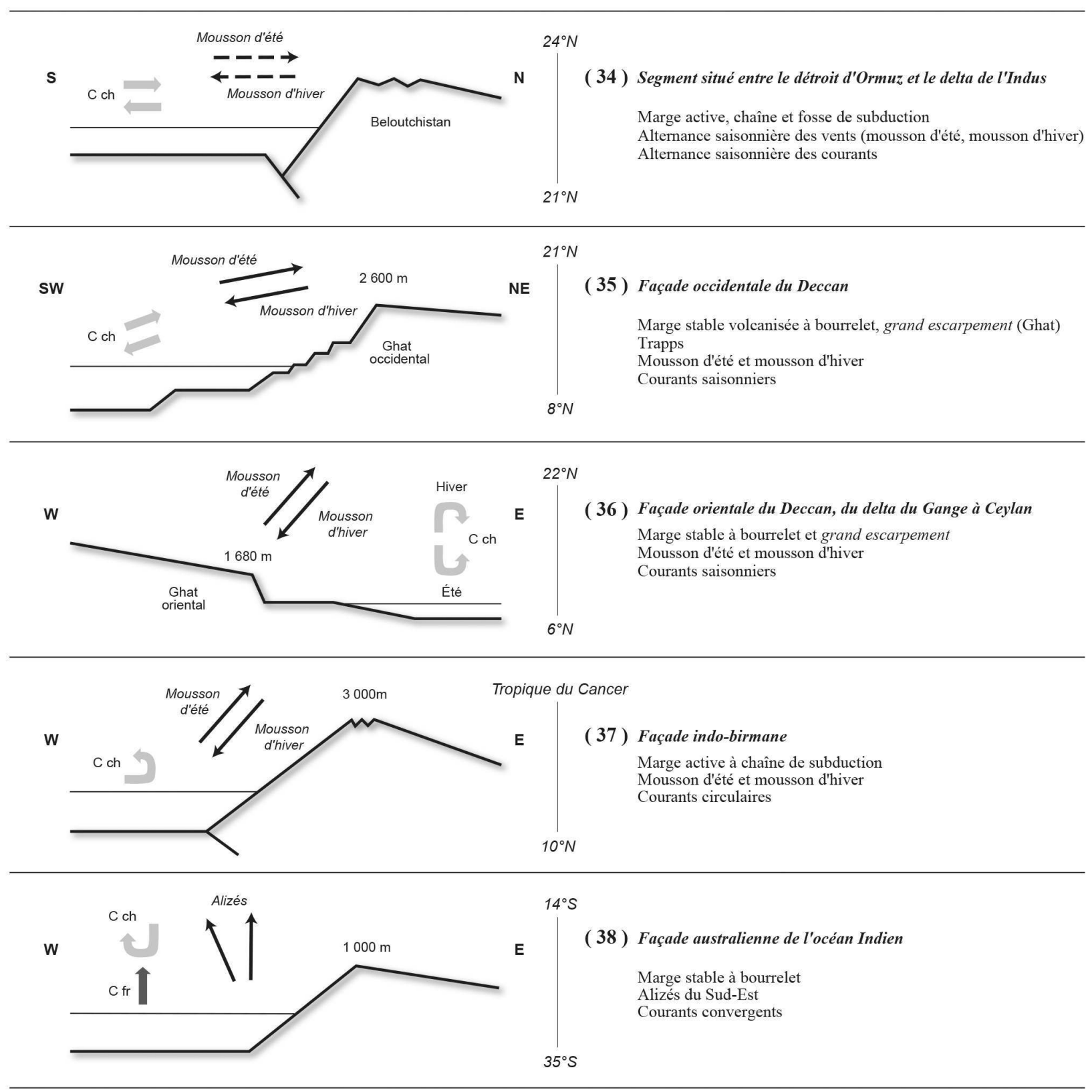

Figure 15 : Façades indiennes et adjacentes

The Indian and contiguous façades

ouest du plateau du Deccan sous forme de trapps. La façade occidentale de l'Inde comprend donc un grand escarpement, proche de la côte, redressé quoiqu'accidenté de marches, ainsi que son nom le dit, qui conduisent à une plaine côtière restreinte, puis à une plate-forme continentale relativement large (côte de Malabar). Cet escarpement s'élève continuellement vers sud, où il atteint $2694 \mathrm{~m}$. Il entraîne, en même temps, l'inclinaison du plateau du Deccan vers l'est, ainsi que sa dissymétrie hydrographique. La circulation atmosphérique méridienne à inversion saisonnière (mousson d'été soufflant du sud-ouest et apportant les pluies, «mousson d'hiver » soufflant du nord-est) renforce encore la singularité de cette façade. Les pluies littorales et orographiques occasionnées par l'affrontement direct des masses d'air tropical (saturées d'humidité par leur passage au-dessus de l'océan) avec un tel obstacle, en été, provoquent une dissymétrie climatique qui s'ajoute aux précédentes. Le Ghat occi- 
dental est la façade chaude et pluvieuse de l'Inde. La chaleur est entretenue par les courants alternatifs qui passent entre l'équateur et le subcontinent indien (courant de la mousson du sud-ouest en été, courant de la «mousson » du nord-est en hiver). Les précipitations annuelles dépassent $3000 \mathrm{~mm}$ près de la côte. La forêt tropicale comprend de plus en plus d'espèces sempervirentes vers le sud. La mousson participe ici à un puissant effet de façade qui brouille les influences de la zonalité aux latitudes concernées. En contrepartie, l'arrière-pays s'arrête au sommet du Ghat : ligne de crête et de partage des eaux, située à une centaine de kilomètres des côtes seulement, mais aussi limite d'une aire semi-aride qui occupe le revers du Deccan immédiatement plus à l'est.

(36) La façade orientale du Deccan, du delta du Gange $\left(22^{\circ} \mathrm{N}\right)$ à Ceylan $\left(6^{\circ} \mathrm{N}\right)$, s'oppose à la précédente par son orientation vers l'est, son relief et ses climats. Le Ghat oriental, disséqué par les fleuves, ne dépasse pas $1680 \mathrm{~m}$ d'altitude et s'abaisse souvent en dessous de $1000 \mathrm{~m}$ en raison de l'inclinaison du Deccan vers le golfe du Bengale. Il domine des plaines côtières, cônes alluviaux et deltas d'étendues proportionnelles à celles des bassins versants. Cette façade est soumise au même régime de moussons d'été (moins humide, en raison de sa trajectoire sud ouest-nord est) et d'hiver (plus sèche, en raison de son origine continentale). Les totaux annuels demeurent néanmoins supérieurs à $500 \mathrm{~mm}$, souvent à $1000 \mathrm{~mm}$. Mais la majeure partie des pluies provient de l'intérieur, ce qui est rare sur une façade. Les moussons conditionnent ici comme ailleurs les courants, qui viennent du sud et qui décrivent des mouvements rotatoires alternés selon les saisons à l'intérieur du golfe du Bengale (dans le sens horaire en hiver et en sens inverse en été).

(37) La façade indo-birmane, située entre le delta du Brahmapoutre (tropique du Cancer) et le golfe de Martaban $\left(10^{\circ} \mathrm{N}\right)$, correspond, à nouveau, à une marge active, partiellement symétrique de celle qui se trouve à l'ouest de l'Indus (34), mais subméridienne et plus complexe. Cette marge est associée à la convergence de la plaque indo-australienne et de la plaque continentale asiatique. Son relief résulte de la collision du subcontinent indien et de l'Asie, du poinçonnement qui l'a accompagnée, en même temps que de la subduction de la portion océanique de la plaque indo-australienne sous la plaque asiatique. Depuis l'Assam, l'ensemble comprend donc les chaînes plissées birmanes, supérieures à 3000 m, de tracé nord-sud, entrecoupées par les vallées de fleuves d'origine tibétaine. Au sud de Rangoon, ces chaînes de subduction laissent place à un arc insulaire qui devance le bassin marginal de la mer d'Andaman, la presqu'île malaise, le golfe de Thaïlande et la presqu'île Indochinoise. L'avantpays présente une pente continentale, qui laisse place, pour sa part, vers le sud, à la fosse d'Indonésie. Tous les flux en action le long de cette façade sont de dimensions extraordinaires : les transferts de sédiments à l'échelle de l'Himalaya, situé en amont, la sédimentation responsable des deltas du Brahmapoutre, du Gange (Bangladesh) et du Irrawaddy (Birmanie), le cône sous-marin du Gange qui occupe le fond du golfe du Bengale, la mousson et les précipitations d'été, les inondations liées à ces dernières et à la configuration des bassins versants, la circulation des eaux de surface, compliquée par les trajets alternés des moussons mais aussi par les courants de marée provoqués par le tracé des côtes et la proximité de grands détroits, les séismes et les tsunamis, dont les ravages rappellent que cette façade est aussi l'une des plus peuplées au monde.

(38) La façade australienne de l'océan Indien, de la mer de Timor $\left(14^{\circ} \mathrm{S}\right)$ à la pointe d'Entrecasteaux $\left(35^{\circ} \mathrm{S}\right)$, est la plus isolée de toutes. Elle correspond à une marge stable issue de la déchirure et de la dérive du Gondwana, plus précisément au type de marge à bourrelet "évolué », comme celle de l'Afrique du Sud-Est, discontinu, presque partout inférieur à $1000 \mathrm{~m}$, raviné, précédé de plaines côtières, doté d'une plate-forme continentale, d'une pente continentale et d'un glacis précontinental relativement étendus (Peulvast et Vanney, 2002). Pour le reste, elle se rapporte à un « vieux socle de la zone chaude » (Birot, 1970), longé par les courants (le courant ouest-australien venant du sud, donc relativement froid, mais rapidement relayé au nord par le courant sud-équatorial) et par les alizés qui soufflent toute l'année du sud vers le nord ou le nord-ouest, en fonction de l'anticyclone sudindien. La circulation essentiellement méridienne de la façade limite en l'occurrence les flux transversaux. Dans ces conditions, la zonalité retrouve une influence déterminante : le climat aride et semiaride, encore renforcé par un phénomène d'upwel- 
ling, s'étend jusqu'aux côtes de part et d'autre des tropiques; un climat tropical à steppe et savane le remplace au nord, tandis qu'un climat à été sec, de type méditerranéen réapparait au sud, comme aux mêmes latitudes sur les autres continents, quoique toujours sur les façades occidentales.

\section{4/ Articulations et limites des façades océaniques (figure 4, 9 et 13)}

Les façades océaniques n'échappent pas aux problèmes inhérents à la géographie régionale, c'est-àdire aux questions de limites, donc implicitement de liaisons, de transitions, de discontinuités et de terminaisons. Ces façades ont été d'abord identifiées par rapport à l'océan qu'elles côtoient (façades atlantiques, pacifiques, indiennes), puis à partir de leur orientation (façades occidentales ou orientales de continent, sinon exposées vers le sud, comme dans l'océan Indien). Elles ont été ensuite divisées en fonction de leurs relations avec les plaques lithosphériques (principalement eurasiatique, africaine, américaines, indo-australienne). Les questions de découpage et de limites portent ensuite sur quatre objets : les articulations existant entre les principales façades, les segments distingués au sein de chaque façade, les limites internes et externes de chacun de ces segments, les bordures situées aux extrémités des façades vers les milieux polaires, qui méritent un traitement à part. Ces questions sont extrêmement vastes et ne peuvent être ici qu'abordées.

Sept articulations interfaçades ont été distinguées. Ces articulations se différencient des façades par l'absence d'arrière-pays étendu (Antilles, Falkland, Béring), souvent par la présence d'un détroit (Gibraltar, Malacca, Béring), donc par la proximité de deux mers, voire le passage d'un océan à l'autre (Indonésie, Falkland, Béring). Elles jalonnent en même temps des discontinuités structurales majeures qui proviennent du démembrement, lointain, de la Pangée et de dynamiques de divergence ou de convergence ultérieures. Elles appartiennent, de ce point de vue, à trois types :

- les articulations intracontinentales, procédant d'une dynamique de divergence intraplaque, perpendiculaire aux façades et ainsi bordées de marges stables (détroit de Davis et golfe d'Aden);

- les articulations associées à des arcs insulaires intraocéaniques et à une fosse de subduction, donc à une marge active, en distinguant encore le cas de la convergence de deux plaques océaniques (arc Antillais, arc des Falkland) et celui de la convergence d'une plaque océanique et d'une plaque continentale à bassins marginaux (arc Indonésien, arc des Aléoutiennes);

- enfin une articulation intercontinentale procédant d'une dynamique de collision (golfe Ibéromarocain).

(39) Le détroit de Davis, entre le bouclier canadien et le Groenland $\left(53^{\circ}-77^{\circ} \mathrm{N}\right)$, est un bras de mer de moins de $800 \mathrm{~km}$ de large et de près de $3000 \mathrm{~km}$ de longueur, qui succède au bassin du Labrador et qui se prolonge par la mer de Baffin jusqu'à l'île d'Ellesmere. Il représente une ramification de la dorsale atlantique en direction du nord-ouest à travers la plaque continentale d'Amérique du Nord. Il résulte en effet d'un rifting intracontinental interrompu, qui commence à s'accomplir par le sud, au Crétacé, qui atteint le «stade océanique » avec l'apparition de croûte océanique jusqu'en mer de Baffin, mais qui ne progresse presque plus au Tertiaire, alors que l'Atlantique continue de s'élargir vers le nord et vers le sud à partir de la dorsale médio-atlantique (André, 1982). Ce vaste couloir océanique est profond de plus de $3000 \mathrm{~m}$ dans le détroit de Davis et encore de plus de $2000 \mathrm{~m}$ en mer de Baffin. Il est encadré de bourrelets marginaux au Labrador (monts Torngat, $1676 \mathrm{~m}$ ) et au Groenland (monts Umatausak, $1518 \mathrm{~m}$ ), issus du rehaussement des rebords des fragments divergents du bouclier canadien et de son annexe groenlandaise. La circulation atmosphérique s'opère du nord vers le sud, sous l'influence des centres d'action des hautes latitudes. Celle des eaux de surface, déterminée par des courants, méridiens, s'effectue depuis le nord le long de la côte canadienne (courant du Labrador) et depuis le sud, donc depuis des milieux océaniques plus tempérés le long de la côte groenlandaise, sans beaucoup compenser les effets thermiques de l'inlandsis groenlandais. Le détroit de Davis se comporte principalement comme une bouche de froid sur la façade est de l'Amérique du Nord.

(40) Le golfe d'Aden $\left(11-15^{\circ} \mathrm{N}\right)$ s'ouvre entre la mer d'Oman et la corne de l'Afrique. Il se prolonge par la mer Rouge, entre la plaque africaine et la plaque arabique. Il entre également en contact avec le rift est-africain à partir du point chaud de l'Afar 
et ses reliefs basaltiques. Il procède d'un modèle plus évolué que le précédent : la divergence entre une grande plaque continentale (Afrique) et l'un de ses blocs annexes (Arabie) à partir d'un rift intracontinental, a atteint, en l'occurrence, le «stade mer Rouge ». Le golfe d'Aden s'ouvre à partir d'une dorsale axiale, cisaillée, tracée d'est en ouest, dans la suite de celle de Carlsberg. Il se trouve encadré par des bourrelets marginaux «à maturité commençante ", épaulements montagneux, de plus de $3200 \mathrm{~m}$ au sud-ouest du Yémen et de plus de $2400 \mathrm{~m}$ au nord de la Somalie, à profils redressés vers les côtes (Peulvast et Vanney, 2002). Les vents soufflent du sud (Corne de l'Afrique) en été et du nord (Arabie) en hiver, à partir de régions qui comptent parmi les plus arides et ne provoquent de pluies sur les côtes qu'en raison de l'élévation des reliefs marginaux. Les courants sortent du golfe en été et y entrent en hiver, en véhiculant des eaux qui comptent toute l'année parmi les plus chaudes.

(41) Les archipels antillais (du tropique $d u$ Cancer an 10e parallèle nord) jalonnent un arc insulaire situé entre la plaque de l'Amérique du Nord et celle de l'Amérique du Sud. Cet arc procède de la subduction intraocéanique, vers l'ouest, du plancher océanique de l'Atlantique sous le plancher océanique de la mer des Caraïbes (plaque des Caraïbes). Il s'accompagne d'une fosse de subduction (fosse de Porto Rico, 9219 m). Cette dynamique de convergence, inaugurée à l'Eocène, a produit plusieurs alignements d'îles, majoritairement volcaniques, culminant à SaintDomingue (3 $140 \mathrm{~m})$. Ces alignements s'étendent en avant d'une Méditerranée américaine (selon le terme de Max Sorre, 1928), formée de deux bassins marginaux, cisaillés par la grande faille transformante nordcaraïbe, entre le sud de Cuba et le Yucatán : d'une part le golfe du Mexique au nord-ouest $(4380 \mathrm{~m}$ de profondeur, entre les montagnes mexicaines, le cap Sable en Floride et le cap Catiche au Yucatán), d'autre part la mer des Caraïbes au sud-est (plus de 7000 m de profondeur, entre Cuba et les chaînes du Venezuela, près de l'embouchure de l'Orénoque). Il s'agit d'une marge très dynamique comme l'attestent la vitesse de la subduction ( $2 \mathrm{~cm}$ par an), le volcanisme (à éruptions explosives), la sismicité, la profondeur des fosses, sans parler des particularités climatiques (cyclones tropicaux spécialement dévastateurs sur des îles) et océaniques (départ du Gulf Stream). À défaut d'arrière-pays continental, autre que celui, étroit, qui provient d'une dynamique de subduction péripacifique (Mexique), cet arc antillais et cette mer intérieure ne bordent pas de façade océanique authentique. Il souligne cependant la limite entre les plaques d'Amérique du Nord et d'Amérique du Sud.

(42) L'arc insulaire Terre de Feu-Terre de Graham $\left(51^{\circ}-63^{\circ} \mathrm{S}\right)$ limite, pour sa part, la plaque de l'Amérique du Sud et la plaque antarctique. Au-delà du cap Horn, il est ponctué d'archipels subantarctiques éloignés les uns des autres : Falkland, Géorgie du Sud, Sandwich du Sud, Orcades du Sud, Shetland du Sud, qui se prolongent par la péninsule antarctique et les marges littorales de l'Antarctique occidental, mais qui constitue en fait la plus océanique des articulations identifiées ici. Il procède d'une même subduction intraocéanique, associée à la fosse d'Argentine (6255 m), elle-même bordée au nord par l'escarpement des Falkland, et à la fosse des Sandwich du Sud (8268 m). Il est traversé en permanence par les eaux froides du courant circumpolaire antarctique (ou dérive vers l'est) et balayé par les vents d'ouest $\left(50^{\mathrm{e}}\right.$ hurlants...). Les îles concernées se trouvent aux limites du domaine subantarctique (Falkland, Géorgie, Sandwich) et du domaine antarctique (Orcades, Shetland). Les Falkland sont épargnées de l'englacement des mers; les autres connaissent la banquise saisonnière.

(43) L'arc insulaire des Aléoutiennes $\left(50^{\circ}-66^{\circ} \mathrm{N}\right)$ se situe entre la presqu'île de l'Alaska et celle du Kamtchatka (île du Commandeur), entre la plaque asiatique et la plaque d'Amérique du Nord. Il est délimité au sud par la fosse de subduction des Aléoutiennes (7682 m), mais se distingue du précédent par la présence d'un grand bassin marginal (comme les arcs échelonnés le long de la façade pacifique de l'Asie). Ce bassin est occupé par la mer de Béring, qui comprend une large plate-forme continentale au nord-est. L'arrière-pays, au nord, se réduit à l'Extrême-Orient russe et à la partie occidentale de l'Alaska, de part et d'autre du détroit de Béring. Cette articulation correspond ainsi à la terminaison septentrionale du Pacifique et à sa communication avec l'océan Arctique. La banquise saisonnière concerne la majeure partie de la mer de Béring. Les côtes sont occupées par la toundra et enregistrent la transition entre les domaines subpolaires et polaires. Le pergélisol les atteint partout mais n'est continu qu'aux abords du détroit de Béring. 
(44) L'arc insulaire indonésien, recoupé par l'équateur $\left(8^{\circ} \mathrm{N}-8^{\circ} \mathrm{S}\right)$, entre Asie et Australie, océan Indien et océan Pacifique, se singularise par les dimensions et la morphologie de l'archipel qui le compose. Il appartient à un type complexe, encore différent des précédents, qui associe trois éléments. Le premier est une fosse, longue $(3000 \mathrm{~km})$ et profonde (7500 m), qui s'étire du sud du golfe du Bengale à la mer de Timor; cette fosse souligne la subduction de la partie océanique de la plaque indo-australienne sous la plaque asiatique. Le deuxième est formé par les îles de la Sonde (Sumatra, Java et les Petites îles de la Sonde), qui correspondent à une chaîne liminaire de subduction, étroite (moins de $200 \mathrm{~km}$ en général), dissymétrique, redressée (3800 m), en même temps qu'à un arc volcanique effectivement soumis à une sismicité élevée et à un volcanisme explosif (Debelmas et Mascle, 2000). Le dernier est un " arrière-pays » insulaire, restreint et morcelé, formé de croûte continentale plissée, qui comprend de grandes îles comme Bornéo et une mer épicontinentale communiquant avec le Pacifique. L'ensemble ne présente donc pas, là non plus, les propriétés d'une façade. L'Indonésie appartient, par ailleurs, au domaine équatorial, soumis au passage des alizés transéquatoriaux déviés et occupé par la forêt sempervirente. Le courant de Java longe les îles de la Sonde, en inversant son sens selon les saisons, mais la circulation des eaux de surface est fortement perturbée par la configuration de l'archipel et par les courants de marée.

(45) Le golfe Ibéro-marocain, si on l'étend du cap Saint-Vincent $\left(37^{\circ} \mathrm{N}\right)$ à Agadir, appartient à un type d'articulation interfaçade encore différent de tous les précédents, et exactement opposé au premier (39) par sa structure, sa dynamique et son relief. Le contact entre la plaque africaine et la plaque européenne, en mer et à terre, implique en effet des accidents particulièrement complexes, significatifs d'un coulissement océanique transversal à l'ouest, associé à une convergence continentale à l'est. Du côté de l'océan, l'archipel des Açores et le détroit de Gibraltar s'alignent sur une faille transformante à partir de la dorsale médio-atlantique. Sur le continent, les reliefs s'intègrent à un ensemble de chaînes plissées intracontinentales, perpendiculaires à la façade atlantique, qui résultent de la collision des plaques africaine et européenne au cours du Tertiaire. Ces montagnes jeunes, issues d'une dynamique de convergence nord-sud constituent une exception parmi les reliefs bordiers de l'océan Atlantique, sans pour autant modifier l'ordonnance structurale des façades encadrantes, fondée sur la formation de marges stables et sur une dynamique de divergence est-ouest. Elles la compliquent cependant au niveau régional. Du côté africain, les montagnes les plus proches de la façade atlantique sont les chaînes marocaines de l'Anti-Atlas, du Haut et du Moyen Atlas, qui culminent à plus de 4000 m. Du côté européen, les resserrements de la croûte continentale ont produit la Cordillère bétique (3 481 m dans la Sierra Nevada) et, indirectement, au nord de la péninsule Ibérique, la chaîne intracratonique des Pyrénées (3 404 m au Pic d'Aneto). La chaîne Cantabrique (2665 m au Picos de Europa), formée dans le prolongement de ces derniers, représente ce cas particulier de subduction localisée du fond océanique du golfe de Gascogne sous la croûte continentale ibérique qui contribue, en même temps, à la caractérisation de la façade atlantique européenne dans sa partie méridionale $(2,3)$.

La segmentation des façades constitue, quant à elle, la part essentielle des faits exposés précédemment. Cette segmentation repose sur cinq critères, comprenant chacun plusieurs variables $(\$ 12$ et figure 2) : tectonique des plaques (marges actives ou stables), circulation atmosphérique (depuis l'ouest, depuis l'est ou alternée), circulation océanique de surface (courants chauds, froids ou alternés), orientation (vers l'ouest, l'est ou le sud), zonalité (latitudes hautes, moyennes ou basses). Le choix des emplacements des jonctions latérales établies entre les 38 segments de façades répertoriés à partir de ces critères n'évite évidemment pas une part de subjectivité. Néanmoins, ces jonctions coïncident souvent avec plusieurs discontinuités remarquables.

Les limites externes et internes des segments de façade discernés, donc celles de leur avant-pays et de leur arrière-pays, font pleinement partie de leur identité, mais constitueraient un sujet d'étude à elles seules. Leur justification implique de se fonder sur le sens, la profondeur et l'intensité des flux qui les caractérisent. Ces flux présentent des causes, des effets et des interactions dont les aspects généraux ont été abordés (\$13). Leur détermination, pour chaque segment de façade, impose de changer de niveau d'analyse et d'être traitée au cas par 
cas, sachant que leur dégradation (comme la continentalisation progressive des climats océanisés) est plus souvent de règle que leur interruption ou leur disparition à partir d'un seuil (comme une crête de montagne ou une ligne de partage des eaux). Il convient encore d'observer, au passage, que certains segments de façade sont l'objet de répliques, créées par la présence d'espaces marins dans ou vers l'arrière-pays (comme sur la façade atlantique, avec la mer du Nord et la mer Baltique, ou sur les côtes de Madagascar et celles de l'Afrique).

Quoi qu'il en soit, les flux en cause, résumés sur la figure 16, sont nombreux. Beaucoup se traduisent par des enchaînements d'effets principaux et secondaires. Ceux qui proviennent des espaces océaniques et qui ont pour cause la divergence ou la convergence de plaques, la circulation des masses d'air vers les continents, ou la circulation océanique aux abords des côtes, apparaissent globalement plus dynamiques et plus conséquents que ceux qui proviennent des espaces continentaux, quoique les apports en eaux (qui s'inscrivent dans le cycle de l'eau en enregistrant les fluctuations climatiques en permanence) et les apports en sédiments (corrélatifs de l'érosion continuelle des continents) provoquent des transferts de matières liquides et solides considérables.

\section{5/ Les bordures polaires}

Une dernière question concerne les terminaisons des façades océaniques en direction des pôles. Ces «bordures polaires », où le soleil disparaît une partie de l'année, ont en commun de s'inscrire à l'intérieur des hautes latitudes, mais s'opposent entre elles par leur ordonnance spatiale (un océan entouré de terres dans l'Arctique et un continent entouré d'océans dans l'Antarctique). Elles se différencient complètement des façades considérées auparavant par leur disposition et par leur dynamique, mais d'abord par leur tracé circulaire et non plus méridien. Les flux qui s'y expriment les longent le plus souvent suivant des trajets giratoires au lieu de les traverser. Par ailleurs, tout est contrôlé par un froid persistant et intense qui s'accompagne de la brièveté ou de l'absence d'été et qui implique le gel saisonnier ou permanent de l'eau dans l'atmosphère (précipitations neigeuses), à la surface des terres (couverture neigeuse durable et glaciers), dans les roches et les sols (sols à gel saisonnier et pergélisols), à la surface des eaux douces (embâcle des lacs et des fleuves) et à celle des mers (banquise saisonnière ou permanente).

Au moins, l'Arctique n'est-il pas complètement clos. La dorsale de Nansen, dans la suite de celle de Reykjanes, et la cuvette océanique du Fram se poursuivent jusqu'au pôle. Une partie de « l'océan Arctique » est donc la suite de l'Atlantique (croûte océanique). L'autre correspond surtout à un précontinent qui prolonge les plaques nord-américaine et euro-asiatique vers le nord. L'Arctique est, en fait, une autre Méditerranée, où la circulation des eaux de surface effectue d'abord une rotation dans le sens horaire (courant de Nansen, courant de Beaufort). Cette mer demeure entrouverte sur l'océan mondial. Elle communique avec le Pacifique par le détroit de Béring et surtout avec l'Atlantique par la mer de Norvège et le détroit du Fram, où des trajets méridiens des courants atlantiques et arctiques entretiennent des échanges qui participent à la compensation du bilan thermique négatif de l'Arctique : expulsion d'eau froide par le courant du Groenland oriental (qui prolonge le courant de Nansen) et surtout remontée de la dérive nord-atlantique (Gulf Stream) qui fonctionne comme une bouche de chaleur et augmente les températures de 10 à $14{ }^{\circ} \mathrm{C}$ par rapport aux latitudes antarctiques homologues. Cette organisation assure donc un puissant réchauffement de l'Arctique, qui profite surtout aux domaines les plus proches de l'Atlantique nord, en deçà de la Nouvelle-Zemble, mais qui n'accroît pas tellement pour autant les flux thermiques entre l'océan et les côtes des continents qui le bordent. La circulation atmosphérique des hautes latitudes arctiques est elle-même soumise à une grande dépression d'origine dynamique centrée sur le pôle, qui anime des vents géostrophiques dont les trajectoires suivent normalement le tracé des isobares d'ouest en est. L'influence dominante du froid se traduit cependant au niveau des vents, agents actifs d'advection thermique. Des inversions thermiques liées à la présence des glaciers, au gel des continents ou à l'albedo des banquises, proviennent des anticyclones pelliculaires qui se forment dans les couches atmosphériques les plus basses et qui provoquent des vents de surface. Les plus remarquables sont les vents catabatiques qui descendent de l'inlandsis groenlandais vers les côtes en les refroidissant, mais 


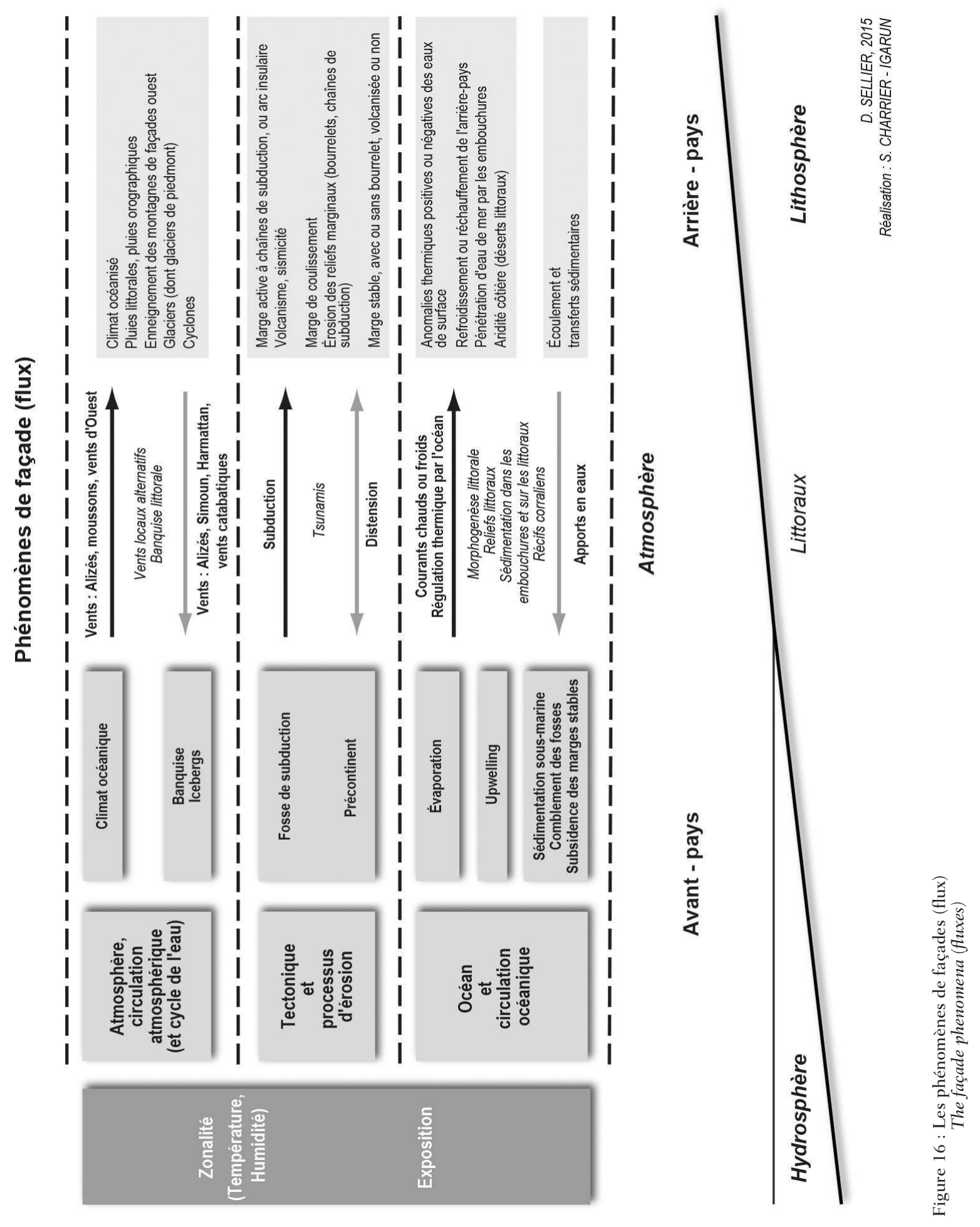


qui se trouvent parfois contrés en été par des brises de mer anabatiques, là où la banquise a disparu. L'une des principales propriétés de l'océan Glacial Arctique demeure en effet son engel en surface, qui est l'une des manifestations les plus remarquables du froid : banquise permanente qui occupe les trois quarts du bassin à partir de son centre, banquise saisonnière qui occupe le reste en hiver, mais aussi banquise côtière, qui se disloque après la précédente en été, expression d'un des flux qui s'opèrent dans l'Arctique, là encore, des terres vers les mers. La banquise entrave l'évaporation dans un milieu où le froid des masses d'air réduit déjà les précipitations. Elle contribue donc à accroître l'aridité des régions les plus proches des côtes, les Barren grounds du Canada, équivalents des déserts polaires nord-sibériens.

À l'opposé, l'Antarctique représente, en partie, un modèle réduit du Gondwana, qui brise le schéma méridien des façades de dernière génération, c'està-dire de celles qui dérivent de la tectonique des plaques postérieure à la dislocation de la Pangée et qui contribuent à montrer que les «vieilles structures » continuent d'exercer des influences durables. Le système de flux en action présente naturellement des points communs avec le précédent. Il accorde toutefois au froid une influence encore plus tyrannique, en raison du rôle central exercé ici par un inlandsis qui s'élève jusqu'à plus de 4000 m et qui recouvre le continent presque partout jusqu'aux côtes (alors que le pôle Nord se trouve au niveau de la mer). Il accorde également aux circulations atmosphériques et océaniques circulaires, donc zonales, une importance capitale. Les masses d'air polaire maritime froid qui entourent l'Antarctique sont entraînées par des vents permanents et puissants qui gravitent autour du continent vers l'est à partir des centres de hautes pressions tropicales. Des courants froids suivent le même trajet circumpolaire et le même rythme (Dérive vers l'est), sans possibilité d'apports en eaux plus chaudes, comme dans l'hémisphère nord. De plus, des flux tous dirigés vers l'océan expulsent des eaux froides, de l'air froid (par l'intermédiaire des vents catabatiques issus d'un continent massif et élevé) et de la glace (qui recouvre parfois la mer sous forme de shelfs et qui fournit des icebergs plus grands et plus nombreux que dans l'Arctique). La banquise permanente encercle, cette fois au plus près des côtes, un continent lui-même glacé. La banquise saisonnière s'étend à sa périphérie jusqu'au $50^{\mathrm{e}}$ parallèle, alors que les glaces dérivantes atteignent occasionnellement le $40^{\mathrm{e}}$. Les flux continent-océan s'expriment ici à sens unique. Les influences océaniques tendent à disparaître. La zonalité tend à reprendre une importance exclusive en restreignant corrélativement les dynamiques de façades.

\section{Conclusions}

La place et les fonctions des façades sont bien connues en géographie humaine et économique. Les façades constituent en effet des milieux spécialement attractifs, comme l'attestent les cartes de densités de population. Elles offrent l'opportunité, commune aux interfaces, d'exploiter les ressources de plusieurs milieux juxtaposés : conditions d'installation facilitées par les éléments naturels (plaines côtières, climats océanisés, potentialités en eau), productions alimentaires continentales et marines cumulées (agricoles, halieutiques, conchylicoles), proximité de sources d'énergie (installations marémotrices, pétrole ou éoliennes offshore), sites d'échanges en même temps que sites industrialoportuaires et surtout ouverture sur le monde, par la mer.

L'objet initial de ce travail était de souligner les spécificités des façades en géographie physique audelà de propriétés notoires comme l'océanicité des climats, les dissymétries entre façades ouest et est, les propriétés des marges liées aux dynamiques des plaques. Le sujet nécessite cependant de distinguer deux objets géographiques. Le premier correspond aux façades en tant qu'espaces, qui ne se réduisent pas qu'à des marges; ces façades, axées sur un contact triple entre océan, continent et atmosphère, constituent une entité objective, permanente, sinon stable à l'échelle historique; elles sont encadrées par des limites qui demeurent souvent indécises. Le deuxième correspond à "l'effet de façade », qui ne se réduit pas, pour sa part, aux défilés de perturbations pluviogènes sur la pointe Saint-Mathieu, mais qui s'exprime aussi par des déserts côtiers et qui est donc perçu différemment en Bretagne et au Pérou. Cet effet de façade s'exprime par les conséquences, sans équivalents par ailleurs sur le globe, de flux produits à partir de la lithosphère, de l'hydrosphère et de l'atmosphère; il se traduit plus exactement par 
des «phénomènes de façades » élémentaires, successifs, ou interactifs, dont la figure 16 n'illustre que le nombre et la complexité. Partant de là, les façades fonctionnent comme des systèmes différents les uns des autres, qui impliquent effectivement plusieurs catégories de flux.

Ces flux se différencient par leur provenance et par leur sens. Ils peuvent être classés en trois catégories. Les premiers circulent de l'océan vers le continent, comme les flux thermiques qui atténuent les amplitudes des températures, les flux pluviogènes accompagnés par les grands vents d'ouest, les alizés ou la mousson, mais aussi et d'abord l'ensemble des contraintes produites par la convergence de deux plaques et leurs épiphénomènes. Les deuxièmes circulent du continent vers l'océan; ils portent moins sur le climat (alizés, vents catabatiques, rôle réfrigérant des inlandsis), que sur l'hydrologie (apports permanents et massifs d'eaux douces vers les océans) et sur les produits de l'érosion des continents (sédiments); ils concernent en fait des volumes gigantesques. Les derniers sont longitudinaux et, dans ce cas, le plus souvent méridiens; ils sont liés à des vents qui peuvent être déviés par des montagnes proches des côtes, mais le plus souvent à des courants qui longent les côtes en provoquant - latéralement - des anomalies thermiques et une aridité qui modifient les propriétés des façades concernées. Ces flux se différencient ensuite par leurs rythmes (continus, saisonniers, temporaires, alternatifs), leur intensité et leur degré de pénétration vers les terres, en fonction des obstacles et de la configuration des reliefs à partir des côtes, ce qui rejoint le problème de leur limite interne.

Une quantification précise reste difficile en l'espèce, quoique les flux issus des océans, de leurs planchers et des portions de l'atmosphère qui les surmontent semblent les plus déterminants. Un classement des façades par rapport à une exemplarité théorique semble aussi compliqué à établir, quoiqu'il existe des façades traversées par des flux particulièrement puissants, comme la façade occidentale du Deccan (35) ou la façade indo-birmane (37), sinon spécialement disposées pour les laisser circuler, comme le centre de la façade atlantique européenne (1) ou le segment de façade atlantique de l'Amérique du Sud situé entre l'Orénoque et l'Amazone (12); il en existe d'autres où les flux qui caractérisent le paradigme demeurent très modé- rés, comme les segments de façades africaines situés entre le Maroc et la Casamance (7) ou entre Zanzibar et Socotra (33). Il reste donc instructif, de ce fait, de mener des comparaisons ou d'exploiter les oppositions entre façades pour en préciser les propriétés en fonction des expositions et des latitudes, mais aussi des facteurs fondamentaux : types de marge, circulations atmosphérique et océanique.

Une des perspectives de ce travail pouvait être d'aboutir implicitement à une typologie. La subdivision des façades en 38 segments, auxquels s'ajoutent sept articulations et encore deux bordures polaires a cependant montré qu'il existe en fait autant de types que de cas ce qui rend, par les faits, toute typologie impossible, à partir des seuls critères retenus. Il n'y a en effet d'objets simples que les grands ensembles définis en fonction d'un seul critère (façade sur marge active ou stable, façades ouest ou est...). En revanche, chaque segment de façade s'avère unique en son genre, ce qui ne doit finalement pas surprendre en raison du nombre de critères en cause et des alternances ou dégradations qu'ils impliquent. Plusieurs centaines de situations possibles se présenteraient ainsi selon les statistiques. Mais chacune d'entre elles est exclusive dans la nature et non reproductible au niveau d'échelle considéré (quelques milliers de kilomètres). L'exercice, fondé sur l'analyse successive des singularités de chaque segment tient donc du corpus ou de la nomenclature argumentée plus que de la classification. La situation n'en est pas moins sans enseignement et n'entame en rien la réalité des façades en tant qu'entité physiographique à la surface du globe et en tant qu'outil d'analyse, effectivement global, des espaces géographiques.

Les façades et leurs segments enregistrent les effets de la zonalité, dans des proportions diverses. Elles constituent surtout de puissants agents de perturbation de cette zonalité, notion principalement climatique, bioclimatique et morphoclimatique. Les façades connaissent généralement une extension transzonale par leur tracé méridien. Les flux climatiques qui les caractérisent modifient les propriétés zonales en direction des océans et aussi, de façon plus notoire, en direction des continents par « l'océanicité » (Vigneau, 2000). Cette dynamique s'exprime par ce que Birot (1968) avait déjà qualifié de quadrillage climatique du globe. Mais la zonalité se manifeste aussi par une circulation des 
eaux océaniques, elle-même déviée par la disposition des continents et implicitement par les façades, responsables de courants méridiens et de perturbations transzonales considérables. La configuration, la direction et l'élévation du relief des marges continentales, donc des façades, représentent, pour leur part, des éléments passifs, mais efficients dans ce « système » des façades, puisqu'ils modifient les propriétés zonales aux latitudes concernées, ainsi que la portée des flux en action. L'ensemble de ces facteurs et de ces relations ne se limite donc pas aux climats et relève en fait d'un quadrillage physiographique du globe.

Une dernière propriété des façades concerne leur mobilité, dont une première expression se rapporte aux risques, thème en vogue, qui trouve effectivement un champ d'application au-delà des littoraux et qui pourrait contribuer aussi à la délimitation de ces façades. Ces risques se caractérisent par leur diversité et par leur intensité. Ils proviennent d'aléas climatiques (tempêtes, cyclones, inondations, vimers), océaniques (instabilité des courants, submersion, érosion des côtes) ou géologiques (séismes, tsunamis et volcanisme), sinon de la combinaison de plusieurs processus (figure 17). Dans ce registre, les façades les plus fréquemment et les plus gravement touchées sont évidemment celles du Pacifique, installées sur des marges actives, et les moins exposées sont celles de l'Atlantique, correspondant à des marges stables, quoique les tempêtes des moyennes latitudes et les cyclones tropicaux demeurent indépendants de ces distinctions morphostructurales. Cette mobilité trouve une seconde expression à travers l'enregistrement des fluctuations climatiques, comme dans le cas de toutes les interfaces majeures (marges des déserts, étages montagnards, limites des régions polaires). Dans le cas des façades océaniques, les réponses à ces fluctuations sont immédiates. Elles s'observent d'abord sur les littoraux, à partir du niveau de la mer (eustatisme, modifications de températures des eaux et des courants), à des rythmes simultanés et non à des rythmes différés comme dans le cas des autres interfaces. Quand ces fluctuations deviennent des ten-

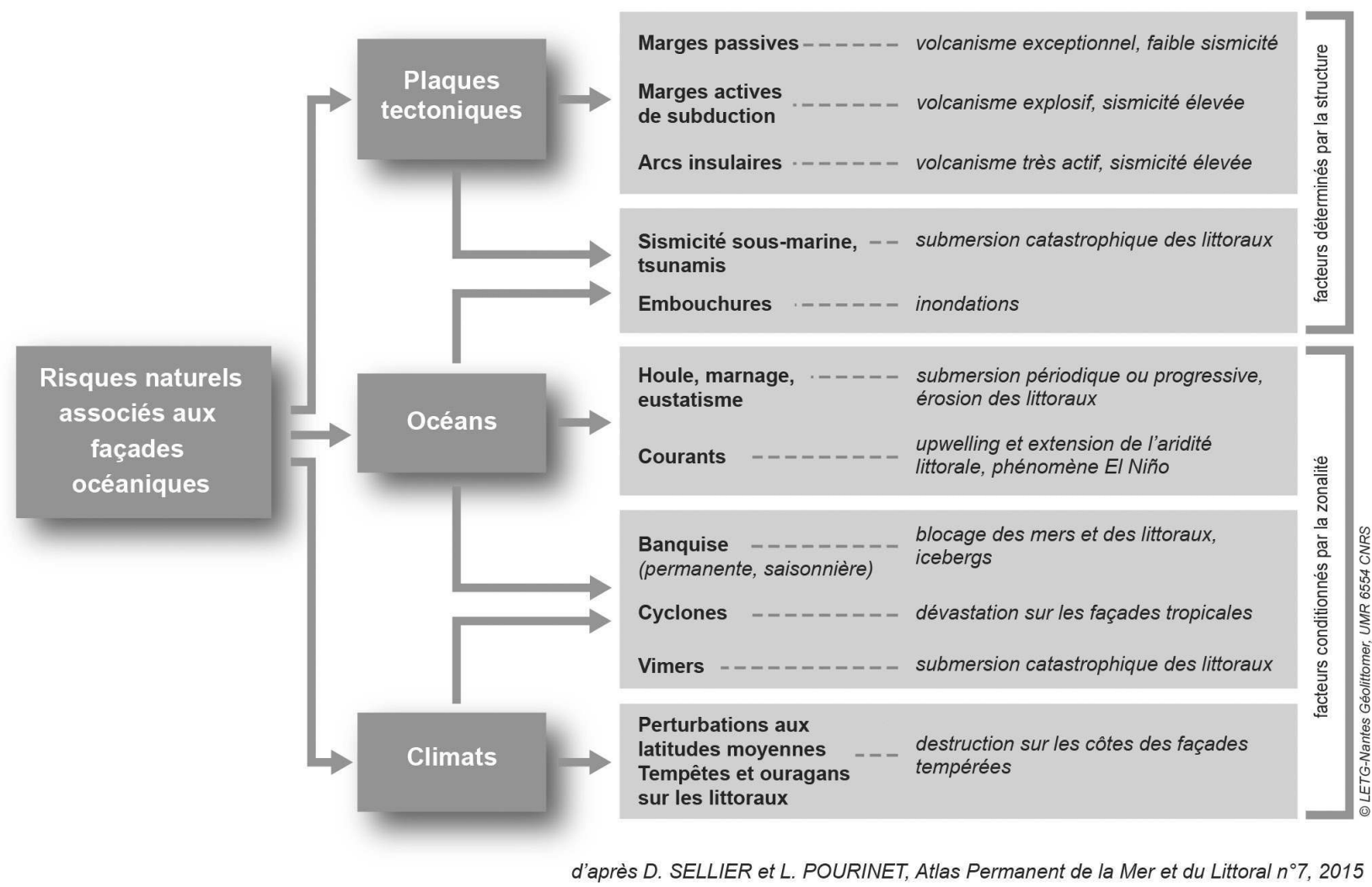

Figure 17 : Les risques naturels associés aux façades océaniques Natural hazards related to oceanic façades 
dances durables leurs effets gagnent l'intérieur des continents en modifiant les systèmes d'érosion, les conditions d'écoulement et les formations végétales. Celles qui se sont manifestées par le passé (comme, par exemple, la répartition des inlandsis), montrent aussi que les façades océaniques comptent parmi les lieux privilégiés de conservation des héritages.

\section{Remerciements}

L'auteur remercie Bernard Bousquet, professeur honoraire de l'université de Nantes, Yannick Lageat, professeur émérite de l'université de Brest et Nicolas Rollo, maître de conférences en géographie à l'IGARUN, de l'avoir fait bénéficier de leurs avis et de leurs conseils à la suite de la rédaction de ce travail. Il remercie le rédacteur en chef de la revue Norois, Grégoire Maillet et les relecteurs de cette publication, pour l'intérêt de leurs expertises. Il remercie Simon Charrier, cartographe à l'IGARUN pour avoir reconstruit et redessiné avec rigueur et compétence l'ensemble des illustrations.

\section{Bibliographie}

Allègre C., 1999. L'écume de la Terre, Fayard, 366 p.

Andre M.-F., 1982. Reconnaissance géomorphologique dans les socles des hautes latitudes : l'exemple du Nord du Labrador, thèse de $\mathrm{III}^{\mathrm{e}}$ cycle, Paris I, $357 \mathrm{p}$.

ВіRот P., 1965. Formations végétales du globe, SEDES, 508 p.

Віrot P., 1968. Précis de géographie physique générale, Paris, Colin, $340 \mathrm{p}$.

Birot P., 1970. Les régions naturelles du globe, Masson, 380 p.

Birot P., Godard A. 1982. Les bourrelets marginaux des vieux socles, Bulletin de l'Association de Géographes Français, $n^{\circ}$ 489-490, p. 231-269.

Boillot G., Coulon C., 1998. La déchirure continentale et l'ouverture océanique, Gordon et Breach, 208 p.

Chadenas C, Sellier D. 2014. Les oiseaux de mer et les espaces maritimes dans le monde, in Miossec A. Géographie des océans et des mers, Rennes, PUR, p. 65-100.

DAviES J.L., 1964. A morphogenic approach to world shorelines, Zeitschrift für Geomorphologie, Bd 8, p. 127-142.

Debelmas J., Mascle G., 1997. Les grandes structures géologiques, Paris, Dunod, 312 p.

Demangeot J., 1999. Tropicalité, Paris, Colin, 340 p.

Demangeot J., Bernus E., 2001. Les milieux désertiques, Paris, Colin, $295 \mathrm{p}$.

Dresch J., 1982. Géographie des régions arides, Paris, PUF, 277 p.
Dupont P., 1962. La flore atlantique européenne, thèse d'État, Sciences, Toulouse, $414 \mathrm{p}$.

Godard A., Andre M.-F., 1999. Les milieux polaires, Paris, Colin, $451 \mathrm{p}$.

Godard A., Tabeaud M., 2004. Les climats, mécanismes, variabilité, répartition, Paris, Colin Cursus, 217 p.

Guilcher A., 1953. Sur deux caractères du climat océanique tempéré, Information Géographique, 2, p. 52-57.

Guilcher A., 1954. Morphologie littorale et sous-marine, Paris, Orbis/PUF, 242 p.

Guilcher A., 1966. Les grandes falaises et mégafalaises des côtes sud-ouest et ouest de l'Irlande, Annales de Géographie, 407, p. 26-38.

Guilcher A., 1979. Précis d'hydrologie marine et continentale, Masson, 344 p.

Lageat Y., 2004. Les milieux physiques continentanx, Paris, Belin, 191 p.

Lageat Y., 2014. L'océan Indien in Miossec A., Géographie des océans et des mers, Rennes, PUR, p. 367-387.

Lageat Y, Miossec A., 2003. Zonalité, plurizonalité et azonalité en géomorphologie littorale, Cahiers Nantais, n 59, p. 29-45.

Le Cceur C., Dorize L., Аmat J.-P., 1996. Éléments de géographie physique, Bréal, 416 p.

Peguy C.-P., 1970. Précis de climatologie, Paris, Masson, 468 p.

Peulvast J.-P., Vanney J.-R., 2001-2002. Géomorphologie structurale, SGF-Gordon et Breach, t. 1, 504 p., t. 2524 p.

Pinot J.-P., 1998. La gestion du littoral, Paris, Institut océanographique, $759 \mathrm{p}$.

Pirazzoli P.A., 1991. World atlas of Holocene sea-level changes, Elsevier Oceanography series, 58, p. 69-82

Pirazzoli P.A., 1996. Sea level changes: the last 20.000 years, Willey, Chichester, 341 p.

Planchon O. 2000. Les climats maritimes dans le monde, Villeneuve-d'Asq, Presses universitaires du Septentrion, 242 p.

Rougerie G., 2003. Géographie des marges, Paris, L'Harmattan, $150 \mathrm{p}$.

SELlier D., 2006. Les limites inférieures de l'étage périglaciaire fonctionnel dans les montagnes de la façade atlantique de l'Europe : éléments d'identification à partir de marqueurs morphologiques, Environnements périglaciaires, Commission pour l'étude des milieux périglaciaires, CNFG, 31, n 13. p. 41-59.

SEllier D., 2009a. Les milieux périglaciaires et la mer : phénomènes de façade actuels et hérités, rythmes morphogéniques simultanés et différés, Environnements périglaciaires, Commission pour l'étude des phénomènes périglaciaires, CNFG, 34, n 16, p. 5-11.

SEllier D., 2009b. Falaises rocheuses et versants réglés sur les côtes du Massif armoricain : l'insertion de l'érosion littorale dans le continuum de régularisation des versants, Environnements périglaciaires, Commission pour l'étude des phénomènes périglaciaires, $C N F G, 34, n^{\circ} 16$, p. 23-37.

Sorre M., 1928. Mexique, Amérique centrale, Géographie universelle, Colin, tome XV, p. 234 p.

Tonnerre M.-A., 2001. Contribution à l'étude des tempêtes sur la façade atlantique de la Manche au nord de l'île de Noirmoutier, thèse d'État, Lille, 363 p. et annexes. 
Tuck G., Heinzel H. 1985. Guide des oiseaux de mer, Paris, Delachaux et Niestlé, 310 p.

VANNEY J.-R., 1982. Les bourrelets des boucliers anciens et leurs marges continentales, Bulletin de l'Association de Géographes Français, 59, n 489, p. 231-238.

VANNEY J.-R., 1991. Introduction à la Géographie de l'Océan, Institut océanographique, Paris, Océanis, 214 p.

VAnney J.-R., 2002a. Géographie de l'océan global, Paris, SGFGB, coll. « Géosciences », 335 p.
VAnney J.-R., 2002b. La mer domine la Terre, Annuaire du droit de la mer 2001, t. VI, p. 645-668.

VANNEY J.-R. 2003. Une frontière physiographique majeure, le rebord de la plate-forme continentale, Annuaire du droit de la mer 2003, t. VIII, p. 352-403.

Vanney J.-R., Menanteau L., 2004. Géographie du golfe IberoMarocain, Casa de Velazquez et Instituto hidrografico, Madrid, Lisbonne, 245 p.

Vigneau J.-P., 2000. Géoclimatologie, Paris, Ellipses, 334 p. 